\title{
Article \\ Open Issues for Protein Function Assignment in Haloferax volcanii and Other Halophilic Archaea
}

\author{
Friedhelm Pfeiffer ${ }^{1, *(1)}$ and Mike Dyall-Smith ${ }^{1,2}(\mathbb{C}$ \\ 1 Computational Biology Group, Max-Planck-Institute of Biochemistry, 82152 Martinsried, Germany; \\ mike.dyallsmith@gmail.com \\ 2 Veterinary Biosciences, Faculty of Veterinary and Agricultural Sciences, University of Melbourne, \\ Parkville 3010, Australia \\ * Correspondence: fpf@biochem.mpg.de
}

Citation: Pfeiffer, F.; Dyall-Smith, M. Open Issues for Protein Function Assignment in Haloferax volcanii and Other Halophilic Archaea. Genes 2021, 12, 963. https://doi.org/10.3390/ genes12070963

Academic Editors: María José Bonete, Mónica Camacho and Julia Esclapez

Received: 16 May 2021

Accepted: 15 June 2021

Published: 24 June 2021

Publisher's Note: MDPI stays neutral with regard to jurisdictional claims in published maps and institutional affiliations.

Copyright: () 2021 by the authors. Licensee MDPI, Basel, Switzerland. This article is an open access article distributed under the terms and conditions of the Creative Commons Attribution (CC BY) license (https:// creativecommons.org/licenses/by/ $4.0 /)$.

\begin{abstract}
Background: Annotation ambiguities and annotation errors are a general challenge in genomics. While a reliable protein function assignment can be obtained by experimental characterization, this is expensive and time-consuming, and the number of such Gold Standard Proteins (GSP) with experimental support remains very low compared to proteins annotated by sequence homology, usually through automated pipelines. Even a GSP may give a misleading assignment when used as a reference: the homolog may be close enough to support isofunctionality, but the substrate of the GSP is absent from the species being annotated. In such cases, the enzymes cannot be isofunctional. Here, we examined a variety of such issues in halophilic archaea (class Halobacteria), with a strong focus on the model haloarchaeon Haloferax volcanii. Results: Annotated proteins of $H f x$. volcanii were identified for which public databases tend to assign a function that is probably incorrect. In some cases, an alternative, probably correct, function can be predicted or inferred from the available evidence, but this has not been adopted by public databases because experimental validation is lacking. In other cases, a probably invalid specific function is predicted by homology, and while there is evidence that this assigned function is unlikely, the true function remains elusive. We listed 50 of those cases, each with detailed background information, so that a conclusion about the most likely biological function can be drawn. For reasons of brevity and comprehension, only the key aspects are listed in the main text, with detailed information being provided in a corresponding section of the Supplementary Materials. Conclusions: Compiling, describing and summarizing these open annotation issues and functional predictions will benefit the scientific community in the general effort to improve the evaluation of protein function assignments and more thoroughly detail them. By highlighting the gaps and likely annotation errors currently in the databases, we hope this study will provide a framework for experimentalists to systematically confirm (or disprove) our function predictions or to uncover yet more unexpected functions.
\end{abstract}

Keywords: haloarchaea; genome annotation; Gold Standard Protein; Haloferax volcanii; annotation error

\section{Introduction}

Haloferax volcanii is a model organism for halophilic archaea [1-6], for which an elaborate set of genetic tools has been developed [7-9]. Its genome has been sequenced and carefully annotated $[1,10,11]$. A plethora of biological aspects have been successfully tackled in this species, with examples including DNA replication [4]; cell division and cell shape [12-16]; metabolism [17-25]; protein secretion [26-29]; motility and biofilms [30-35]; mating [36]; signaling [37]; virus defense [38]; proteolysis [39-44]; posttranslational modification (N-glycosylation; SAMPylation) [45-50]; gene regulation [21,25,51-55]; microproteins [56-58] and small noncoding RNAs (sRNAs) [59-62].

Genome annotations are frequently compromised by annotation errors [11,63-65]. Many of these errors are caused by an invalid annotation transfer between presumed 
homologs, which, once introduced, are further spread by annotation robots. This problem can be partially overcome by using a Gold Standard Protein (GSP)-based annotation strategy [11]. Since the GSP has itself been subjected to an experimental analysis, its annotation cannot be caused by an invalid annotation transfer process. The GSP strategy was already applied to a detailed analysis of the metabolism of halophilic archaea [66]. However, with a decreasing level of sequence identity, the assumption of isofunctionality becomes increasingly uncertain. Although this may be counterbalanced by additional evidence, e.g., gene clustering, experimental confirmation would be the best option for validation of the annotation.

There are additional and much more subtle genome annotation problems. In some cases, GSPs are true homologs, and the annotated function in the database is correct. Nevertheless, the biological context in the query organism makes it unlikely that the homologs are isofunctional, e.g., when the substrate of the GSP is lacking in the query organism. Additionally, paralogs may have distinct but related functions that cannot be assigned by a sequence analysis but may be assigned based on phylogenetic considerations. Here, again, experimental confirmation is the preferred option for validation of the annotation. A lack of experimental confirmation may keep high-level databases like KEGG or the SwissProt section of UniProt from adopting assignments based on well-supported bioinformatic analyses, so that the database entries continue to provide information that is probably incorrect. We refer to annotation problems in these databases solely to underscore that the biological issues raised by us are far from trivial. There is no intention to question the exceedingly high quality of the SwissProt and KEGG databases $[67,68]$ and their tremendous value for the scientific community. We have actively supported them by providing feedback and encourage others to do the same, e.g., with the recently implemented "Add a publication" functionality in the UniProt entries that allows users to connect a protein to a publication that describes its experimental characterization (https://community.uniprot.org/bbsub/bbsubinfo.html).

In this study, we describe a number of annotation issues for haloarchaea, with a strong emphasis on Hfx. volcanii. We denote such cases as "open annotation issues" with the hope of attracting members of the Haloferax community and other groups working with halophilic archaea to apply experimental analyses to elucidate the true function(s) of these proteins. This will increase the number of Gold Standard Proteins that originate from Hfx. volcanii or other haloarchaea, reduce genome annotation ambiguities and perhaps uncover novel metabolic processes.

\section{Materials and Methods}

\subsection{Curation of Genome Annotation and Gold Standard Protein Identification}

The Gold Standard Protein-based curation of haloarchaeal genomes has been described previously [11] (see, also, next paragraph). Since then, a systematic comparison to the KEGG data was performed for a subset of the curated genomes [69]. The Hfx. volcanii genome annotation is continuously scrutinized, especially when a closely related genome is annotated [70].

In brief, the core rule of Gold Standard Protein-based genome annotation is to assign a specific function only when a homologous protein has been confirmed experimentally to have this function. Two types of data must be available for that homolog: (a) a reference describing the experimental characterization and (b) an entry in a sequence database, so that the level of sequence similarity can be determined. The decision on whether isofunctionality can be assumed at this level of sequence similarity and, thus, if the annotation can be transferred represents an informed prediction by the annotator based on the available evidence. This decision may be taken only once for a set of closely related orthologs, such as those from halophilic archaea.

\subsection{Additional Bioinformatics Tools}

The key databases were UniProtKB/SwissProt [68], InterPro [71], KEGG [67] and OrthoDB [72]. The SyntTax server was used for inspecting the conservation of the gene 
neighborhood [73]. As general tools, the BLAST suite of programs [74,75] was used for sequence comparisons.

\section{Results}

The open issues are organized below under Section 3.1, the respiratory chain and oxidative decarboxylation; Section 3.2, amino acid metabolism; Section 3.3, heme and cobalamin biosynthesis; Section 3.4, coenzyme F420; Section 3.5, tetrahydrofolate as opposed to methanopterin; Section 3.6, NAD and riboflavin; Section 3.7, lipid metabolism; Section 3.8, genetic information processing and Section 3.9, stand-alone (miscellaneous) cases. We collected this set of open annotation issues during our continuous efforts to keep the Hfx. volcanii genome up-to-date since its initial publication in 2010 [1]. Not covered in this study are enigmatic reactions and pathways (e.g., archaeal signal peptidase II or the haloarchaeal O-glycosylation pathway) for which no support from experimentally characterized homologs (GSP proteins) is available.

\subsection{The Respiratory Chain and Oxidative Decarboxylation}

In the respiratory chain, the coenzymes that were reduced during catabolism (e.g., glycolysis) are reoxidized, with the energy being saved as an ion gradient. The textbook examples of a respiratory chain are the five mitochondrial complexes [76,77]: complex I (NADH dehydrogenase), complex II (succinate dehydrogenase), complex III (cytochrome $\mathrm{bc}_{1}$ complex), complex IV (cytochrome-c oxidase as a prototype for a terminal oxidase) and complex V (F-type ATP synthase). In mitochondria, a significant part of the NADH that feeds into the respiratory chain originates from oxidative decarboxylation: the conversion of pyruvate to acetyl-CoA by the pyruvate dehydrogenase complex and conversion of $\alpha$ ketoglutarate to succinyl-CoA by the homologous 2-oxoglutarate dehydrogenase complex. While complexes I and II transfer reducing elements to a lipid-embedded two-electron carrier (ubiquinone), the $\mathrm{bc}_{1}$ complex transfers the electrons to the one-electron carrier cytochrome-c, a heme (and, thus, iron) protein, which then transfers electrons to the terminal oxidase.

Bacteria like Escherichia coli and Paracoccus denitrificans have related complexes and enzymes: NADH dehydrogenase (encoded by the nuo operon), succinate dehydrogenase (encoded by $s d h A B C D$ ) and the related fumarate reductase (encoded by frd $A B C D$ ) [78], several terminal oxidases (e.g., products of $c y o A B C D E$ and $c y d A B C$ ) and an F-type ATP synthase (encoded by atp genes). E. coli lacks a bc $c_{1}$ complex, which, however, occurs in Paracoccus denitrificans [79]. E. coli contains the canonical complexes of oxidative decarboxylation (the pyruvate dehydrogenase complex, encoded by aceEF+lpdA, and the 2-oxoglutarate dehydrogenase complex, encoded by suc $A B+l p d A$ ).

The respiratory chain of $H f x$. volcanii and other haloarchaea deviates considerably from those of mitochondria and bacteria such as Paracoccus and E. coli (reviewed by [80]), and a number of questions remain unresolved. We focus on the equivalents of complexes I, III and IV, because these have unresolved issues. We also cover some aspects relevant for the NADH levels (oxidative decarboxylation enzymes and type II NADH dehydrogenase). We do not cover complexes that have already been studied in haloarchaea: complex II (succinate dehydrogenase) [81-83] and complex V (ATP synthase) [84,85].

(a) In haloarchaea, oxidative decarboxylation is not linked to the reduction of NAD to NADH but to the reduction of a ferredoxin (encoded by $f d x$, e.g., OE_4217R, HVO_2995), which has a redox potential similar to that of the NAD/NADH pair [86]. The enzymes for oxidative decarboxylation are pyruvate-ferredoxin oxidoreductase (por $A B$, e.g., OE_2623R/2622R and HVO_1305/1304) and 2-oxoglutarate-ferredoxin oxidoreductase (korAB, e.g., OE_1711R/1710R and HVO_0888/0887), and these have been characterized from Halobacterium salinarum [87-89].

(b) It is yet unresolved how ferredoxin Fdx is reoxidized, but this might be achieved by the Nuo complex. This ferredoxin may well be involved in additional metabolic processes. In Hfx. volcanii, ferredoxin Fdx (HVO_2995) plays an essential role in nitrate 
assimilation [90]. However, in Hbt. salinarum, this metabolic process for Fdx reoxidation does not exist.

(c) The nuo cluster of haloarchaea resembles that of E. coli, a type I NADH dehydrogenase, with the genes and gene order highly conserved and just a few domain fissions and fusions. However, haloarchaea lack NuoEFG [91], which is a subcomplex that mediates interaction with NADH $[92,93]$. Thus, the haloarchaeal nuo complex is unlikely to function as NADH dehydrogenase, despite its annotation as such in KEGG (as of April 2021).

(d) Other catabolic enzymes generate NADH, which must also be reoxidized. Based on inhibitor studies, NADH is not reoxidized by a type I but, rather, by a type II NADH dehydrogenase in Hbt. salinarum [82]. A tentative gene assignment has been made for $\mathrm{Na}-$ tronomonas pharaonis [66]. However, for reasons detailed in Supplementary Text S1 Section $\mathrm{S} 1$, this assignment is highly questionable, so this issue calls for an experimental analysis.

(e) About one-third of the haloarchaea, especially the Natrialbales, do not code for a complex III equivalent (the cytochrome $\mathrm{bc}_{1}$ complex encoded by pet $A B C$ ), according to OrthoDB analysis. The $\mathrm{bc}_{1}$ complex is required to transfer electrons from the lipidembedded two-electron carrier (menaquinone in haloarchaea) to the one-electron carrier associated with terminal oxidases (probably halocyanin). How electrons flow in the absence of a complex III equivalent is currently unresolved.

The haloarchaeal pet $A B C$ genes resemble those of the chloroplast b6- $\mathrm{f}$ complex rather than those of the mitochondrial bc 1 complex (see Supplementary Text S1 Section S1 for more details).

(f) A bc cytochrome was purified from Nmn. pharaonis, but with an atypical 1:1 ratio between the b-type and c-type hemes [81]. The complex is heterodimeric, with subunits of $18 \mathrm{kDa}$ and $14 \mathrm{kDa}$. The 18- $\mathrm{kDa}$ subunit carries the covalently attached heme group [81]. An attempt was made to identify the genes coding for these subunits [94] (for details, see Supplementary Text S1 Section S1). Two approaches were used to obtain protein sequence data, one being the N-terminal protein sequencing of the two subunits extracted from a SDS-polyacrylamide gel. In the other attempt, peptides from the purified complex were separated by HPLC, and a peptide which absorbed at $280 \mathrm{~nm}$ (protein), as well as 400 $\mathrm{nm}$ (heme), was isolated. Absorption at $400 \mathrm{~nm}$ clearly indicates that the isolated peptide contains a covalently attached heme group. The sequences from the two approaches overlapped and resulted in a contiguous sequence of 41 aa, with only the penultimate position remaining undefined [94]. Based on this information, a PCR probe was generated (designated "cyt-C Sonde") that allowed the gene to be identified and sequenced, including its genomic neighborhood. It turned out that the genes coding for the four subunits of succinate dehydrogenase $(s d h C D B A)$ were isolated. The obtained protein sequence corresponds to the N-terminal region of $s d h D$ (with the initiator methionine cleaved off) and only two sequence discrepancies, in addition to the unresolved penultimate residue.

In the $\mathrm{PhD}$ thesis [94], this unambiguous result was rated to be a failure (and the data were never formally published). The reason is that $\mathrm{SdhD}$ is free of cysteine residues, while standard textbooks state that a pair of cysteines is required for covalent heme attachment [95]. The lack of the required cysteine pair was taken to indicate that the results were incorrect and that the identified genes did not encode the cytochrome bc that the study was seeking [94]. In contrast, we speculate that the results were completely correct, despite being in conflict with the cysteine pair paradigm. In our opinion, a paradigm shift is required. The obtained results call for a yet-unanticipated novel mode of covalent heme attachment, exemplified by the $18-\mathrm{kDa}$ subunit of Natronomonas succinate dehydrogenase subunit SdhD. It should be noted that the 41-aa protein sequence, which was obtained, turned out to contain three histidine residues upon translation of the gene, but none of these were detected upon Edman degradation.

In Halobacterium, a small c-type cytochrome was purified (cytochrome $c_{552}, 14.1 \mathrm{kDa}$ ) [96]. Heme staining after SDS-PAGE indicated a covalent heme attachment, but no sequence or composition data were reported, so that it was not possible to identify the protein based on the available information. We speculate that the Halobacterium cytochrome $c_{552}$ 
also represents SdhD (as detailed in Supplementary Text S1 Section S1). In that case, the proposed novel type of covalent heme attachment would not be restricted to Nmn. pharaonis but might be a general property of haloarchaea. This would also solve the "Halobacterium paradox" [95].

(g) The haloarchaeal one-electron carrier is the copper protein halocyanin rather than the iron-containing heme protein cytochrome-c. A halocyanin from Nmn. pharaonis (NP_3954A) was characterized, including its redox potential [97-99]. A gene fusion supports the close connection of a halocyanin with a subunit of a terminal oxidase. For further details, see Supplementary Text S1 Section S1.

(h) Terminal oxidases are highly diverse in haloarchaea, and we restricted our analysis to three species (Nmn. pharaonis, Hfx. volcanii and Hbt. salinarum), because in each of these, at least one terminal oxidase has been experimentally studied (Table 1). The details are described in Supplementary Text S1 Section S1 with subunits of all analyzed terminal oxidases listed in Supplementary Table S1. 
Table 1. Proteins with open annotation issues and their Gold Standard Protein homologs (Section 3.1).

\begin{tabular}{|c|c|c|c|c|c|c|c|c|c|}
\hline \multicolumn{10}{|c|}{ Gold Standard Protein } \\
\hline Section & Code & Gene & Isofunc & \%seq_id & Locus Tag & UniProt & Reference & PMID & Comment \\
\hline \multirow{3}{*}{$1 \mathrm{a}$} & HVO 1305 & \multirow{3}{*}{ por $A B$} & \multirow{3}{*}{ yes } & $67 \%$ & \multirow{3}{*}{$\begin{array}{l}\text { OE2623R } \\
\text { OE2622R }\end{array}$} & \multirow{3}{*}{$\begin{array}{l}\text { B0R } 4 \times 6 \\
\text { B0R } 4 \times 5\end{array}$} & [87] & 1555599 & \\
\hline & HVO 1304 & & & $\begin{array}{l}6 / \% \\
80 \%\end{array}$ & & & [88] & 6266826 & \\
\hline & & & & & & & [89] & 6266827 & \\
\hline \multirow{2}{*}{$1 \mathrm{a}$} & HVO_0888 & \multirow{2}{*}{ kor $A B$} & \multirow{2}{*}{ yes } & $77 \%$ & OE1711R & B0R3G0 & [88] & 6266826 & \\
\hline & HVO_0887 & & & $77 \%$ & OE1710R & B0R3F9 & [89] & 6266827 & \\
\hline \multirow[b]{2}{*}{$1 \mathrm{a} / 1 \mathrm{~b}$} & \multirow[b]{2}{*}{ HVO_2995 } & \multirow[b]{2}{*}{$f d x$} & \multirow[b]{2}{*}{ yes } & \multirow[b]{2}{*}{$88 \%$} & \multirow[b]{2}{*}{ OE4217R } & \multirow[b]{2}{*}{ B0R7I9 } & [100] & 964365 & \multirow{2}{*}{$\begin{array}{l}\text { role in oxidative } \\
\text { decarboxylation }\end{array}$} \\
\hline & & & & & & & {$[101]$} & 188650 & \\
\hline $1 \mathrm{a} / 1 \mathrm{~b}$ & $\begin{array}{l}\text { HVO_2995 } \\
\text { (cont.) }\end{array}$ & & & & self & D4GY89 & [90] & 22103537 & role in nitrate assimilation \\
\hline \multirow{3}{*}{ 1c } & \multirow{3}{*}{$\begin{array}{l}\text { HVO_0979 } \\
\text { (complex) }\end{array}$} & \multirow{3}{*}{ пиов } & \multirow{3}{*}{ possibly } & \multirow{3}{*}{$50 \%$} & \multirow{3}{*}{ tlr0705 } & \multirow{3}{*}{ Q8DKZ4 } & [102] & 15910282 & \multirow{3}{*}{ reoxidizes ferredoxin } \\
\hline & & & & & & & [103] & 30573545 & \\
\hline & & & & & & & [104] & 32001694 & \\
\hline \multirow{2}{*}{ 1c } & \multirow{2}{*}{$\begin{array}{l}\text { HVO_0979 } \\
\text { (cont.) }\end{array}$} & & \multirow[b]{2}{*}{ no } & \multirow{2}{*}{$48 \%$} & \multirow{2}{*}{ b2287 } & $\mathrm{P} \cap \triangle \mathrm{E} C 7$ & [92] & 7607227 & reoxidizes NADH in \\
\hline & & & & & & POAFC7 & [93] & 9485311 & E. coli \\
\hline $1 d$ & NP_3508A & $n d h 1$ & special & 26\% (N-term 140 aa) & - & Q7ZAG8 & & & reassigned (from ndh1 to \\
\hline & & & & & & & & & $\begin{array}{c}\text { sqr) after } \\
\text { annotation transfer }\end{array}$ \\
\hline & NP 3508A & & & & & & & & type II NADH \\
\hline $1 \mathrm{~d}$ & (cont.) & & possibly & $30 \%$ & BpOF4_04810 & A7LKG4 & [105] & 18359284 & $\begin{array}{l}\text { type II NADH } \\
\text { dehydrogenase }\end{array}$ \\
\hline & HVO_2620 & & & & SYNPCC7002 & & & & HVO 0842 (net $B$ ) related \\
\hline $1 \mathrm{e}$ & HVO_0842 & $\operatorname{pet} A B D$ & yes & $39 \%$ & ${ }^{\text {AYNPC }} 0842$ & P28056 & [106] & 11245788 & to cytochome b6 \\
\hline & HVO_0841 & & & & & & & & \\
\hline if & HVO 2810 & $s d h D$ & ves & $66 \%$ & NP $4268 \mathrm{~A}$ & O3INS7 & [81] & 9109654 & \\
\hline If & HVO_2810 & $\operatorname{sen} D$ & yes & $66 \%$ & NP_4268A & Q3INS/ & [94] & PhD_Mattar & \\
\hline $1 \mathrm{~g}$ & HVO_0943 & $c b a D$ & yes & $57 \%$ & NP_2966A & A0A1U7EWW4 & [107] & 9428682 & \\
\hline & $\begin{array}{l}\text { HVO_0943 } \\
\text { (cont.) }\end{array}$ & & - & $63 \%$ & $\begin{array}{l}\text { OE_4073R } \\
\text { (C-term) }\end{array}$ & B0R7A9 & & - & $\begin{array}{l}\text { halocyanin/cbaD fusion } \\
\text { protein, uncharacterized }\end{array}$ \\
\hline $1 \mathrm{~g}$ & HVO_2150 & $h c p G$ & - & $44 \%$ & $\begin{array}{l}\text { OE_4073R } \\
\text { (N-term) }\end{array}$ & B0R7A9 & & - & $\begin{array}{l}\text { halocyanin/cbaD fusion } \\
\text { protein, uncharacterized }\end{array}$ \\
\hline
\end{tabular}


Table 1. Cont.

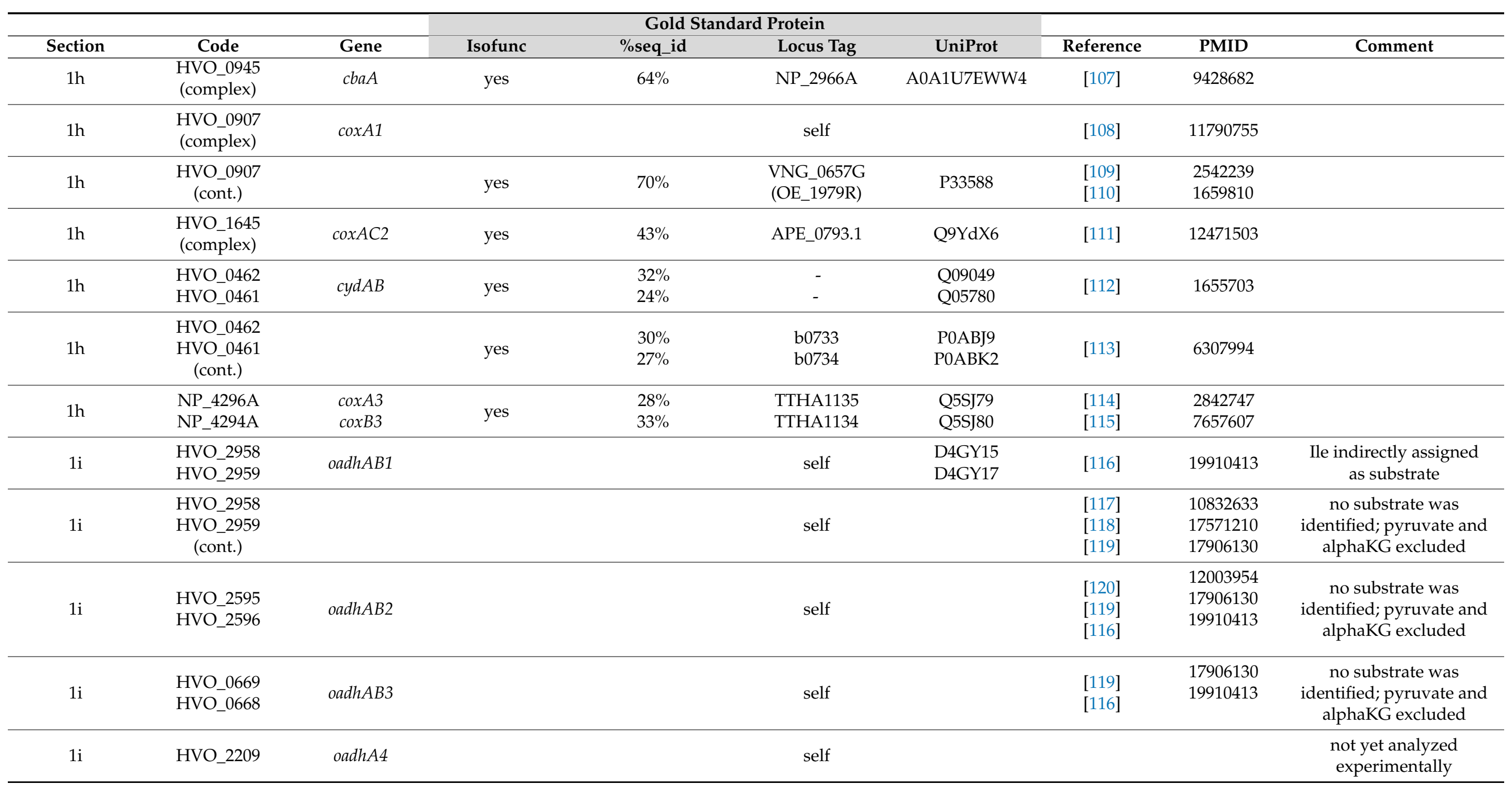


Table 1. Cont.

\begin{tabular}{|c|c|c|c|c|c|c|c|c|c|}
\hline \multicolumn{10}{|c|}{ Gold Standard Protein } \\
\hline Section & Code & Gene & Isofunc & \%seq_id & Locus Tag & UniProt & Reference & PMID & Comment \\
\hline $1 \mathrm{i}$ & $\begin{array}{c}\text { HVO_2958 } \\
\text { HVO_2959 } \\
\text { (cont.) }\end{array}$ & & yes/no & $\begin{array}{l}38 \% \\
52 \%\end{array}$ & $\begin{array}{l}\text { TA1438 } \\
\text { TA1437 }\end{array}$ & $\begin{array}{l}\text { Q9HIA3 } \\
\text { Q9HIA4 }\end{array}$ & [121] & 17894823 & substrates are Ile, Leu, Val \\
\hline $1 \mathrm{i}$ & $\begin{array}{c}\text { HVO_2595 } \\
\text { HVO_2596 } \\
\text { (cont.) }\end{array}$ & & no & $\begin{array}{l}41 \% \\
41 \%\end{array}$ & - & $\begin{array}{l}\text { Q57102 } \\
\text { Q57041 }\end{array}$ & [122] & 1898934 & substrate is acetoin \\
\hline $1 \mathrm{i}$ & $\begin{array}{c}\text { HVO_2595 } \\
\text { HVO_2596 } \\
\text { (cont.) }\end{array}$ & & unknown & $\begin{array}{l}40 \% \\
43 \%\end{array}$ & $\begin{array}{l}\text { BSU08060 } \\
\text { BSU08070 }\end{array}$ & $\begin{array}{l}\text { O31404 } \\
\text { O34591 }\end{array}$ & [123] & 10368162 & substrate is acetoin \\
\hline $1 \mathrm{i}$ & $\begin{array}{c}\text { HVO_0669 } \\
\text { HVO_0668 } \\
\text { (cont.) }\end{array}$ & & unknown & $\begin{array}{l}54 \% \\
47 \%\end{array}$ & $\begin{array}{l}\text { BSU08060 } \\
\text { BSU08070 }\end{array}$ & $\begin{array}{l}\text { O31404 } \\
\text { O34591 }\end{array}$ & [123] & 10368162 & substrate is acetoin \\
\hline $1 \mathrm{i}$ & $\begin{array}{c}\text { HVO_0669 } \\
\text { HVO_0668 } \\
\text { (cont.) }\end{array}$ & & unknown & $\begin{array}{l}49 \% \\
43 \%\end{array}$ & - & $\begin{array}{l}\text { Q57102 } \\
\text { Q57041 }\end{array}$ & [122] & 1898934 & substrate is acetoin \\
\hline
\end{tabular}

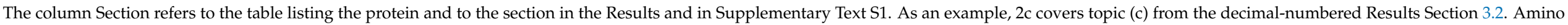

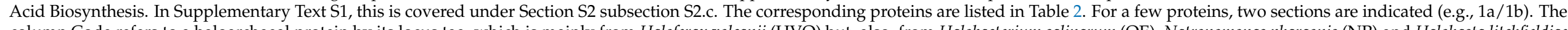

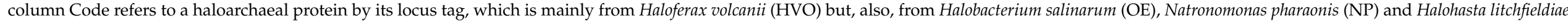

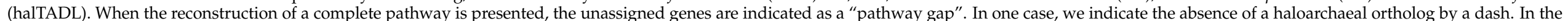

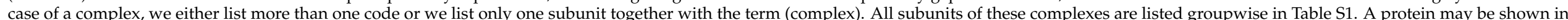

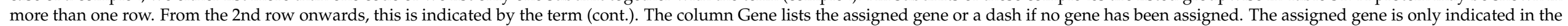

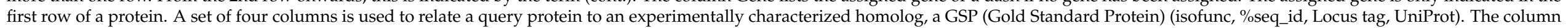

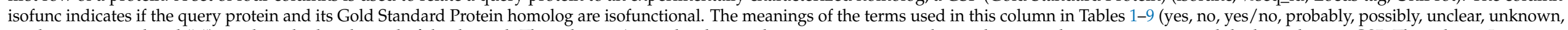

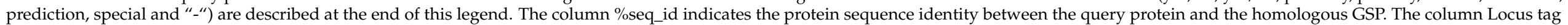

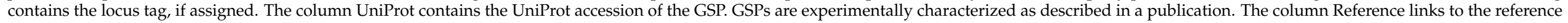

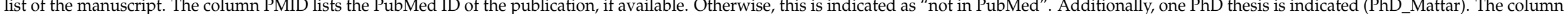

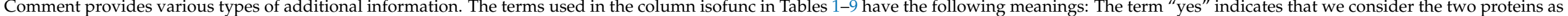

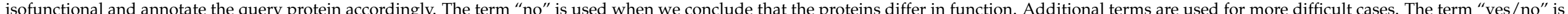
(

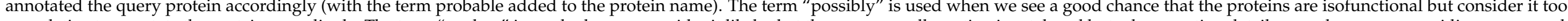

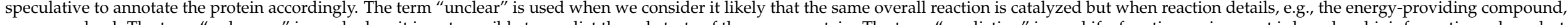

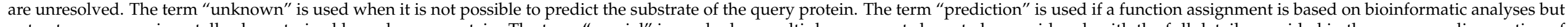

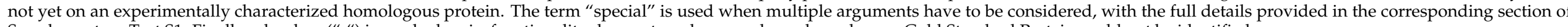
Supplementary Text S1. Finally, a hyphen ("-") is used when isofunctionality does not apply, e.g., when a homologous Gold Standard Protein could not be identified. 
(i) NAD-dependent oxidative decarboxylation is a canonical reaction to convert pyruvate into acetyl-CoA and $\alpha$-ketoglutarate into succinyl-CoA. In haloarchaea, the conversion of pyruvate to acetyl-CoA and $\alpha$-ketoglutarate to succinyl-CoA is dependent on ferredoxin, not on NAD (see above). Nevertheless, most haloarchaeal genomes also code for homologs of enzymes catalyzing NAD-dependent oxidative decarboxylation, such as the E. coli pyruvate dehydrogenase complex. In most cases, the substrates could not be identified, an exception being a paralog involved in isoleucine catabolism [116]. In several cases, the enzymes were found not to show catalytic activity with pyruvate or $\alpha$-ketoglutarate (see Supplementary Text S1 Section S1 for details). Additionally, a conditional lethal por $A B$ mutant was unable to grow on glucose or pyruvate, thus excluding that alternative enzymes for the conversion of pyruvate to acetyl-CoA exist in Hfx. volcanii [22]. Nonetheless, despite experimental results to the contrary, pyruvate has been assigned as a substrate for some of the homologs of the pyruvate dehydrogenase complex in KEGG (as of April 2021).

\subsection{Amino Acid Metabolism}

While most amino acid biosynthesis and degradation pathways can be reliably reconstructed, a few open issues remain, which are discussed below.

(a) The first and last steps of arginine biosynthesis deal with blocking and unblocking of the $\alpha$-amino group of the substrate (glutamate) and a product intermediate (ornithine). As detailed in Supplementary Text S1 Section S2, it is highly likely that glutamate is attached to the $\gamma$-carboxyl group of a carrier protein, and ornithine is released from that carrier protein. This is based on characterized proteins from Thermus thermophilus [124], Thermococcus kodakarensis [125] and Sulfolobus acidocaldarius [126]. The assignment is strongly supported by clustering of the arginine biosynthesis genes. Some of the homologs are bifunctional, being involved in arginine biosynthesis but, also, in lysine biosynthesis via the prokaryotic variant of the $\alpha$-aminoadipate pathway. This ambiguity is not assumed to occur in haloarchaea, which use the diaminopimelate pathway for lysine biosynthesis [127] (see Supplementary Text S1 Section S2 for further discussion of this issue).

Expanding the above, we provided full details underlying our reconstruction of arginine and lysine biosynthesis in Hfx. volcanii in Table 2.

Table 2. Proteins with open annotation issues and their Gold Standard Protein homologs (Section 3.2). For a description of this table, see the legend to Table 1.

\begin{tabular}{|c|c|c|c|c|c|c|c|c|c|}
\hline \multicolumn{10}{|c|}{ Gold Standard Protein } \\
\hline Section & Code & Gene & isofunc & \%seq_id & Locus tag & UniProt & Reference & PMID & Comment \\
\hline $2 \mathrm{a}$ & HVO_0047 & $\arg W$ & no & $54 \%$ & TT_C1544 & Q72HE5 & [128] & 25392000 & $\begin{array}{l}\text { for Arg, not for } \\
\text { Lys biosynthesis }\end{array}$ \\
\hline $2 a$ & $\begin{array}{c}\text { HVO_0047 } \\
\text { (cont.) }\end{array}$ & & yes/no & $39 \%$ & Saci_0753 & Q4JAQ0 & & & $\begin{array}{c}\text { only for Arg, not } \\
\text { for Lys } \\
\text { biosynthesis }\end{array}$ \\
\hline $2 a$ & $\begin{array}{c}\text { HVO_0047 } \\
\text { (cont.) }\end{array}$ & & yes/no & $61 \%$ & TK0279 & Q5JFV9 & [125] & 27566549 & $\begin{array}{c}\text { only for Arg, not } \\
\text { for Lys } \\
\text { biosynthesis }\end{array}$ \\
\hline $2 \mathrm{a}$ & HVO_0046 & $\arg X$ & no & $44 \%$ & TT_C1543 & Q72HE6 & [124] & 19620981 & $\begin{array}{l}\text { for Arg, not for } \\
\text { Lys biosynthesis }\end{array}$ \\
\hline $2 a$ & $\begin{array}{l}\text { HVO_0046 } \\
\text { (cont.) }\end{array}$ & & yes & $30 \%$ & Saci_1621 & Q4J8E7 & & & $\begin{array}{l}\text { only for Arg, not } \\
\text { for Lys } \\
\text { biosynthesis }\end{array}$ \\
\hline $2 a$ & $\begin{array}{c}\text { HVO_0046 } \\
\text { (cont.) }\end{array}$ & & yes/no & $37 \%$ & TK0278 & Q5JFW0 & [125] & 27566549 & $\begin{array}{c}\text { only for Arg, not } \\
\text { for Lys } \\
\text { biosynthesis }\end{array}$ \\
\hline $2 \mathrm{a}$ & HVO_0044 & $\arg B$ & no & $41 \%$ & TT_C1541 & O50147 & $\begin{array}{l}{[124]} \\
{[128]}\end{array}$ & $\begin{array}{l}19620981 \\
25392000\end{array}$ & $\begin{array}{l}\text { for Arg, not for } \\
\text { Lys biosynthesis }\end{array}$ \\
\hline $2 a$ & $\begin{array}{l}\text { HVO_0044 } \\
\text { (cont.) }\end{array}$ & & yes/no & $33 \%$ & Saci_0751 & Q4JAQ2 & [126] & 23434852 & $\begin{array}{c}\text { only for Arg, not } \\
\text { for Lys } \\
\text { biosynthesis }\end{array}$ \\
\hline
\end{tabular}


Table 2. Cont.

\begin{tabular}{|c|c|c|c|c|c|c|c|c|c|}
\hline \multicolumn{10}{|c|}{ Gold Standard Protein } \\
\hline Section & Code & Gene & isofunc & \%seq_id & Locus tag & UniProt & Reference & PMID & Comment \\
\hline $2 a$ & $\begin{array}{l}\text { HVO_0044 } \\
\text { (cont.) }\end{array}$ & & yes/no & $32 \%$ & TK0276 & Q5JFW2 & [125] & 27566549 & $\begin{array}{c}\text { only for Arg, not } \\
\text { for Lys } \\
\text { biosynthesis }\end{array}$ \\
\hline $2 \mathrm{a}$ & HVO_0045 & $\arg C$ & no & $48 \%$ & TT_C1542 & O50146 & $\begin{array}{l}{[124]} \\
{[129]}\end{array}$ & $\begin{array}{l}19620981 \\
26966182\end{array}$ & $\begin{array}{l}\text { for Arg, not for } \\
\text { Lys biosynthesis }\end{array}$ \\
\hline $2 a$ & $\begin{array}{l}\text { HVO_0045 } \\
\text { (cont.) }\end{array}$ & & yes/no & $42 \%$ & Saci_0750 & Q4JAQ3 & [126] & 23434852 & $\begin{array}{c}\text { only for Arg, not } \\
\text { for Lys } \\
\text { biosynthesis }\end{array}$ \\
\hline $2 a$ & $\begin{array}{l}\text { HVO_0045 } \\
\text { (cont.) }\end{array}$ & & yes/no & $46 \%$ & TK0277 & Q5JFW1 & [125] & 27566549 & $\begin{array}{c}\text { only for Arg, not } \\
\text { for Lys } \\
\text { biosynthesis }\end{array}$ \\
\hline $2 a$ & HVO_0043 & $\arg D$ & no & $45 \%$ & TT_C1393 & Q93R93 & [130] & 11489859 & $\begin{array}{l}\text { for Arg, not for } \\
\text { Lys biosynthesis }\end{array}$ \\
\hline $2 a$ & $\begin{array}{l}\text { HVO_0043 } \\
\text { (cont.) }\end{array}$ & & yes/no & $40 \%$ & Saci_0755 & Q4JAP8 & [126] & 23434852 & $\begin{array}{c}\text { only for Arg, not } \\
\text { for Lys } \\
\text { biosynthesis }\end{array}$ \\
\hline $2 a$ & $\begin{array}{l}\text { HVO_0043 } \\
\text { (cont.) }\end{array}$ & & yes/no & $42 \%$ & TK0275 & Q5JFW3 & [125] & 27566549 & $\begin{array}{c}\text { only for Arg, not } \\
\text { for Lys } \\
\text { biosynthesis }\end{array}$ \\
\hline $2 a$ & HVO_0042 & $\arg E$ & no & $36 \%$ & TT_C1396 & Q8VUS5 & $\begin{array}{l}{[124]} \\
{[131]}\end{array}$ & $\begin{array}{l}19620981 \\
28720495\end{array}$ & $\begin{array}{l}\text { for Arg, not for } \\
\text { Lys biosynthesis }\end{array}$ \\
\hline $2 a$ & $\begin{array}{l}\text { HVO_0042 } \\
\text { (cont.) }\end{array}$ & & yes/no & $29 \%$ & Saci_0756 & Q4JAP7 & [126] & 23434852 & $\begin{array}{c}\text { only for Arg, not } \\
\text { for Lys } \\
\text { biosynthesis }\end{array}$ \\
\hline $2 a$ & $\begin{array}{l}\text { HVO_0042 } \\
\text { (cont.) }\end{array}$ & & yes/no & $37 \%$ & TK0274 & Q5JFW4 & [125] & 27566549 & $\begin{array}{c}\text { only for Arg, not } \\
\text { for Lys } \\
\text { biosynthesis }\end{array}$ \\
\hline $2 \mathrm{a}$ & HVO_0041 & $\arg F$ & yes & $50 \%$ & P18186 & BSU11250 & [132] & 4216455 & \\
\hline $2 \mathrm{a}$ & $\begin{array}{l}\text { HVO_0041 } \\
\text { (cont.) }\end{array}$ & & yes & $47 \%$ & OE_5205R & B0R9X3 & [133] & 7868583 & \\
\hline $2 a$ & HVO_0049 & $\arg G$ & yes & $35 \%$ & - & P00966 & [134] & 8792870 & human \\
\hline $2 \mathrm{a}$ & $\begin{array}{l}\text { HVO_0049 } \\
\text { (cont.) }\end{array}$ & & yes & $23 \%$ & b3172 & P0A6E4 & [135] & 10666579 & E. coli \\
\hline $2 \mathrm{a}$ & HVO_0048 & $\operatorname{argH}$ & yes & $38 \%$ & МMP0013 & O74026 & [136] & 10220900 & \\
\hline $2 a$ & HVO_0008 & lys $C$ & yes & $32 \%$ & BSU28470 & P08495 & [137] & 15033471 & \\
\hline $2 a$ & HVO_2487 & asd & yes & $51 \%$ & MJ0205 & Q57658 & [138] & 16225889 & \\
\hline $2 a / 9 e$ & HVO_1101 & $\operatorname{dap} A$ & yes & $45 \%$ & PA1010 & Q9I4W3 & [139] & 21396954 & \\
\hline $2 a$ & HVO_1100 & $\operatorname{dap} B$ & yes & $33 \%$ & b0031 & P04036 & [140] & 7893644 & \\
\hline $2 a$ & HVO_1099 & $\operatorname{dapD}$ & yes & $32 \%$ & b0166 & P0A9D8 & [141] & 6365916 & \\
\hline $2 a$ & HVO_1096 & dapE & yes & $29 \%$ & b2472 & P0AED7 & [142] & 3276674 & $\begin{array}{c}\text { function } \\
\text { supported by } \\
\text { gene clustering }\end{array}$ \\
\hline $2 \mathrm{a}$ & HVO_1097 & dapF & yes & $35 \%$ & b3809 & P0A6K1 & [143] & 6378903 & \\
\hline $2 a$ & HVO_1098 & $\operatorname{lys} A$ & yes & $38 \%$ & b2838 & P00861 & [144] & 14343156 & \\
\hline $2 a$ & HVO_A0634 & - & unknown & $25 \%$ & b2472 & P0AED7 & [142] & 3276674 & $\begin{array}{l}\text { function assigned } \\
\text { to HVO_1096 in } \\
\text { dap cluster }\end{array}$ \\
\hline $2 b$ & HVO_0790 & $f b a 2$ & special & $67 \%$ & OE_1472F & B0R334 & [145] & 25216252 & $\begin{array}{c}\text { EC 2.2.1.10 } \\
\text { activity of } \\
\text { OE_1472F not yet } \\
\text { confirmed } \\
\text { in vitro }\end{array}$ \\
\hline $2 b$ & $\begin{array}{l}\text { HVO_0790 } \\
\text { (cont.) }\end{array}$ & & special & $45 \%$ & MJ0400 & Q57843 & [146] & 15182204 & $\begin{array}{l}\text { substrate } \\
\text { uncertain }\end{array}$ \\
\hline
\end{tabular}


Table 2. Cont.

\begin{tabular}{|c|c|c|c|c|c|c|c|c|c|}
\hline \multicolumn{10}{|c|}{ Gold Standard Protein } \\
\hline Section & Code & Gene & isofunc & \%seq_id & Locus tag & UniProt & Reference & PMID & Comment \\
\hline $2 b$ & HVO_0792 & $\operatorname{aroB}$ & yes & $69 \%$ & OE_1475F & B0R336 & [145] & 25216252 & $\begin{array}{c}\text { OE_1475F only } \\
\text { partially } \\
\text { characterized }\end{array}$ \\
\hline $2 b$ & $\begin{array}{l}\text { HVO_0792 } \\
\text { (cont.) }\end{array}$ & & yes & $44 \%$ & MJ1249 & Q58646 & [146] & 15182204 & \\
\hline $2 b$ & HVO_0602 & aroD1 & yes & $44 \%$ & OE_1477R & B0R338 & [145] & 25216252 & \\
\hline $2 b$ & $\begin{array}{l}\text { HVO_0602 } \\
\text { (cont.) }\end{array}$ & & yes & $31 \%$ & MMP1394 & Q6LXF7 & [147] & 15262931 & \\
\hline $2 c$ & HVO_0009 & $\operatorname{tnaA}$ & yes & $41 \%$ & b3708 & P0A853 & $\begin{array}{l}{[148]} \\
{[149]}\end{array}$ & $\begin{array}{c}2659590 \\
14284727\end{array}$ & \\
\hline $2 d$ & HVO_A0559 & hutH & yes & $42 \%$ & BSU39350 & P10944 & $\begin{array}{l}{[150]} \\
{[151]}\end{array}$ & $\begin{array}{c}2454913 \\
14066617\end{array}$ & \\
\hline $2 d$ & HVO_A0562 & hutU & yes & $62 \%$ & BSU39360 & P25503 & [152] & 4990470 & \\
\hline $2 d$ & HVO_A0560 & hutI & yes & $42 \%$ & BSU39370 & P42084 & [153] & 16990261 & \\
\hline $2 d$ & HVO_A0561 & hutG & yes & $33 \%$ & BSU39380 & P42068 & [152] & 4990470 & \\
\hline $2 \mathrm{e}$ & HVO_0431 & - & - & & & & & & no GSP available \\
\hline $2 \mathrm{e}$ & HVO_0644 & leuA1 & yes/no & $47 \%$ & MJ1392 & Q58787 & [154] & 9864346 & $\begin{array}{c}\text { HVO_0644 } \\
\text { monofunc } \\
\text { (CimA) or bifunc } \\
\text { (CimA+LeuA); } \\
\text { MJ1392 CimA }\end{array}$ \\
\hline $2 \mathrm{e}$ & $\begin{array}{l}\text { HVO_0644 } \\
\text { (cont.) }\end{array}$ & & unclear & $44 \%$ & MJ1195 & Q58595 & [155] & 9665716 & $\begin{array}{c}\text { HVO_0644 } \\
\text { monofunc } \\
\text { (CimA) or bifunc } \\
\text { (CimA+LeuA); } \\
\text { MJ1195 LeuA }\end{array}$ \\
\hline $2 \mathrm{e} / 2 \mathrm{f}$ & HVO_1510 & leuA2 & yes & $47 \%$ & MJ1195 & Q58595 & [155] & 9665716 & $\begin{array}{l}\text { HVO_1510 LeuA; } \\
\text { MJ1195 LeuA }\end{array}$ \\
\hline $2 \mathrm{e} / 2 \mathrm{f}$ & $\begin{array}{l}\text { HVO_1510 } \\
\text { (cont.) }\end{array}$ & & no & $41 \%$ & MJ1392 & Q58787 & [154] & 9864346 & $\begin{array}{l}\text { HVO_1510 LeuA } \\
\text { MJ1392 CimA }\end{array}$ \\
\hline $2 \mathrm{e}$ & HVO_A0489 & - & no & $31 \%$ & MJ1392 & Q58787 & [154] & 9864346 & $\begin{array}{c}\text { HVO_A0489 } \\
\text { general function } \\
\text { only; } \\
\text { MJ1392 CimA }\end{array}$ \\
\hline $2 \mathrm{e}$ & $\begin{array}{l}\text { HVO_A0489 } \\
\text { (cont.) }\end{array}$ & & no & $30 \%$ & MJ1195 & Q58595 & [155] & 9665716 & $\begin{array}{c}\text { HVO_A0489 } \\
\text { general function } \\
\text { only; } \\
\text { MJ1195 LeuA }\end{array}$ \\
\hline $2 \mathrm{e}$ & HVO_1153 & - & - & & & & & & $\begin{array}{c}\text { function } \\
\text { unassigned; } \\
\text { no GSP }\end{array}$ \\
\hline
\end{tabular}

(b) Archaea use a different precursor for aromatic amino acid biosynthesis than the classical pathway. This has been resolved for Methanocaldococcus jannaschii and for Methanococcus maripaludis $[146,156]$. However, the initial steps may differ from those reported for Methanocaldococcus in that fructose 1,6-bisphosphate, rather than 6-deoxy-5ketofructose, might be a substrate [145]. Up to now, a clean deletion of the corresponding enzymes and confirmation with in vitro assays has not yet been achieved (for details, see Supplementary Text S1 Section S2).

(c) The gene for tryptophanase (tpa) is stringently regulated in Haloferax, which is the basis for using its promoter in the toolbox for regulated gene expression [157]. The shutdown of this gene avoids tryptophan degradation when supplies are scarce. Tryptophanase cleaves tryptophan into indole, pyruvate and ammonia. The fate of indole is, however, yet unresolved. 
(d) A probable histidine utilization cluster exists, based on the characterized homologs from Bacillus subtilis, but has not yet been experimentally verified.

(e) Among the 16 auxotrophic mutants observed in a $H f x$. volcanii transposon insertion library [9], some could grow only in the presence of one (or several) supplied amino acids. In many cases, the affected genes were known to be involved in the corresponding pathway, but the others may lead to novel function assignments. One affected gene resulted in histidine auxotrophy, and the product of this gene (HVO_0431) is an interesting candidate. The InterPro domain assignment (HAD family hydrolase) fits into the only remaining pathway gap in histidine biosynthesis (histidinol-phosphatase). In this context, it should be noted that the enzyme that catalyzes the preceding reaction (encoded by hisC) is part of a highly conserved three-gene operon involved in polar lipid biosynthesis (see below). For details, see Supplementary Text S1 Section S2. One affected gene resulted in isoleucine auxotrophy. The product of this gene (HVO_0644) is currently annotated to catalyze two reactions, one being an early step in isoleucine biosynthesis (EC 2.3.1.182) and the other being the first step after leucine biosynthesis branches off from valine biosynthesis (EC 2.3.3.13) (see below, (f)) (for details, see Supplementary Text S1 Section S2).

(f) $H f x$. volcanii codes for two paralogs with an attributed function as 2-isopropylmalate synthase (EC 2.3.3.13). This is the first reaction specific to leucine biosynthesis when the pathway branches off valine biosynthesis. One paralog, HVO_0644, is annotated as bifunctional, also catalyzing a chemically similar reaction that is an early step in isoleucine biosynthesis (EC 2.3.1.182). When the gene encoding HVO_0644 is disrupted by transposon integration, cells cannot grow in the absence of isoleucine. It is unclear if the protein is really bifunctional and is really involved in leucine biosynthesis, catalyzing the reaction of EC 2.3.3.13. The other paralog, HVO_1510, belongs to an ortholog set with major problems concerning the start codon assignment. The ortholog set from the 16 genomes listed in Supplementary Table S2 was analyzed. When only canonical start codons are considered (ATG, GTG and TTG), the orthologs from Haloferax mediterranei, Nmn. pharaonis, Natronomonas moolapensis and Halohasta litchfieldiae either lack a long highly conserved $\mathrm{N}$-terminal region or they are disrupted (pseudogenes), being devoid of a potential start codon. The gene from $H f x$. volcanii has a start codon (GTG) that is consistent with that of Haloferax gibbonsii strain LR2-5 (but a GTA in Hfx. gibbonsii strain ARA6). In this region, the gene from Hfx. mediterranei is closely related but has in-frame stop codons. HVO_1510 is considerably longer than the orthologs from Haloquadratum walsbyi, Haloarcula hispanica and Natrialba magadii. The first alternative start codon for HVO_1510 codes for Met-93. This protein was proteomically identified in three ArcPP datasets [2], and peptides upstream of Met-93 were identified. This gene might be translated from an atypical start codon, either an in-frame CTG or an out-of-frame ATG, which would require ribosomal slippage (for details, see Supplementary Text S1 Section S2 and Supplementary Figure S1). It is tempting to speculate that translation occurs only when leucine is not available.

\subsection{Coenzymes I: Cobalamin and Heme}

The classical heme biosynthesis pathway branches off cobalamin biosynthesis at the level of uroporphyrinogen III. A second pathway exists in bacteria (CPD pathway). Haloarchaea use the alternative heme biosynthesis pathway [158], which has an additional common step with cobalamin biosynthesis, the conversion of uroporphyrinogen III to precorrin-2. For heme biosynthesis, precorrin-2 is converted into siroheme. This pathway was reconstructed [159], except for the iron insertion step. For de novo cobalamin biosynthesis, haloarchaea use the cobalt-early pathway. A key reaction in this pathway variant, catalyzed by $\mathrm{CbiG}$, is cobalt-dependent. Thus, cobalt must be inserted early and is present in all intermediates [160]. Several aspects of heme and cobalamin biosynthesis in haloarchaea have yet to be resolved. This is illustrated in Figure 1. 

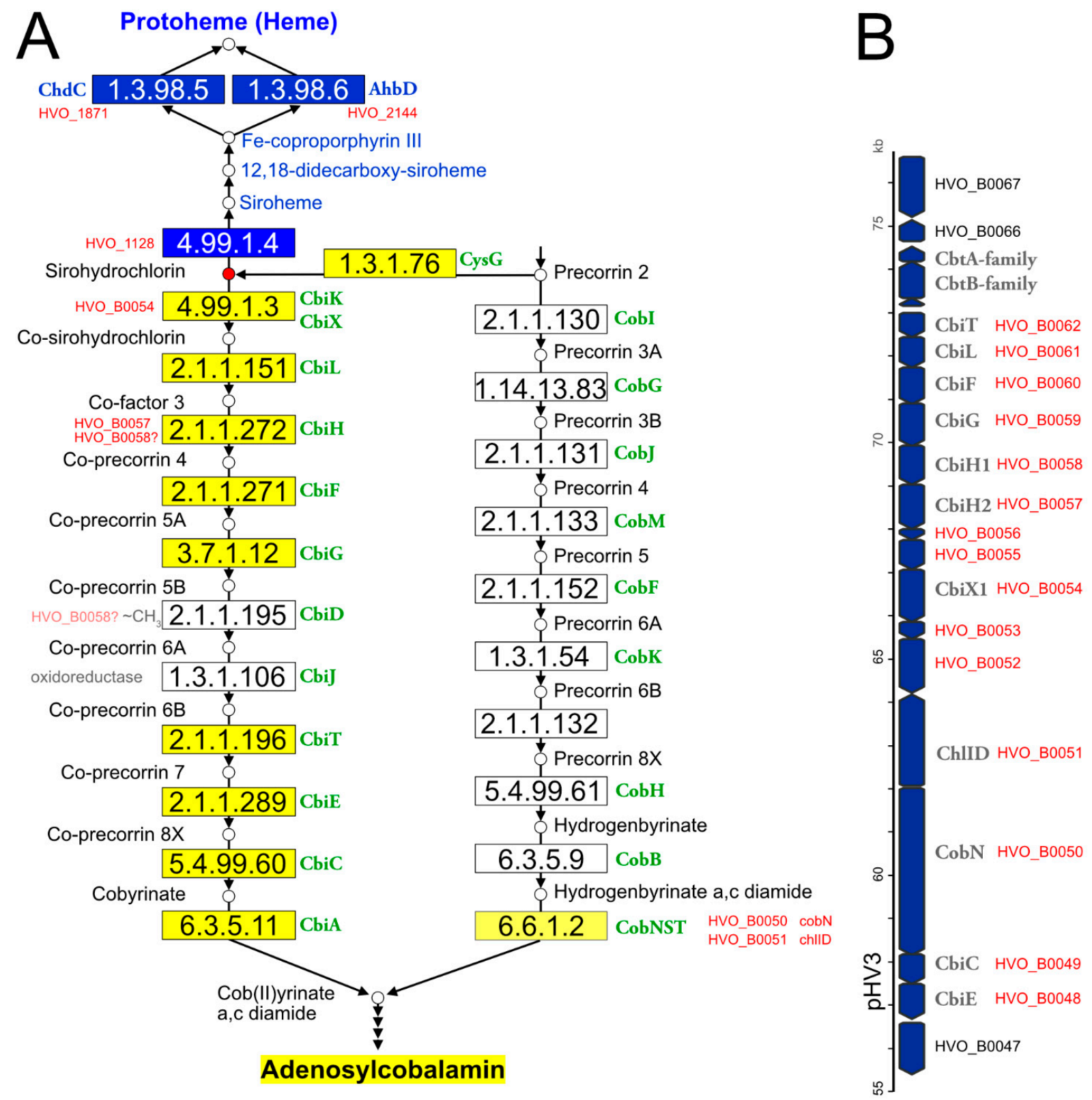

Figure 1. Illustration of the haloarchaeal cobalamin and heme biosynthesis pathways and of the major cobalamin biosynthesis gene cluster. (A) Biosynthesis pathways. This illustration is based on the corresponding KEGG map 00860. Small circles represent pathway intermediates and have their names assigned. Pathway intermediates upstream of precorrin-2 are not displayed. The circle for sirohydrochlorin is highlighted in red, as this is the branchpoint for heme and cobalamin biosynthesis in haloarchaea. Enzymatic reactions are shown by arrows, the EC numbers being provided in rectangular boxes. Rectangles are colored when the enzyme has been reconstructed for haloarchaea (blue: heme biosynthesis; dark yellow: de novo cobalamin biosynthesis; light yellow: late cobaltochelatase, which may be a salvage reaction). Gene names in green are adopted from KEGG and represent those from bacterial model pathways. Consecutive arrowheads indicate reaction series that are not shown in detail for space reasons. Additionally, some enzymes of the heme biosynthesis pathway are omitted for space reasons. For enzymatic reactions that are considered to be open issues, Hfx. volcanii locus tags are provided. For two pathway gaps (white boxes in the cobalt-early pathway), the type of reaction is indicated (oxidoreductase and $\sim \mathrm{CH} 3$, indicating a methylation reaction). The question mark after HVO_B0058 indicates that this protein, currently co-attributed to EC 2.1.1.272, is a candidate for the yet-unassigned EC 2.1.1.195 reaction. We note that haloarchaea might use a deviating biosynthesis pathway, e.g., by swapping the methylation and oxidoreductase reactions (not illustrated). (B) The major cobalamin cluster, encoded on megaplasmid pHV3. Arrows are used to indicate the coding strand and are roughly drawn to scale. If assigned, the gene name is provided in addition to the Hfx. volcanii locus tag. Locus tags in red indicate genes that are part of the cobalamin cluster. 
(a) Hfx. volcanii contains two annotated cbiX genes. For the reasons detailed in Supplementary Text S1 Section S3, we predict that one is a cobaltochelatase, involved in cobalamin biosynthesis, while the other is a ferrochelatase, responsible for the conversion of precorrin-2 to siroheme in the alternative heme biosynthesis pathway.

(b) De novo cobalamin biosynthesis has been extensively reconstructed upon curation of the genome annotation [11]. All enzymes of the pathway and their associated GSPs are listed in Table 3. Only two pathway gaps remained, and because these are consecutive, it may be possible that the haloarchaeal pathway is noncanonical and proceeds via a novel biosynthetic intermediate. There are only four genes with yet-unassigned functions in the $H f x$. volcanii cobalamin gene cluster, and their synteny is well-conserved in the majority of haloarchaeal genomes. Thus, these genes are obvious candidates for filling the pathway gaps (for details, see Supplementary Text S1 Section S3).

(c) The cobalamin biosynthesis and salvage reactions (those beyond ligand cobyrinate $a, c$ diamide) involve "adenosylation of the corrin ring, attachment of the aminopropanol arm, and assembly of the nucleotide loop that bridges the lower ligand dimethylbenzimidazole and the corrin ring" [161]. The enzymes of these branches of cobalamin biosynthesis and their associated GSPs are listed in Table 3. Only two pathway gaps remain open. For one of these, a candidate was proposed upon a detailed bioinformatic analysis [161] (for further details, see Supplementary Text S1 Section S3).

(d) In the cobalt-late (aerobic) pathway variant, the intermediates are cobalt-free, and cobalt is inserted only late in the pathway. Even though haloarchaea do not use the cobalt-late pathway, so that a late cobaltochelatase is not required, they code for a homolog of the large subunit of a characterized heterotrimeric late cobaltochelatase. The adjacent gene is homologous to small subunits of other chelatases. We speculate that this late cobaltochelatase may be involved in cobalamin salvage. The chelatase has a mosaic subunit structure, as also reported previously [161] (see Supplementary Text S1 Section S3 for details).

(e) In the alternative heme biosynthesis pathway, siroheme is decarboxylated to 12,18 didecarboxysiroheme, which is attributed to the proteins encoded by $a h b A$ and $a h b B$. These are homologous to each other and are organized as two two-domain proteins. It is unclear if $\mathrm{AhbA}$ and $\mathrm{AhbB}$ function independently or if they form a complex.

(f) Two of the three heme biosynthesis pathways (AHB and CPD) share a common last step (decarboxylation of Fe-coproporphyrin III to protoheme (heme b)). They use, however, distinct types of enzymes (AHB: ahbD, EC 1.3.98.6, adenosylmethionine-dependent heme synthase, a radical SAM enzyme; CPD: chdC, EC 1.3.98.5, peroxide-dependent heme synthase). Nearly all haloarchaea contain a chdC gene, and two-thirds also contain an $a h b D$ gene. $H f x$. volcanii was shown to use AhbD under anaerobic conditions and ChdC under aerobic conditions [162].

Table 3. Proteins with open annotation issues and their Gold Standard Protein homologs (Section 3.3). For a description of this table, see the legend to Table 1.

\begin{tabular}{|c|c|c|c|c|c|c|c|c|c|}
\hline \multicolumn{10}{|c|}{ Gold Standard Protein } \\
\hline Section & Code & Gene & Isofunc & \%seq_id & Locus Tag & UniProt & Reference & PMID & Comment \\
\hline $3 a$ & HVO_B0054 & $c b i X 1$ & yes & $30 \%$ & - & O87690 & [163] & 12408752 & cobaltochelatase \\
\hline $3 a$ & $\begin{array}{c}\text { HVO_B0054 } \\
\text { (cont.) }\end{array}$ & & yes & $27 \%$ & MTH_1397 & $\mathrm{O} 27448$ & [164] & 12686546 & cobaltochelatase \\
\hline $3 a$ & HVO_1128 & $c b i \mathrm{X} 2$ & no & $29 \%$ & AF0721 & O29537 & [165] & 16835730 & cobaltochelatase \\
\hline $3 a$ & $\begin{array}{c}\text { HVO_1128 } \\
\text { (cont.) }\end{array}$ & & no & $28 \%$ & MTH_1397 & $\mathrm{O} 27448$ & [164] & 12686546 & cobaltochelatase \\
\hline $3 a$ & $\begin{array}{c}\text { HVO_1128 } \\
\text { (cont.) }\end{array}$ & & no & $29 \%$ & AF0721 & O29537 & [165] & 16835730 & cobaltochelatase \\
\hline $3 a$ & NP_0734A & $c b i X 3$ & - & & & & & & $\begin{array}{l}\text { function } \\
\text { unassigned; no } \\
\text { GSP; distantly } \\
\text { related to paralogs }\end{array}$ \\
\hline
\end{tabular}


Table 3. Cont.

\begin{tabular}{|c|c|c|c|c|c|c|c|c|c|}
\hline \multicolumn{10}{|c|}{ Gold Standard Protein } \\
\hline Section & Code & Gene & Isofunc & \%seq_id & Locus Tag & UniProt & Reference & PMID & Comment \\
\hline $3 a$ & HVO_2312 & $\operatorname{sir} C$ & yes/no & $31 \%$ & Mbar_A1461 & Q46CH4 & [166] & 21197080 & $\begin{array}{l}\text { precorrin-2 DH; } \\
\text { no analysis for } \\
\text { Fe-chelatase }\end{array}$ \\
\hline $3 a$ & $\begin{array}{l}\text { HVO_2312 } \\
\text { (cont.) }\end{array}$ & & yes/no & $29 \%$ & STM3477 & P25924 & $\begin{array}{l}{[167]} \\
{[168]}\end{array}$ & $\begin{array}{l}14595395 \\
32054833\end{array}$ & $\begin{array}{l}\text { matches to the } \\
\mathrm{N} \text {-term domain } \\
\text { which is } \\
\text { bifunctional as } \\
\text { precorrin-2 DH } \\
\text { and Fe-chelatase }\end{array}$ \\
\hline $3 a$ & $\begin{array}{l}\text { HVO_2312 } \\
\text { (cont.) }\end{array}$ & & yes/no & $29 \%$ & - & P61818 & $\begin{array}{l}{[163]} \\
{[169]}\end{array}$ & $\begin{array}{l}12408752 \\
18588505\end{array}$ & $\begin{array}{l}\text { precorrin-2 DH; } \\
\text { devoid of } \\
\text { Fe-chelatase } \\
\text { activity }\end{array}$ \\
\hline $3 b$ & HVO_B0061 & $c b i L$ & no & $32 \%$ & STM2024 & Q05593 & [170] & 1451790 & $\begin{array}{l}\text { equivalent } \\
\text { reaction on } \\
\text { cobalt-free } \\
\text { substrate }\end{array}$ \\
\hline $3 b$ & HVO_B0057 & $c b i H 2$ & yes & $45 \%$ & - & O87689 & [160] & 23922391 & $\begin{array}{c}\text { corresponds to } \\
\text { N-term of O87689 } \\
\text { which has a } \\
\text { C-term extension }\end{array}$ \\
\hline $3 b$ & $\begin{array}{c}\text { HVO_B0057 } \\
\text { (cont.) }\end{array}$ & & no & $40 \%$ & STM2027 & Q05590 & $\begin{array}{l}{[171]} \\
{[172]}\end{array}$ & $\begin{array}{c}9331403 \\
16198574\end{array}$ & $\begin{array}{c}\text { equivalent } \\
\text { reaction on } \\
\text { cobalt-free } \\
\text { substrate }\end{array}$ \\
\hline $3 b$ & HVO_B0058 & cbiH1 & special & $32 \%$ & - & O87689 & [160] & 23922391 & $\begin{array}{l}\text { corresponds to } \\
\text { N-term of O87689 } \\
\text { which has a } \\
\text { C-term extension; } \\
\text { more distant to } \\
\text { O87689 than } \\
\text { CbiH2 }\end{array}$ \\
\hline $3 b$ & $\begin{array}{c}\text { HVO_B0058 } \\
\text { (cont.) }\end{array}$ & & no & $30 \%$ & STM2027 & Q05590 & $\begin{array}{l}{[171]} \\
{[172]}\end{array}$ & $\begin{array}{c}9331403 \\
16198574\end{array}$ & $\begin{array}{l}\text { equivalent } \\
\text { reaction on } \\
\text { cobalt-free } \\
\text { substrate }\end{array}$ \\
\hline $3 b$ & HVO_B0060 & $c b i F$ & no & $40 \%$ & STM2029 & P0A2G9 & $\begin{array}{l}{[170]} \\
{[173]}\end{array}$ & $\begin{array}{c}1451790 \\
16866557\end{array}$ & $\begin{array}{l}\text { equivalent } \\
\text { reaction on } \\
\text { cobalt-free } \\
\text { substrate }\end{array}$ \\
\hline $3 b$ & $\begin{array}{c}\text { HVO_B0060 } \\
\text { (cont.) }\end{array}$ & & yes & $38 \%$ & - & O87686 & [160] & 23922391 & \\
\hline $3 b$ & HVO_B0059 & $c b i G$ & yes & $24 \%$ & - & O87687 & [160] & 23922391 & \\
\hline $3 b$ & $\begin{array}{c}\text { pathway } \\
\text { gap }\end{array}$ & & & & & & & & EC 2.1.1.195 \\
\hline $3 b$ & $\begin{array}{l}\text { pathway } \\
\text { gap }\end{array}$ & & & & & & & & EC 1.3.1.106 \\
\hline $3 b$ & HVO_B0062 & $c b i T$ & yes & $36 \%$ & - & O87694 & [160] & 23922391 & $\begin{array}{l}\text { corresponds to } \\
\text { the C-term of } \\
\text { bifunctional } \\
\text { O87694 }\end{array}$ \\
\hline $3 b$ & HVO_B0048 & $c b i E$ & yes & $28 \%$ & - & O87694 & [160] & 23922391 & $\begin{array}{l}\text { corresponds to } \\
\text { the N-term of } \\
\text { bifunctional } \\
\text { O87694 }\end{array}$ \\
\hline $3 b$ & HVO_B0049 & $c b i C$ & yes & $33 \%$ & - & O87692 & [160] & 23922391 & \\
\hline
\end{tabular}


Table 3. Cont

\begin{tabular}{|c|c|c|c|c|c|c|c|c|c|}
\hline \multicolumn{10}{|c|}{ Gold Standard Protein } \\
\hline Section & Code & Gene & Isofunc & \%seq_id & Locus Tag & UniProt & Reference & PMID & Comment \\
\hline $3 b$ & HVO_A0487 & $\operatorname{cbiA}$ & no & $37 \%$ & STM2035 & P29946 & [174] & 15311923 & $\begin{array}{l}\text { equivalent } \\
\text { reaction on } \\
\text { cobalt-free } \\
\text { substrate }\end{array}$ \\
\hline $3 b$ & HVO_B0052 & - & - & & & & & & $\begin{array}{l}\text { function } \\
\text { unassigned; } \\
\text { no GSP }\end{array}$ \\
\hline $3 b$ & HVO_B0053 & - & - & & & & & & $\begin{array}{l}\text { function } \\
\text { unassigned; } \\
\text { no GSP }\end{array}$ \\
\hline $3 b$ & HVO_B0055 & - & - & & & & & & $\begin{array}{l}\text { function } \\
\text { unassigned; } \\
\text { no GSP }\end{array}$ \\
\hline $3 b$ & HVO_B0056 & - & - & & & & & & $\begin{array}{l}\text { function } \\
\text { unassigned; } \\
\text { no GSP }\end{array}$ \\
\hline $3 c$ & HVO_A0488 & $\operatorname{cob} A$ & yes & $31 \%$ & MM_3138 & Q8PSE1 & [175] & 16672609 & \\
\hline $3 c$ & $\begin{array}{l}\text { HVO_A0488 } \\
\text { (cont.) }\end{array}$ & & yes & $30 \%$ & STM1718 & P31570 & [176] & 12080060 & \\
\hline $3 c$ & HVO_2395 & $p d u O$ & yes & $37 \%$ & - & Q9XDN2 & [177] & 11160088 & $\begin{array}{l}\text { PduO and CobA } \\
\text { are isofunctional; } \\
\text { In Q9XDN2, the } \\
\text { PduO domain } \\
\text { (N-term) is fused } \\
\text { to a DUF336 } \\
\text { domain }\end{array}$ \\
\hline $3 c$ & HVO_A0553 & $c b i P$ & yes & $63 \%$ & $\begin{array}{l}\text { VNG_1576G } \\
\text { OE_3246F }\end{array}$ & $\begin{array}{l}\text { Q9HPL5 } \\
\text { B0R5X2 }\end{array}$ & [178] & 14645280 & \\
\hline $3 c$ & HVO_0587 & $c b i B$ & yes & $58 \%$ & $\begin{array}{l}\text { VNG_1578H } \\
\text { OE_3253F }\end{array}$ & $\begin{array}{l}\text { Q9HPL3 } \\
\text { B0R5X4 }\end{array}$ & [178] & 14645280 & \\
\hline $3 c$ & HVO_0592 & cbiZ & yes & $57 \%$ & $\begin{array}{l}\text { VNG_1583C } \\
\text { OE_3261F }\end{array}$ & $\begin{array}{l}\text { Q9HPL3 } \\
\text { B0R5X8 }\end{array}$ & [179] & 14990804 & \\
\hline $3 c$ & HVO_0589 & $\operatorname{cob} Y$ & yes & $47 \%$ & $\begin{array}{l}\text { VNG_1581C } \\
\text { OE_3257F }\end{array}$ & $\begin{array}{l}\text { Q9HPL1 } \\
\text { B0R5X6 }\end{array}$ & [180] & 12486068 & \\
\hline $3 c$ & HVO_0588 & $\operatorname{cobS}$ & yes & $30 \%$ & STM2017 & Q05602 & [181] & 17209023 & \\
\hline $3 c$ & - & & & & STM0643 & P39701 & [182] & 7929373 & $\begin{array}{c}\text { EC 3.1.3.73; CobC; } \\
\text { no homolog in } \\
\text { haloarchaea }\end{array}$ \\
\hline $3 c$ & HVO_0586 & - & prediction & - & - & - & [161] & 12869542 & $\begin{array}{c}\text { EC 3.1.3.73; } \\
\text { prediction for } \\
\text { HSL01294 } \\
\text { (VNG_1577C) }\end{array}$ \\
\hline $3 c$ & $\begin{array}{l}\text { pathway } \\
\text { gap }\end{array}$ & & & & & & & & EC 2.7.1.177 \\
\hline $3 c$ & HVO_0591 & cobD1 & yes & $31 \%$ & STM0644 & P97084 & [183] & 9446573 & \\
\hline $3 c$ & HVO_0593 & $\operatorname{cobD} 2$ & yes & & & & & & $\begin{array}{l}\text { no GSP; } 51 \% \\
\text { seq_id to } \\
\text { HVO_0591 } \\
\text { (cobD1) }\end{array}$ \\
\hline $3 c$ & HVO_0590 & cobT & prediction & & & & [161] & 12869542 & $\begin{array}{l}\text { prediction for } \\
\text { VNG_1572C }\end{array}$ \\
\hline $3 c$ & halTADL_3045 & $\operatorname{cobT}$ & yes & $39 \%$ & STM0644 & Q05603 & [184] & 8206834 & \\
\hline $3 d$ & HVO_B0051 & $\operatorname{cobN}$ & yes & $34 \%$ & - & P29929 & [185] & 1429466 & \\
\hline $3 d$ & $\begin{array}{l}\text { HVO_B0051 } \\
\text { (cont.) }\end{array}$ & & no & $29 \%$ & - & Q55284 & $\begin{array}{l}{[186]} \\
{[187]}\end{array}$ & $\begin{array}{l}8663186 \\
9716491\end{array}$ & Mg chelatase \\
\hline
\end{tabular}


Table 3. Cont.

\begin{tabular}{|c|c|c|c|c|c|c|c|c|c|}
\hline \multicolumn{10}{|c|}{ Gold Standard Protein } \\
\hline Section & Code & Gene & Isofunc & \%seq_id & Locus Tag & UniProt & Reference & PMID & Comment \\
\hline $3 \mathrm{~d}$ & HVO_B0050 & chliD & no & $46 \%$ & slr1030 & P51634 & $\begin{array}{l}{[186]} \\
{[187]}\end{array}$ & $\begin{array}{l}8663186 \\
9716491\end{array}$ & $\begin{array}{l}\text { match to N-term; } \\
\text { Mg chelatase }\end{array}$ \\
\hline $3 d$ & $\begin{array}{l}\text { HVO_B0050 } \\
\text { (cont.) }\end{array}$ & & no & $33 \%$ & slr1777 & P52772 & $\begin{array}{l}{[186]} \\
{[187]}\end{array}$ & $\begin{array}{l}8663186 \\
9716491\end{array}$ & $\begin{array}{c}\text { match to } \\
\text { complete } \\
\text { sequence, incl } \\
\text { distant match to } \\
\text { N-term; } \\
\text { Mg chelatase }\end{array}$ \\
\hline $3 e$ & HVO_2227 & $a h b A$ & yes & $35 \%$ & - & I6UH61 & [158] & 21969545 & \\
\hline $3 e$ & HVO_2313 & $a h b B$ & yes & $32 \%$ & - & I6UH61 & [158] & 21969545 & \\
\hline $3 \mathrm{f}$ & HVO_1121 & $a h b C$ & yes & $47 \%$ & Mbar_A1793 & Q46BK8 & $\begin{array}{l}{[158]} \\
{[188]}\end{array}$ & $\begin{array}{l}21969545 \\
24669201\end{array}$ & \\
\hline $3 f$ & HVO_2144 & $a h b D$ & & & self & & [162] & 29284023 & EC 1.3.98.6 \\
\hline $3 \mathrm{f}$ & $\begin{array}{l}\text { HVO_2144 } \\
\text { (cont.) }\end{array}$ & & yes & $42 \%$ & Mbar_A1458 & Q46CH7 & [188] & 24669201 & \\
\hline $3 \mathrm{f}$ & HVO_1871 & $\operatorname{chd} \mathrm{C}$ & & & self & & [162] & 29284023 & EC 1.3.98.5 \\
\hline $3 \mathrm{f}$ & $\begin{array}{c}\text { HVO_1871 } \\
\text { (cont.) }\end{array}$ & & yes & $46 \%$ & BSU37670 & P39645 & [189] & 28123057 & \\
\hline
\end{tabular}

\subsection{Coenzymes II: Coenzyme F420}

Even though coenzyme F420 is predominantly associated with methanogenic archaea [190,191], it occurs also in bacteria, and a small amount of this coenzyme has been detected in non-methanogenic archaea, including halophiles [192]. The genes required for the biosynthesis of this coenzyme are encoded in haloarchaeal genomes, but the origin and attachment of the phospholactate moiety are not completely resolved (see below). To the best of our knowledge, only a single coenzyme F420-dependent enzymatic reaction has yet been reported for halophilic archaea [193]. Thus, the importance of this coenzyme in haloarchaeal biology is currently enigmatic and awaits experimental analysis.

(a) The pathway that creates the carbon backbone of this coenzyme has been reconstructed. We list the enzymes with their associated GSPs in Table 4. Coenzyme F420 contains a phospholactate moiety, which was reported to originate from 2-phospholactate [194], but this compound is metabolically not well-connected. As summarized in Supplementary Text S1 Section S4, there are various new insights regarding this pathway from recent studies in other prokaryotes $[195,196]$. To the best of our knowledge, the haloarchaeal coenzyme F420 biosynthesis pathway has never been experimentally analyzed.

(b) The prediction of coenzyme F420-specific oxidoreductases in Mycobacterium and actinobacteria has been reported [197], leading to patterns and domains that are also found in haloarchaea. Several such enzymes are described in Supplementary Text S1 Section S4.

(c) HVO_1937 might be a coenzyme F420-dependent 5,10-methylenetetrahydrofolate reductase (see, also, below: C1 metabolism, and Supplementary Text S1 Section S4).

(d) The precursor for coenzyme F420 may be used by a photolyase involved in DNA repair. 
Table 4. Proteins with open annotation issues and their Gold Standard Protein homologs (Section 3.4). For a description of this table, see the legend to Table 1.

\begin{tabular}{|c|c|c|c|c|c|c|c|c|c|}
\hline \multicolumn{7}{|c|}{ Gold Standard Protein } & \multirow[b]{2}{*}{ Reference } & \multirow[b]{2}{*}{ PMID } & \multirow[b]{2}{*}{ Comment } \\
\hline Section & Code & Gene & Isofunc & \%seq_id & Locus Tag & UniProt & & & \\
\hline $4 a$ & HVO_2198 & $\operatorname{cofH}$ & yes & $35 \%$ & MJ1431 & Q58826 & $\begin{array}{l}\text { [198] } \\
\text { [199] }\end{array}$ & $\begin{array}{l}14593448 \\
25781338\end{array}$ & \\
\hline $4 a$ & HVO_2201 & $\operatorname{cofG}$ & yes & $43 \%$ & MJ0446 & Q57888 & $\begin{array}{l}{[198]} \\
{[200]} \\
{[199]}\end{array}$ & $\begin{array}{l}14593448 \\
23072415 \\
25781338\end{array}$ & \\
\hline $4 a$ & HVO_2202 & $\operatorname{cofC}$ & yes & $25 \%$ & MJ0887 & Q58297 & $\begin{array}{l}{[194]} \\
{[195]} \\
{[196]}\end{array}$ & $\begin{array}{l}18260642 \\
30952857 \\
31469543\end{array}$ & \\
\hline $4 a$ & HVO_2479 & $\operatorname{cofD}$ & yes & $39 \%$ & MM_1874 & Q8PVT6 & $\begin{array}{l}{[201]} \\
{[196]}\end{array}$ & $\begin{array}{l}18252724 \\
31469543\end{array}$ & \\
\hline $4 a$ & $\begin{array}{c}\text { HVO_2479 } \\
\text { (cont.) }\end{array}$ & & yes & $32 \%$ & MJ1256 & Q58653 & [202] & 11888293 & \\
\hline $4 \mathrm{a}$ & HVO_1936 & $\operatorname{cof} E$ & yes & $47 \%$ & AF_2256 & O28028 & [203] & 17669425 & \\
\hline $4 a$ & $\begin{array}{c}\text { HVO_1936 } \\
\text { (cont.) }\end{array}$ & & yes & $38 \%$ & MJ0768 & Q58178 & [204] & 12911320 & \\
\hline $4 b$ & HVO_0433 & $n p d G$ & yes & $38 \%$ & AF_0892 & O29370 & [205] & $\begin{array}{l}\text { not in } \\
\text { PubMed }\end{array}$ & \\
\hline $4 b$ & HVO_B0113 & - & no & $27 \%$ & Rv0132c & P96809 & [206] & 24349169 & $\begin{array}{l}\text { too distant } \\
\text { to assume } \\
\text { isofunctionality }\end{array}$ \\
\hline $4 b$ & HVO_B0342 & - & unknown & $29 \%$ & - & O93734 & $\begin{array}{l}{[207]} \\
{[208]}\end{array}$ & $\begin{array}{c}8706724 \\
15016352\end{array}$ & $\begin{array}{l}\text { too distant } \\
\text { to assume } \\
\text { isofunctionality }\end{array}$ \\
\hline $4 b$ & NP_1902A & - & no & $28 \%$ & - & Q9UXP0 & $\begin{array}{l}{[209]} \\
{[210]}\end{array}$ & $\begin{array}{l}1735436 \\
9933933\end{array}$ & $\begin{array}{l}\text { too distant to } \\
\text { assume } \\
\text { isofunctionality }\end{array}$ \\
\hline $4 b$ & NP_4006A & - & no & $27 \%$ & MJ0870 & Q58280 & [211] & 16048999 & $\begin{array}{l}\text { too distant } \\
\text { to assume } \\
\text { isofunctionality }\end{array}$ \\
\hline $4 c / 5 c$ & HVO_1937 & mer & no & $38 \%$ & MTH_1752 & O27784 & $\begin{array}{l}{[212]} \\
{[213]} \\
{[214]}\end{array}$ & $\begin{array}{c}2298726 \\
7649177 \\
10891279\end{array}$ & \\
\hline $4 d$ & HVO_2911 & $p h r 2$ & yes & $62 \%$ & $\begin{array}{l}\text { VNG_1335G } \\
\text { OE_2907R }\end{array}$ & $\begin{array}{l}\text { Q9HQ46 } \\
\text { B0R5D6 }\end{array}$ & $\begin{array}{l}{[215]} \\
{[216]}\end{array}$ & $\begin{array}{c}2681164 \\
12773185\end{array}$ & \\
\hline $4 d$ & HVO_2843 & phr1 & no & $45 \%$ & sll1629 & P77967 & [217] & 12535521 & $\begin{array}{l}\text { sll1629 } \\
\text { implicated in } \\
\text { transcription } \\
\text { regulation }\end{array}$ \\
\hline $4 d$ & $\begin{array}{c}\text { HVO_2843 } \\
\text { (cont.) }\end{array}$ & & possibly & $45 \%$ & At5g24850 & Q84KJ5 & $\begin{array}{l}{[218]} \\
{[219]}\end{array}$ & $\begin{array}{l}12834405 \\
17062752\end{array}$ & $\begin{array}{l}\text { mediates } \\
\text { photo-repair } \\
\text { of ssDNA }\end{array}$ \\
\hline $4 d$ & HVO_1234 & phr3 & possibly & $40 \%$ & Atu4765 & А9СН39 & [220] & 23589886 & \\
\hline
\end{tabular}

3.5. Coenzymes III: Coenzymes of C1 Metabolism: Tetrahydrofolate in Haloarchaea and Methanopterin in Methanogens

Halophilic and methanogenic archaea use distinct coenzymes as one-carbon carriers (C1 metabolism): tetrahydrofolate in haloarchaea and methanopterin in methanogens [221,222]. Several characterized methanogenic proteins that act on or with methanopterin have comparably close homologs in haloarchaea (Table 5), which results in the misannotation of haloarchaeal proteins (e.g., in SwissProt) as being involved in methanopterin biology. We assume that the haloarchaeal proteins function with the haloarchaeal one-carbon carrier tetrahydrofolate and that this shift in coenzyme specificity is possible due to the structural similarity between methanopterin and tetrahydrofolate (a near-identical core structure consisting of a pterin heterocyclic ring linked via a methylene bridge to a phenyl ring) 
(Figure 2). A detailed review on the many variants of the tetrahydrofolate biosynthetic pathway is available [223].
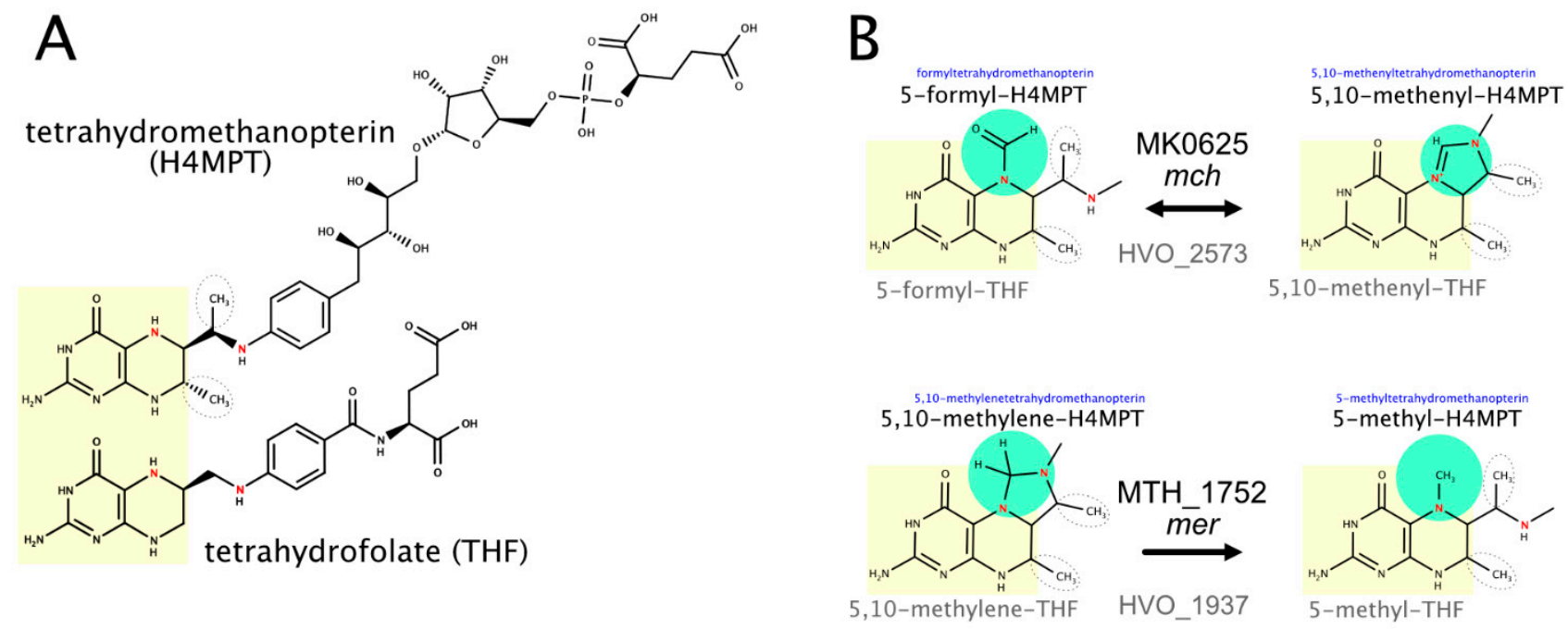

Figure 2. The structure of the $\mathrm{C} 1$ coenzymes tetrahydrofolate and methanopterin and two enzymes that act on the attached C1 compound. (A) The structures of tetrahydromethanopterin (top) and tetrahydrofolate (bottom) illustrate the similarities and differences between these $\mathrm{C} 1$ coenzymes. The common pteridine-based ring system is highlighted in yellow, and the initial biosynthesis step that generates this ring system is catalyzed by homologous enzymes (topic (b)). Two methanopterinspecific methyl groups are outlined by dashed ovals. N5 and N10, which are involved in the binding of the C1 compound, are colored red. (B) Two enzymatic reactions that alter the oxidation level of the C1 compound are illustrated. The methanogenic and haloarchaeal enzymes are homologous, even though they use distinct C1 coenzymes (topic (c)). It should be noted that MTH-1752 uses coenzyme F420 (not illustrated, Section 3.4, topic (c)), and this might also hold true for HVO_1937.

(a) Folate biosynthesis requires aminobenzoate. We proposed candidates for a pathway from chorismate to para-aminobenzoate $[66,224]$ (for details, see Supplementary Text S1 Section S5). However, these predictions have not been adopted by KEGG (accessed April 2021), and without experimental confirmation, this is unlikely to ever happen.

(b) GTP cyclohydrolase MptA (HVO_2348) catalyzes a reaction in the common part of tetrahydrofolate and methanopterin biosynthesis. The enzymes specific for methanopterin biosynthesis are absent from haloarchaea, and thus, the assignment of HVO_2348 to the methanopterin biosynthesis pathway in UniProt is invalid (accessed March 2021).

The next common pathway step (EC 3.1.4.56) has been resolved in M. jannaschii (MJ0837) but is still a pathway gap in halophilic archaea. MJ0837 is very distantly related to HVO_A0533, which is a promising candidate for experimental analysis.

HVO_2628 shows $30 \%$ protein sequence identity with the enzyme catalyzing the first committed step to methanopterin biosynthesis. As detailed in Supplementary Text S1 Section S5, we consider it likely that it does not catalyze that reaction.

(c) Two enzymes that alter the oxidation level of the coenzyme-attached one-carbon compound probably function with tetrahydrofolate, even though their methanogenic homologs function with methanopterin. In contrast to their assignments in KEGG and UniProt (as of March 2021), their probable functions are thus methenyltetrahydrofolate cyclohydrolase (HVO_2573) and 5,10-methylenetetrahydrofolate reductase (HVO_1937) (see Figure 2 and Supplementary Text S1 Section S5). 
Table 5. Proteins with open annotation issues and their Gold Standard Protein homologs (Section 3.5). For a description of this table, see the legend to Table 1.

\begin{tabular}{|c|c|c|c|c|c|c|c|c|c|}
\hline \multirow[b]{2}{*}{ Section } & \multirow[b]{2}{*}{ Code } & \multirow[b]{2}{*}{ Gene } & \multicolumn{4}{|c|}{ Gold Standard Protein } & \multirow[b]{2}{*}{ Reference } & \multirow[b]{2}{*}{ PMID } & \multirow[b]{2}{*}{ Comment } \\
\hline & & & Isofunc & \%seq_id & Locus Tag & UniProt & & & \\
\hline $5 a$ & HVO_0709 & $p a b A$ & no & $47 \%$ & TTHA1843 & P05379 & [225] & 2844259 & Trp biosynthesis \\
\hline $5 a$ & $\begin{array}{l}\text { HVO_0709 } \\
\text { (cont.) }\end{array}$ & & yes/no & $39 \%$ & BSU00750 & P28819 & [226] & 2123867 & $\begin{array}{c}\text { TrpG works with } \\
\text { TrpE and with } \\
\text { PabB }\end{array}$ \\
\hline $5 a$ & HVO_0710 & $p a b B$ & no & $46 \%$ & TTHA1844 & P05378 & [225] & 2844259 & Trp biosynthesis \\
\hline $5 a$ & $\begin{array}{l}\text { HVO_0710 } \\
\text { (cont.) }\end{array}$ & & yes & $44 \%$ & BSU00740 & P28820 & [227] & 19275258 & $\begin{array}{l}\text { PabB; para- } \\
\text { aminobenzoate } \\
\text { biosynthesis }\end{array}$ \\
\hline $5 a$ & HVO_0708 & $p a b C$ & no & $36 \%$ & AF_0933 & O29329 & [228] & 30733943 & $\begin{array}{l}\text { branched-chain } \\
\text { amino acids }\end{array}$ \\
\hline $5 b$ & HVO_2348 & $m p t A$ & & & self & & [229] & 19478918 & $\begin{array}{c}\text { gene deletion } \\
\text { phenotypes }\end{array}$ \\
\hline $5 b$ & $\begin{array}{l}\text { HVO_2348 } \\
\text { (cont.) }\end{array}$ & & yes & $41 \%$ & MJ0775 & Q58185 & [230] & 17497938 & $\begin{array}{l}\text { common part of } \\
\text { methanopterin } \\
\text { and } \\
\text { tetrahydrofolate } \\
\text { biosynthesis }\end{array}$ \\
\hline $5 b$ & HVO_A0533 & - & unknown & $27 \%$ & MJ0837 & Q58247 & [231] & 19746965 & $\begin{array}{c}\text { if isofunctional } \\
\text { would resolve a } \\
\text { pathway gap }\end{array}$ \\
\hline $5 b$ & HVO_2628 & - & no & $31 \%$ & AF_2089 & $\mathrm{O} 28190$ & [232] & 12142414 & $\begin{array}{l}\text { first committed } \\
\text { step to } \\
\text { methanopterin } \\
\text { biosynthesis }\end{array}$ \\
\hline $5 b$ & $\begin{array}{l}\text { HVO_2628 } \\
\text { (cont.) }\end{array}$ & & no & $26 \%$ & MJ1427 & Q58822 & [233] & 15262968 & $\begin{array}{l}\text { first committed } \\
\text { step to } \\
\text { methanopterin } \\
\text { biosynthesis }\end{array}$ \\
\hline $5 c$ & HVO_2573 & mch & no & $45 \%$ & MK0625 & P94954 & [234] & 9676239 & $\begin{array}{l}\text { acts on a } \\
\text { one-carbon } \\
\text { attached to } \\
\text { methanopterin }\end{array}$ \\
\hline $4 c / 5 c$ & HVO_1937 & mer & no & $38 \%$ & MTH_1752 & $\mathrm{O} 27784$ & $\begin{array}{l}{[212]} \\
{[213]} \\
{[214]}\end{array}$ & $\begin{array}{c}2298726 \\
7649177 \\
10891279\end{array}$ & $\begin{array}{l}\text { acts on a } \\
\text { one-carbon } \\
\text { compound } \\
\text { attached to } \\
\text { methanopterin }\end{array}$ \\
\hline
\end{tabular}

\subsection{Coenzymes IV: NAD and FAD (Riboflavin)}

(a) The energy source for NAD kinase may be ATP or polyphosphate. This is unresolved for the two paralogs of probable NAD kinase (HVO_2363, nadK1 and HVO_0837, nadK2). These show only 25\% protein sequence identity to each other (see Supplementary Text S1 Section S6). Polyphosphate was not found in exponentially growing Hfx. volcanii cells [235], and thus ATP is the more likely energy source.

(b) HVO_0781 is encoded in nearly all haloarchaeal genomes, according to OrthoDB, and shows very strong syntenic coupling with the adjacent gene, HVO_0782, according to SyntTax analysis. Characterized homologs to HVO_0781 cleave S-adenosyl-methionine into methionine and adenosine, a reaction that seems wasteful. If so, then this gene would not be expected to be retained in most species and neither would it maintain a strongly conserved gene clustering (see Supplementary Text S1 Section S6). HVO_0782 is an enzyme involved in NAD biosynthesis, which is encoded in most haloarchaeal and archaeal genomes. Thus, HVO_0781 is also a candidate for being involved in NAD biosynthesis.

(c) We described the reconstruction of riboflavin biosynthesis based on a detailed bioinformatic reconstruction [236]. The enzymes and their associated GSPs are listed in 
Table 6. Three pathway gaps remain, with candidate genes predicted for two of these [236] (for details, see Supplementary Text S1 Section S6).

Table 6. Proteins with open annotation issues and their Gold Standard Protein homologs (Section 3.6). For a description of this table, see the legend to Table 1.

\begin{tabular}{|c|c|c|c|c|c|c|c|c|c|}
\hline & & & & Gold Sta & lard Protein & & & & \\
\hline Section & Code & Gene & Isofunc & \%seq_id & Locus Tag & UniProt & Reference & PMID & Comment \\
\hline $6 a$ & HVO_2363 & $\operatorname{nadK1}$ & unclear & $37 \%$ & Rv1695 & P9WHV7 & [237] & 11006082 & $\begin{array}{c}\text { can use ATP and } \\
\text { PP }\end{array}$ \\
\hline $6 a$ & $\begin{array}{l}\text { HVO_2363 } \\
\text { (cont.) }\end{array}$ & & unclear & $31 \%$ & AF_2373 & O30297 & & & $\begin{array}{c}\text { ATP or PP usage } \\
\text { unresolved }\end{array}$ \\
\hline $6 a$ & HVO_0837 & $\operatorname{nadK} 2$ & unclear & $28 \%$ & Rv1695 & P9WHV7 & & & $\begin{array}{c}\text { can use ATP and } \\
\text { PP }\end{array}$ \\
\hline $6 a$ & $\begin{array}{c}\text { HVO_0837 } \\
\text { (cont.) }\end{array}$ & & unclear & partial & AF_2373 & O30297 & & & $\begin{array}{c}\text { ATP or PP usage } \\
\text { unresolved }\end{array}$ \\
\hline $6 b$ & HVO_0782 & $\operatorname{nadM}$ & yes & $53 \%$ & MJ0541 & Q57961 & $\begin{array}{l}{[238]} \\
{[239]}\end{array}$ & $\begin{array}{c}9401030 \\
10331644\end{array}$ & \\
\hline $6 b$ & HVO_0781 & - & unknown & $42 \%$ & Sare_1364 & A8M783 & [240] & 18720493 & \\
\hline $6 b$ & $\begin{array}{l}\text { HVO_0781 } \\
\text { (cont.) }\end{array}$ & & unknown & $35 \%$ & PH0463 & O58212 & [241] & 18551689 & \\
\hline $6 c$ & HVO_0327 & ribB & yes & $43 \%$ & MJ0055 & Q60364 & [242] & 12200440 & \\
\hline $6 c$ & HVO_0974 & $\mathrm{ribH}$ & yes & $45 \%$ & MJ0303 & Q57751 & [243] & 12603336 & \\
\hline $6 c$ & HVO_1284 & $\operatorname{arf} A$ & & self & & & [244] & 21999246 & $\begin{array}{l}\text { gene deletion } \\
\text { leads to } \\
\text { riboflavin } \\
\text { auxotrophy }\end{array}$ \\
\hline $6 c$ & $\begin{array}{l}\text { HVO_1284 } \\
\text { (cont.) }\end{array}$ & & yes & $44 \%$ & MJ0145 & Q57609 & [245] & 12475257 & \\
\hline $6 c$ & HVO_1235 & - & prediction & & & & [236] & 28073944 & $\operatorname{arf} B$ candidate \\
\hline $6 c$ & HVO_1341 & $\operatorname{arfC}$ & yes & $36 \%$ & MJ0671 & Q58085 & $\begin{array}{l}{[246]} \\
{[247]}\end{array}$ & $\begin{array}{l}11889103 \\
18671734\end{array}$ & \\
\hline $6 c$ & HVO_2483 & - & prediction & $34 \%$ & MJ0699 & Q58110 & [236] & 28073944 & $\begin{array}{l}\text { also predicted for } \\
\text { MJ0699 }\end{array}$ \\
\hline $6 c$ & $\begin{array}{l}\text { pathway } \\
\text { gap }\end{array}$ & & & & & & & & EC 3.1.3.104 \\
\hline $6 c$ & HVO_0326 & $r b k R$ & yes & $37 \%$ & TA1064 & Q9HJA6 & [236] & 28073944 & $\begin{array}{l}\text { bifunctional as } \\
\text { gene regulator } \\
\text { and enzyme }\end{array}$ \\
\hline $6 c$ & $\begin{array}{c}\text { HVO_0326 } \\
\text { (cont.) }\end{array}$ & & yes/no & $32 \%$ & MJ0056 & Q60365 & [248] & 18073108 & $\begin{array}{c}\text { enzyme only; } \\
\text { lacks an } \\
\text { N-terminal HTH } \\
\text { domain }\end{array}$ \\
\hline $6 c$ & HVO_1015 & ribL & yes & $50 \%$ & MJ1179 & Q58579 & [249] & 20822113 & \\
\hline
\end{tabular}

\subsection{Biosynthesis of Membrane Lipids, Bacterioruberin and Menaquinone}

Archaeal membrane lipids contain ether-linked isoprenoid side chains (see [250] and the references cited therein). The isoprenoid precursor isopentenyl diphosphate is synthesized in haloarchaea by a modified version of the mevalonate pathway [251]. Isoprenoid units are then linearly condensed into the C20 compound geranylgeranyl diphosphate. The haloarchaeal core lipid, archaeol, consists of 2,3-sn-glycerol with two C20 isoprenoid side chains attached by ether linkages. In some archaea, especially alkaliphiles, C25 isoprenoids are also found (see, e.g., [252,253]). Additionally, a number of distinct headgroups are found in polar lipids (phospholipids) (reviewed in [250]) (Figure 3). Even though polar lipids are used as important taxonomic markers [254], their biosynthetic pathways are not completely resolved. 

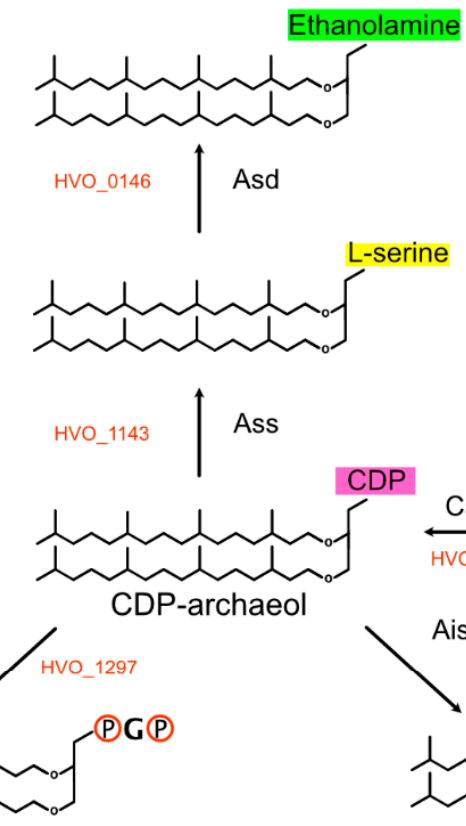

archaetidylglycerol phosphate (PGP)
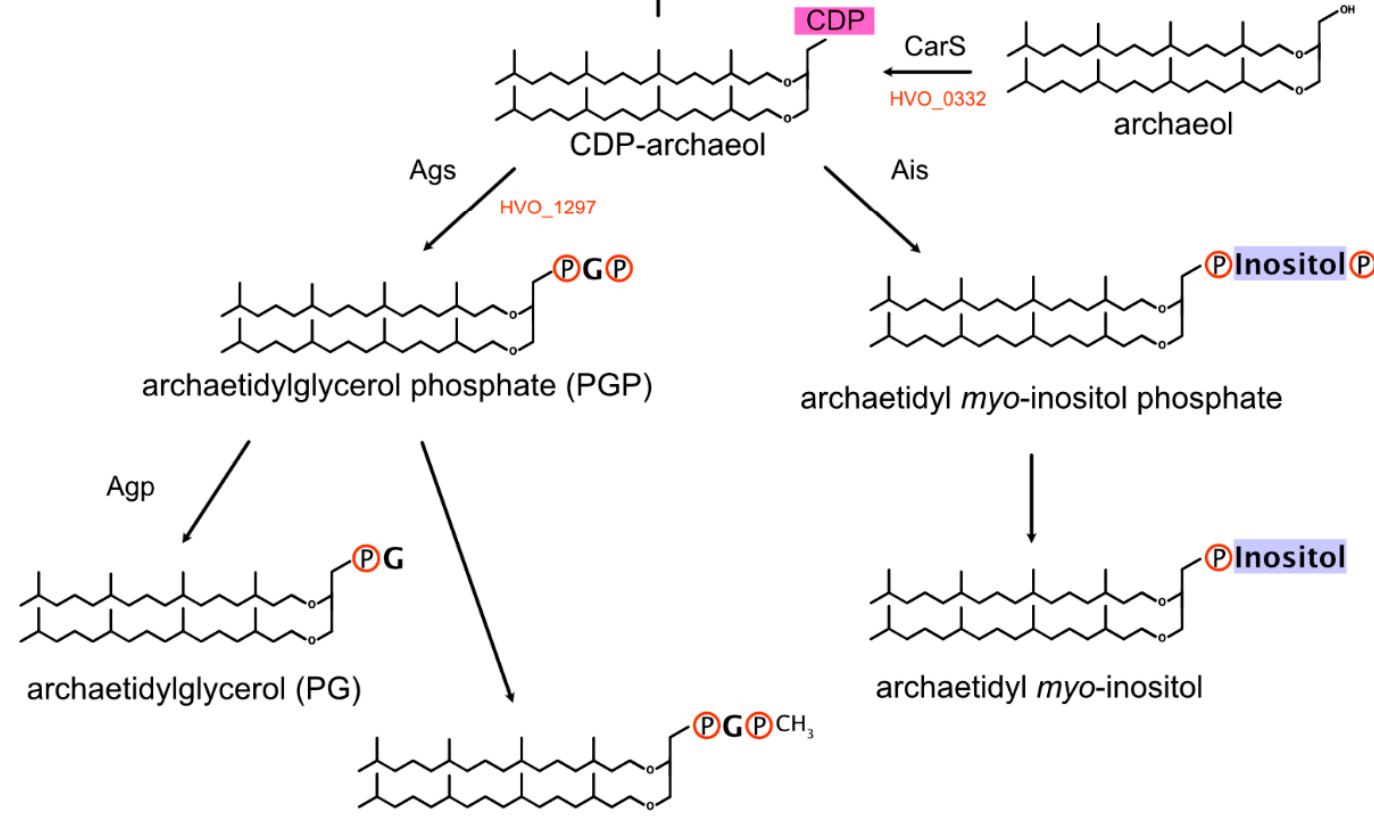

archaetidyl myo-inositol phosphate

archaetidylglycerol methylphosphate (PGP-Me)

Figure 3. Biosynthesis of polar lipids. A key intermediate is CDP-archaeol, which is generated from archaeol (displayed as fully saturated) by CarS. Members of the InterPro:IPR000462 family then transfer the CDP-archaeol to the hydroxyl group (alcohol group) of the target molecule (backbone: serine, glycerol and myo-inositol). Subsequent modifications contribute to the diversity of polar lipids.

Haloarchaea typically have a red color, which is due to carotenoids, mainly the C50 carotenoid bacterioruberin [255-257]. For carotenoid biosynthesis, two molecules of geranylgeranyl diphosphate, a C20 compound, are linked head-to-head to generate phytoene, which is desaturated to lycopene $[66,258]$. The pathway from lycopene to the C50 compound bacterioruberin has been experimentally characterized [257,259].

(a) We assigned HVO_2725 (idsA1, paralog of NP_3696A) and HVO_0303 (idsA2, paralog of NP_0604A) for the linear isoprenoid condensation reactions, resulting in a C20 isoprenoid (EC 2.5.1.10 and EC 2.5.1.29, short-chain isoprenyl diphosphate synthase) (see, also, Supplementary Text S1 Section S7). Some archaea, mainly haloalkaliphiles, also contain C25 isoprenoid side chains. Geranylfarnesyl diphosphate synthase, the enzyme that generates the $\mathrm{C} 25$ isoprenoids, has been purified and enzymatically characterized from Nmn. pharaonis [260], but data required for the assignment to a specific gene have not been collected. Three paralogous genes from Nmn. pharaonis are candidates for this function (NP_0604A, NP_3696A and NP_4556A). Since NP_0604A and NP_3696A have orthologs in $H f x$. volcanii, a species devoid of C25 lipids, we assigned the synthesis of $\mathrm{C} 25$ isoprenoids (geranylfarnesyl diphosphate synthase activity) to the third paralog, NP_4556A. UniProt assigned C25 biosynthesis activity to NP_3696A for undescribed reasons (as of April 2021), and KEGG does not make this assignment for any of the three paralogs (as of April 2021). 
Our assignments are supported by an analysis of the key residues that determine the length of the isoprenoid chain [261]. These authors labeled the cluster containing NP_3696A (WP011323557.1) as "C15/C20" and the cluster containing NP_4556A (WP011323984.1) as "C20->C25->C30?".

(b) Typical polar lipids in haloarchaea (Figure 3) are phosphatidylglycerophosphate methyl ester (PGP-Me) and phosphatidylglycerol (PG) but, also, phosphatidylglycerosulfate (PGS) [261-263]. Other polar lipids are archaetidylserine and its decarboxylation product archaetidylethanolamine, both of which are found in rather low quantities in Haloferax [264]. A third group of polar lipids has a headgroup derived from myo-inositol. The biosynthetic pathway of the headgroup is only partially resolved. One CDP-archaeol 1-archaetidyltransferase that belongs to a highly conserved three-gene operon may attach either glycerol phosphate or myo-inositol phosphate. In Supplementary Text S1 Section S7, we summarize the arguments in favor of each of these candidates, but the true function can only be decided by experimental analysis.

(c) Carotenoid biosynthesis involves the head-to-head condensation of the C20 isoprenoid geranylgeranyl diphosphate to phytoene, which is desaturated to lycopene $[66,258]$. The $c r t B$ gene product (e.g., HVO_2524) catalyzes the head-to-head condensation. It is yet uncertain which gene product is responsible for the desaturation of phytoene to lycopene. The further pathway from lycopene to bacterioruberin has been experimentally characterized in Haloarcula japonica [257]. A three-gene cluster (crtD-lyeJ-cruF) codes for the three enzymes of this pathway. The synteny of this three gene cluster is strongly conserved, according to SyntTax analysis. Several genes that are certainly or possibly involved in carotenoid biosynthesis are encoded in the vicinity of this cluster (for details, see Supplementary Text S1 Section S7).

(d) Halophilic archaea contain menaquinone as a lipid-based two-electron carrier of the respiratory chain $[264,265]$. We described the reconstruction of the menaquinone biosynthesis pathway (Table 7), with two pathway gaps remaining open (see Supplementary Text S1 Section S7 for details).

Table 7. Proteins with open annotation issues and their Gold Standard Protein homologs (Section 3.7). For a description of this table, see the legend to Table 1.

\begin{tabular}{|c|c|c|c|c|c|c|c|c|c|}
\hline \multicolumn{10}{|c|}{ Gold Standard Protein } \\
\hline Section & Code & Gene & Isofunc & \%seq_id & Locus Tag & UniProt & Reference & PMID & Comment \\
\hline $7 a$ & NP_0604A & $i d s A 2$ & yes & $32 \%$ & GACE_1337 & A0A0A7GEY4 & [266] & 30062607 & $\begin{array}{l}\text { ortholog of } \\
\text { HVO_0303 (66\%); } \\
\text { produces a C20 } \\
\text { isoprenoid (same } \\
\text { assignment for } \\
\text { NP_0604A) }\end{array}$ \\
\hline $7 a$ & $\begin{array}{l}\text { NP_0604A } \\
\text { (cont.) }\end{array}$ & $i d s A 2$ & no & $30 \%$ & APE_1764 & $\begin{array}{l}\text { Q9YB31 } \\
\text { Q9UWR6 }\end{array}$ & [267] & 10632701 & $\begin{array}{l}\text { produces a C25 } \\
\text { isoprenoid (C20 } \\
\text { assigned to } \\
\text { NP_0604A) }\end{array}$ \\
\hline $7 \mathrm{a}$ & NP_3996A & $i d s A 3$ & yes & $44 \%$ & GACE_1337 & A0A0A7GEY4 & [266] & 30062607 & $\begin{array}{l}\text { ortholog of } \\
\text { HVO_2725 (67\%); } \\
\text { produces a C20 } \\
\text { isoprenoid (same } \\
\text { assignment for } \\
\text { NP_3996A) }\end{array}$ \\
\hline $7 a$ & $\begin{array}{l}\text { NP_3996A } \\
\text { (cont.) }\end{array}$ & $i d s A 2$ & no & $36 \%$ & APE_1764 & $\begin{array}{c}\text { Q9YB31 } \\
\text { Q9UWR6 }\end{array}$ & [267] & 10632701 & $\begin{array}{l}\text { produces a C25 } \\
\text { isoprenoid (C20 } \\
\text { assigned to } \\
\text { NP_3996A) }\end{array}$ \\
\hline $7 a$ & NP_4556A & $i d s A 1$ & no & $34 \%$ & GACE_1337 & A0A0A7GEY4 & [266] & 30062607 & $\begin{array}{l}\text { no ortholog in } H f x \text {. } \\
\text { volcanii; produces a } \\
\text { C20 isoprenoid } \\
\text { (C25 assigned to } \\
\text { NP_4556A) }\end{array}$ \\
\hline
\end{tabular}


Table 7. Cont.

\begin{tabular}{|c|c|c|c|c|c|c|c|c|c|}
\hline \multicolumn{7}{|c|}{ Gold Standard Protein } & \multirow[b]{2}{*}{ Reference } & \multirow[b]{2}{*}{ PMID } & \multirow[b]{2}{*}{ Comment } \\
\hline Section & Code & Gene & Isofunc & \%seq_id & Locus Tag & UniProt & & & \\
\hline $7 \mathrm{a}$ & $\begin{array}{l}\mathrm{NP} \text { _4556A } \\
\text { (cont.) }\end{array}$ & $i d s A 1$ & yes & $29 \%$ & APE_1764 & $\begin{array}{l}\text { Q9YB31 } \\
\text { Q9UWR6 }\end{array}$ & [267] & 10632701 & $\begin{array}{l}\text { produces a C25 } \\
\text { isoprenoid (same } \\
\text { assignment for } \\
\text { NP_4556A) }\end{array}$ \\
\hline $7 \mathrm{~b}$ & HVO_0332 & $\operatorname{carS}$ & yes & $45 \%$ & AF_1740 & O28537 & [268] & 25219966 & \\
\hline $7 \mathrm{~b}$ & HVO_1143 & $\operatorname{ass} A$ & yes & $32 \%$ & MTH_1027 & O27106 & [269] & 12562787 & $\begin{array}{l}\text { gene synonym: } \\
\qquad g s A 3\end{array}$ \\
\hline $7 \mathrm{~b}$ & HVO_1297 & $\operatorname{ais} A$ & yes & $25 \%$ & MTH_1691 & O27726 & [270] & 19740749 & $\begin{array}{l}\text { gene synonym: } \\
\text { pgs } A 2\end{array}$ \\
\hline $7 \mathrm{~b}$ & HVO_1136 & $p g s A 1$ & - & & & & & & $\begin{array}{l}\text { only distant partial } \\
\text { matches to GSPs }\end{array}$ \\
\hline $7 \mathrm{~b}$ & HVO_1971 & $p g s A 4$ & unclear & $26 \%$ & MTH_1027 & O27106 & [269] & 12562787 & $\begin{array}{c}\text { MTH_1027 is less } \\
\text { distant to } \\
\text { HVO_1143 }\end{array}$ \\
\hline $7 \mathrm{~b}$ & HVO_0146 & asd & no & $39 \%$ & SMc00551 & Q9FDI9 & [271] & 18708506 & $\begin{array}{c}\text { equivalent function } \\
\text { for the bacterial } \\
\text { lipid }\end{array}$ \\
\hline $7 \mathrm{~b}$ & HVO_1295 & hisC & & self & & & [272] & 2345144 & $\begin{array}{l}\text { complements a His } \\
\text { auxotrophy mutant }\end{array}$ \\
\hline $7 \mathrm{~b}$ & $\begin{array}{l}\text { HVO_1295 } \\
\text { (cont.) }\end{array}$ & & yes & $31 \%$ & b2021 & P06986 & [273] & 2999081 & $\begin{array}{l}\text { weak support, } \\
\text { see text }\end{array}$ \\
\hline $7 \mathrm{~b}$ & HVO_1296 & $a d k 2$ & unclear & $34 \%$ & PAB0757 & Q9UZK4 & [274] & 24823650 & $\begin{array}{l}\text { Pyrococcus: involved } \\
\text { in ribosome } \\
\text { biogenesis }\end{array}$ \\
\hline $7 \mathrm{~b}$ & $\begin{array}{l}\text { HVO_1296 } \\
\text { (cont.) }\end{array}$ & & unclear & $32 \%$ & - & Q9Y3D8 & [275] & 15630091 & $\begin{array}{c}\text { human: adenylate } \\
\text { kinase; HVO_1296 } \\
\text { may be } \\
\text { inositol kinase }\end{array}$ \\
\hline $7 \mathrm{~b}$ & HVO_2496 & $a d k 1$ & yes & $45 \%$ & BSU01370 & P16304 & [276] & 31111079 & $\begin{array}{c}\text { Bacillus: adenylate } \\
\text { kinase }\end{array}$ \\
\hline $7 \mathrm{~b}$ & HVO_B0213 & - & yes & $43 \%$ & AF_1794 & $\mathrm{O} 28480$ & $\begin{array}{l}{[277]} \\
{[278]}\end{array}$ & $\begin{array}{l}11015222 \\
22261071\end{array}$ & $\begin{array}{l}\text { Archaeoglobus: } \\
\text { adenylate kinase }\end{array}$ \\
\hline $7 \mathrm{~b}$ & HVO_1135 & - & - & & & & & & $\begin{array}{l}\text { a SAM-dependent } \\
\text { methyltransferase }\end{array}$ \\
\hline $7 \mathrm{c}$ & HVO_2524 & $\operatorname{crtB}$ & & self & & & $\begin{array}{c}{[9]} \\
{[279]}\end{array}$ & $\begin{array}{l}25488358 \\
29038254\end{array}$ & $\begin{array}{l}c r t B \text { mutants } \\
\text { are colorless }\end{array}$ \\
\hline $7 \mathrm{c}$ & $\begin{array}{l}\text { HVO_2524 } \\
\text { (cont.) }\end{array}$ & & yes & $32 \%$ & $\begin{array}{c}\text { Synpcc7942 } \\
\ldots 1984\end{array}$ & P37269 & [280] & 1537409 & \\
\hline 7c & HVO_2527 & lyeJ & & self & & & [259] & 21840984 & \\
\hline 7c & $\begin{array}{l}\text { HVO_2527 } \\
\text { (cont.) }\end{array}$ & & yes & $65 \%$ & $\begin{array}{l}\text { VNG_1682C } \\
\text { OE_3380R }\end{array}$ & $\begin{array}{l}\text { Q9HPD9 } \\
\text { B0R651 }\end{array}$ & [259] & 21840984 & \\
\hline $7 \mathrm{c}$ & $\begin{array}{l}\text { HVO_2527 } \\
\text { (cont.) }\end{array}$ & & yes & $61 \%$ & C444_12922 & M0L7V9 & [257] & 25712483 & \\
\hline $7 \mathrm{c}$ & HVO_2528 & $\operatorname{crtD}$ & & self & & & [279] & 29038254 & $\begin{array}{c}\text { a HVO_2528 } \\
\text { mutant was white }\end{array}$ \\
\hline 7c & $\begin{array}{l}\text { HVO_2528 } \\
\text { (cont.) }\end{array}$ & & yes & $71 \%$ & C444_12917 & A0A0A1GKA2 & [257] & 25712483 & \\
\hline $7 \mathrm{c}$ & HVO_2526 & $c r u F$ & yes & $59 \%$ & C444_12927 & A0A0A1GNF2 & [257] & 25712483 & \\
\hline $7 d$ & HVO_1470 & $\operatorname{men} F$ & yes & $38 \%$ & PA4231 & Q51508 & [281] & 7500944 & \\
\hline $7 d$ & HVO_1469 & menD & yes & $37 \%$ & BSU30820 & P23970 & [282] & 20600129 & \\
\hline $7 d$ & $\begin{array}{l}\text { pathway } \\
\text { gap }\end{array}$ & & & & & & & & EC 4.2.99.20 \\
\hline $7 d$ & HVO_1461 & $\operatorname{men} \mathrm{C}$ & no & $29 \%$ & BSU12980 & O34508 & [283] & 11747447 & Ala/Glu epimerase \\
\hline
\end{tabular}


Table 7. Cont.

\begin{tabular}{|c|c|c|c|c|c|c|c|c|c|}
\hline \multirow[b]{2}{*}{ Section } & \multirow[b]{2}{*}{ Code } & \multirow[b]{2}{*}{ Gene } & \multicolumn{4}{|c|}{ Gold Standard Protein } & \multirow[b]{2}{*}{ Reference } & \multirow[b]{2}{*}{ PMID } & \multirow[b]{2}{*}{ Comment } \\
\hline & & & Isofunc & \%seq_id & Locus Tag & UniProt & & & \\
\hline $7 \mathrm{~d}$ & $\begin{array}{l}\text { HVO_1461 } \\
\text { (cont.) }\end{array}$ & & yes & $24 \%$ & BSU30780 & O34514 & [284] & 10194342 & $\begin{array}{c}\text { o-succinylbenzoate } \\
\text { synthase }\end{array}$ \\
\hline $7 d$ & HVO_1375 & menE & yes & $36 \%$ & BSU30790 & P23971 & [285] & 27933791 & \\
\hline $7 \mathrm{~d}$ & HVO_1465 & men $B$ & yes & $66 \%$ & Rv0548c & P9WNP5 & [286] & 20643650 & \\
\hline $7 d$ & $\begin{array}{l}\text { pathway } \\
\text { gap }\end{array}$ & & & & & & & & EC 3.1.2.28 \\
\hline $7 \mathrm{~d}$ & HVO_1462 & men $A$ & yes & $37 \%$ & b3930 & P32166 & [287] & 9573170 & \\
\hline $7 \mathrm{~d}$ & HVO_0309 & menG & yes/no & $44 \%$ & At3g63410 & Q9LY74 & [288] & 14508009 & $\begin{array}{l}\text { A. thaliana enzyme } \\
\text { also involved in } \\
\text { tocopherol } \\
\text { biosynthesis }\end{array}$ \\
\hline $7 \mathrm{~d}$ & $\begin{array}{l}\text { HVO_0309 } \\
\text { (cont.) }\end{array}$ & & yes & $27 \%$ & - & O86169 & [289] & 9139683 & \\
\hline
\end{tabular}

3.8. Issues Concerning RNA Polymerase, Protein Translation Components and Signal Peptide Degradation

(a) Haloarchaeal RNA polymerase consists of a set of canonical subunits (encoded by rpoA1A2B1B2DEFHKLNP). Hbt. salinarum and a subset of other haloarchaea contain an additional subunit called epsilon [290,291]. Purified RNA polymerase containing the epsilon subunit transcribes native templates efficiently, in contrast to the RNA polymerase devoid of this subunit [291]. The biological relevance of this subunit is enigmatic (see Supplementary Text S1 Section S8).

(b) Two distant paralogs are found for haloarchaeal ribosomal protein S10 (uS10) in nearly all haloarchaeal genomes. It is uncertain if both occur in the ribosome, whether they occur together or are mutually exclusive. The latter distribution would result in heterogeneity of the ribosomes. Alternatively, one of the paralogs may exclusively have a non-ribosomal function.

In a subset of archaea, two distant paralogs are found for haloarchaeal ribosomal protein S14 (uS14) (ca 20\% of the genomes, e.g., in Nmn. pharaonis). For more details, see Supplementary Text S1 Section S8.

(c) The ribosomal protein L43e (eL43) shows heterogeneity with respect to the presence of the C2-C2-type zinc finger motif. This zinc finger is found in L43e from all Halobacteriales and all euryarchaeal proteins outside the order Halobacteria but is not found in Haloferacales and is very rare in Natrialbales. Eukaryotic orthologs (e.g., from rat and yeast) contain this zinc finger, and its biological importance has been experimentally shown for the yeast protein [292] (for details, see Supplementary Text S1 Section S8).

(d) Diphthamide is a complex covalent modification of a histidine residue of translation elongation factor a-EF2. This pathway has been reconstructed (Table 8) based on distant homologs (enzymes encoded by $d p h 2$ and $d p h 5$ ) and by a detailed bioinformatic analysis (enzyme encoded by dph6) [293] (for details, see Supplementary Text S1 Section S8). These uncertain function assignments await experimental confirmation.

(e) N-terminal signal sequences target proteins to the secretion machinery. Subsequent to membrane insertion or transmembrane transfer, the signal sequence is cleaved off by a signal peptidase. After cleavage, the signal peptide must be degraded to avoid clogging of the membrane. Degradation is catalyzed by signal peptide peptidase. Candidates for this activity have been predicted from two protein families [294,295] (for details, see Supplementary Text S1 Section S8). 
Table 8. Proteins with open annotation issues and their Gold Standard Protein homologs (Section 3.8). For a description of this table, see the legend to Table 1.

\begin{tabular}{|c|c|c|c|c|c|c|c|c|c|}
\hline \multirow[b]{2}{*}{ Section } & \multirow[b]{2}{*}{ Code } & \multirow[b]{2}{*}{ Gene } & \multicolumn{4}{|c|}{ Gold Standard Protein } & \multirow[b]{2}{*}{ Reference } & \multirow[b]{2}{*}{ PMID } & \multirow[b]{2}{*}{ Comment } \\
\hline & & & Isofunc & \%seq_id & Locus Tag & UniProt & & & \\
\hline $8 a$ & OE_1279R & rpoeps & & self & & & $\begin{array}{l}\text { [290] } \\
{[291]}\end{array}$ & $\begin{array}{l}2495365 \\
6852054\end{array}$ & \\
\hline $8 b$ & HVO_0360 & rps10a & yes & $94 \%$ & $\operatorname{rrnAC} 2405$ & P23357 & [296] & 1764513 & \\
\hline $8 b$ & HVO_1392 & rps10b & - & & & & & & $\begin{array}{c}\text { no GSP; } 24 \% \text { seq_id } \\
\text { to } \mathrm{HVO}_{(r p s 10 a)}\end{array}$ \\
\hline $8 b$ & NP_4882A & rps14a & yes & $72 \%$ & rrnAC1597.1 & P26816 & [297] & 1832208 & $\begin{array}{l}\text { full-length } \\
\text { similarity; } \\
\text { Haloarcula } \\
\text { protein was not } \\
\text { isolated or } \\
\text { characterized }\end{array}$ \\
\hline $8 b$ & $\begin{array}{l}\text { NP_4882A } \\
\text { (cont.) }\end{array}$ & & yes & $57 \%$ & YDL061C & P41058 & [298] & 18782943 & $\begin{array}{c}\text { yeast YS29B; } \\
\text { N-term } 20 \text { aa } \\
\text { divergent }\end{array}$ \\
\hline $8 b$ & NP_1768A & rps14b & unclear & $80 \%$ & rrnAC1597.1 & P26816 & [297] & 1832208 & $\begin{array}{c}\text { N-term } 20 \text { aa } \\
\text { divergent }\end{array}$ \\
\hline $8 c$ & OE_1373R & rpl43e & yes & $69 \%$ & rrnAC1669 & P60619 & [299] & 10937989 & \\
\hline $8 c$ & $\begin{array}{c}\text { OE_1373R } \\
\text { (cont.) }\end{array}$ & & yes & $39 \%$ & YPR043W & P0CX25 & $\begin{array}{l}{[292]} \\
{[300]}\end{array}$ & $\begin{array}{l}10588896 \\
11866512\end{array}$ & \\
\hline $8 c$ & HVO_0654 & rpl43e & yes & $54 \%$ & rrnAC1669 & P60619 & [299] & 10937989 & $\begin{array}{l}\text { Haloarcula: has } \\
\text { zinc finger; } \\
\text { Haloferax; lacks } \\
\text { zinc finger }\end{array}$ \\
\hline $8 \mathrm{~d}$ & HVO_1631 & $d p h 2$ & yes & $35 \%$ & PH1105 & O58832 & [301] & 20931132 & \\
\hline $8 \mathrm{~d}$ & HVO_0916 & $d p h 5$ & yes & $39 \%$ & PH0725 & O58456 & [302] & 20873788 & \\
\hline $8 \mathrm{~d}$ & HVO_1077 & $d p h 6$ & yes & $31 \%$ & YLR143W & Q12429 & $\begin{array}{l}{[303]} \\
{[304]}\end{array}$ & $\begin{array}{l}23169644 \\
23468660\end{array}$ & \\
\hline $8 \mathrm{e}$ & HVO_0881 & sppA1 & yes & $33 \%$ & BSU19530 & O34525 & $\begin{array}{l}{[305]} \\
{[306]}\end{array}$ & $\begin{array}{l}10455123 \\
22472423\end{array}$ & \\
\hline $8 \mathrm{e}$ & HVO_1987 & $s p p A 2$ & probably & $23 \%$ & BSU19530 & O34525 & $\begin{array}{l}{[305]} \\
{[306]}\end{array}$ & $\begin{array}{l}10455123 \\
22472423\end{array}$ & \\
\hline $8 \mathrm{e}$ & HVO_1107 & - & prediction & & & & & & no GSP \\
\hline
\end{tabular}

\subsection{Miscellaneous Metabolic Enzymes and Proteins with Other Functions}

Here, we list a few other enzymatic or nonenzymatic functions for which candidate genes have been assigned but without experimental validation.

(a) Ketohexokinase from Haloarcula vallismortis has been experimentally characterized [307]. However, the activity was not assigned to a gene. Detailed bioinformatic analyses have been made [308,309] and point to a small set of orthologs represented by Hmuk_2662, the ortholog of HVO_1812 (for further details, see Supplementary Text S1 Section S9).

(b) The assignment of fructokinase activity to the Hht. litchfieldiae candidate gene halTADL_1913 (UniProt:A0A1H6QYL4) is based on a differential proteomic analysis [309] (see Supplementary Text S1 Section S9 for details). Very close homologs are rare in haloarchaea. For this protein family (carbohydrate kinase), it is unclear if more distant homologs (with about $50 \%$ protein sequence identity) are isofunctional.

(c) A candidate gene for glucoamylase is HVO_1711 for the reasons described in Supplementary Text S1 Section S9. The enzyme from Halorubrum sodomense has been characterized [310], but the activity has not yet been assigned to a gene. 
(d) A strong candidate for having glucose-6-phosphate isomerase activity is $H f x$. volcanii HVO_1967 (pgi), based on 36\% protein sequence identity to the characterized enzyme from M. jannaschii (MJ1605) [311] (Table 9).

Table 9. Proteins with open annotation issues and their Gold Standard Protein homologs (Section 3.9). For a description of this table, see the legend to Table 1.

\begin{tabular}{|c|c|c|c|c|c|c|c|c|c|}
\hline & & & & Gold Sta & dard Protein & & & & \\
\hline Section & Code & Gene & Isofunc & \%seq_id & Locus Tag & UniProt & Reference & PMID & Comment \\
\hline $9 a$ & HVO_1812 & - & prediction & & & & & & no GSP \\
\hline $9 b$ & halTADL_1913 & - & yes & $37 \%$ & - & P26984 & [312] & 1809835 & \\
\hline $9 b$ & $\begin{array}{l}\text { halTADL_1913 } \\
\text { (cont.) }\end{array}$ & - & yes & $31 \%$ & OCC_03567 & $\begin{array}{l}\text { Q7LYW8 } \\
\text { H3ZP68 }\end{array}$ & [313] & 15138858 & \\
\hline $9 \mathrm{c}$ & HVO_1711 & - & probably & $33 \%$ & - & P29761 & [314] & 1633799 & $\begin{array}{l}\text { P29761 matches to } \\
\text { C-term half of } \\
\text { HVO_1711 }\end{array}$ \\
\hline $9 \mathrm{c}$ & $\begin{array}{l}\text { HVO_1711 } \\
\text { (cont.) }\end{array}$ & - & probably & $51 \%$ & $\begin{array}{l}\text { SAMN } \\
04487937 \\
2677\end{array}$ & A0A1I6HD35 & [310] & 8305855 & $\begin{array}{c}\text { correlation between } \\
\text { PMID:8305855 and } \\
\text { A0A1I6HD35 likely } \\
\text { (see text) }\end{array}$ \\
\hline $9 d$ & HVO_1967 & $p g i$ & yes & $36 \%$ & MJ1605 & Q59000 & [311] & 14655001 & \\
\hline $9 e$ & OE_1665R & $k d g A$ & no & $31 \%$ & PA1010 & Q9I4W3 & [139] & 21396954 & $\begin{array}{l}\text { GSP for dapA (see } \\
\text { under } 2 a \text { ) }\end{array}$ \\
\hline $9 e$ & $\begin{array}{l}\text { OE_1665R } \\
\text { (cont.) }\end{array}$ & & probably & $30 \%$ & $\begin{array}{l}\text { TTX_1156.1 } \\
\text { TTX_1156a }\end{array}$ & G4RJQ2 & [315] & 15869466 & \\
\hline $9 e$ & $\begin{array}{l}\text { OE_1665R } \\
\text { (cont.) }\end{array}$ & & probably & $25 \%$ & SSO3197 & Q97U28 & [315] & 15869466 & \\
\hline $9 f$ & HVO_1692 & $l u d B$ & & self & & & [21] & 30707467 & \\
\hline 9f & $\begin{array}{l}\text { HVO_1692 } \\
\text { (cont.) }\end{array}$ & & probably & $35 \%$ & BSU34040 & O07021 & [316] & 19201793 & $\begin{array}{c}\text { matches up to } \\
\text { HVO_1692 pos } 490 \\
\text { of } 733\end{array}$ \\
\hline $9 f$ & $\begin{array}{l}\text { HVO_1692 } \\
\text { (cont.) }\end{array}$ & & probably & $35 \%$ & PST_3338 & O4VPR6 & [317] & 25917905 & $\begin{array}{c}\text { matches up to } \\
\text { HVO_1692 pos } 400 \\
\text { of } 733\end{array}$ \\
\hline $9 f$ & HVO_1693 & $\operatorname{ludC}$ & & self & & & [21] & 30707467 & \\
\hline $9 f$ & $\begin{array}{l}\text { HVO_1693 } \\
\text { (cont.) }\end{array}$ & & probably & $30 \%$ & BSU34030 & O32259 & [316] & 19201793 & \\
\hline $9 f$ & $\begin{array}{l}\text { HVO_1693 } \\
\text { (cont.) }\end{array}$ & & probably & $33 \%$ & PST_3339 & O4VPR7 & [317] & 25917905 & partial match \\
\hline $9 f$ & HVO_1697 & - & unclear & $24 \%$ & PST_3340 & O4VPR8 & [317] & 25917905 & \\
\hline $9 f$ & HVO_1696 & lct $P$ & probably & $44 \%$ & PST_3336 & O4VPR4 & [317] & 25917905 & \\
\hline $9 \mathrm{~g}$ & HVO_B0300 & pucL1 & yes & $49 \%$ & BSU32450 & O32141 & [318] & 20168977 & $\begin{array}{c}\text { Bacillus: } \\
\text { bifunctional, } \\
\text { matches to C-term }\end{array}$ \\
\hline $9 \mathrm{~g}$ & HVO_B0299 & pucM & yes & $43 \%$ & BSU32460 & O32142 & [319] & 16098976 & \\
\hline $9 g$ & HVO_B0301 & pucL2 & yes & $43 \%$ & BSU32450 & O32141 & [320] & 17567580 & $\begin{array}{c}\text { Bacillus: } \\
\text { bifunctional, } \\
\text { matches to N-term }\end{array}$ \\
\hline $9 \mathrm{~g}$ & HVO_B0302 & pucH1 & no & $33 \%$ & - & Q8VTT5 & [321] & 12148274 & $\begin{array}{l}\text { paper in Chinese, } \\
\text { abstract in English; } \\
\text { pyrimidine } \\
\text { degradation }\end{array}$ \\
\hline $9 \mathrm{~g}$ & $\begin{array}{l}\text { HVO_B0302 } \\
\text { (cont.) }\end{array}$ & & yes & $30 \%$ & STM0523 & Q7CR08 & [322] & 23287969 & purine degradation \\
\hline $9 \mathrm{~g}$ & $\begin{array}{l}\text { HVO_B0302 } \\
\text { (cont.) }\end{array}$ & & yes & $29 \%$ & BSU32410 & O32137 & [323] & 11344136 & purine degradation \\
\hline $9 \mathrm{~g}$ & HVO_B0306 & amaB4 & no & $39 \%$ & - & Q53389 & [324] & 22904279 & $\begin{array}{l}\text { carbamoyl-AA } \\
\text { hydrolysis }\end{array}$ \\
\hline
\end{tabular}


Table 9. Cont.

\begin{tabular}{|c|c|c|c|c|c|c|c|c|c|}
\hline \multicolumn{10}{|c|}{ Gold Standard Protein } \\
\hline Section & Code & Gene & Isofunc & \%seq_id & Locus Tag & UniProt & Reference & PMID & Comment \\
\hline $9 g$ & $\begin{array}{l}\text { HVO_B0306 } \\
\text { (cont.) }\end{array}$ & & yes & $34 \%$ & At5g43600 & Q8VXY9 & $\begin{array}{l}{[325]} \\
{[326]}\end{array}$ & $\begin{array}{l}19935661 \\
23940254\end{array}$ & purine degradation \\
\hline $9 \mathrm{~g}$ & HVO_B0308 & $\operatorname{cox} S$ & no & $46 \%$ & Saci_2270 & Q4J6M5 & [327] & 10095793 & GAPDH \\
\hline $9 g$ & $\begin{array}{l}\text { HVO_B0308 } \\
\text { (cont.) }\end{array}$ & & no & $41 \%$ & - & P19915 & [328] & 10482497 & $\mathrm{CO}-\mathrm{DH}$ \\
\hline $9 g$ & $\begin{array}{l}\text { HVO_B0308 } \\
\text { (cont.) }\end{array}$ & & yes & $39 \%$ & b2868 & Q46801 & [329] & 10986234 & xanthine DH \\
\hline $9 g$ & HVO_B0309 & $\operatorname{cox} L$ & yes & $33 \%$ & b2866 & Q46799 & [329] & 10986234 & xanthine DH \\
\hline $9 g$ & $\begin{array}{l}\text { HVO_B0309 } \\
\text { (cont.) }\end{array}$ & & no & $28 \%$ & - & P19913 & [328] & 10482497 & $\mathrm{CO}-\mathrm{DH}$ \\
\hline $9 g$ & $\begin{array}{c}\text { HVO_B0309 } \\
\text { (cont.) }\end{array}$ & & no & $26 \%$ & Saci_2271 & Q4J6M3 & [327] & 10095793 & GAPDH \\
\hline $9 g$ & HVO_B0310 & $\operatorname{cox} M$ & no & $31 \%$ & Saci_2269 & Q4J6M6 & [327] & 10095793 & GAPDH \\
\hline $9 g$ & $\begin{array}{l}\text { HVO_B0310 } \\
\text { (cont.) }\end{array}$ & & no & $31 \%$ & - & P19914 & [328] & 10482497 & CO-DH \\
\hline $9 g$ & $\begin{array}{l}\text { HVO_B0310 } \\
\text { (cont.) }\end{array}$ & & yes & $25 \%$ & b2867 & Q46800 & [329] & 10986234 & xanthine DH \\
\hline $9 g$ & HVO_B0303 & uraA4 & yes & $38 \%$ & b3654 & P0AGM9 & [330] & 16096267 & \\
\hline $9 \mathrm{~h}$ & HVO_0197 & - & possibly & $39 \%$ & lp_0105 & F9UST0 & [331] & 27114550 & LarB family protein \\
\hline $9 \mathrm{~h}$ & HVO_2381 & - & possibly & $31 \%$ & $\begin{array}{l}\text { lp_0106/ } \\
\text { lp_0107 }\end{array}$ & F9UST1 & [331] & 27114550 & LarC family protein \\
\hline $9 \mathrm{~h}$ & HVO_0190 & - & possibly & $34 \%$ & lp_0109 & F9UST4 & [331] & 27114550 & LarE family protein \\
\hline $9 \mathrm{i}$ & HVO_1660 & dacZ & & self & & & [37] & 30884174 & \\
\hline $9 \mathrm{i}$ & HVO_0756 & - & prediction & & & & [332] & 32095817 & \\
\hline $9 \mathrm{i}$ & HVO_0990 & - & prediction & & & & [332] & 32095817 & \\
\hline $9 \mathrm{i}$ & HVO_1690 & - & prediction & & & & [332] & 32095817 & \\
\hline $9 j$ & HVO_2763 & - & & self & & & [333] & 22350204 & $\begin{array}{l}\text { no function could } \\
\text { be assigned }\end{array}$ \\
\hline $9 j$ & $\begin{array}{l}\text { HVO_2763 } \\
\text { (cont.) }\end{array}$ & & no & $27 \%$ & HVO_0144 & D4GZ88 & [334] & 18437358 & Rnase Z \\
\hline $9 \mathrm{k}$ & HVO_2410 & $d a b A$ & yes & $33 \%$ & Hneap_0211 & D0KWS7 & [335] & 31406332 & \\
\hline $9 \mathrm{k}$ & HVO_2411 & $d a b B$ & yes & $31 \%$ & Hneap_0212 & D0KWS8 & [335] & 31406332 & \\
\hline
\end{tabular}

(e) A candidate gene for specifying an enzyme with 2-dehydro-3-deoxy-(phospho) gluconate aldolase activity is $\mathrm{Hbt}$. salinarum $k d g A\left(\mathrm{OE} \_1665 \mathrm{R}\right)$. It is rather closely related (36\% protein sequence) to Hfx. volcanii HVO_1101 (encoded by dapA), which is involved in lysine biosynthesis, a biosynthetic pathway that is absent from Hbt. salinarum. The function assignment is based on distant homologs from Saccharolobus (Sulfolobus) solfataricus and Thermoproteus tenax, which have been characterized [315] (for details, see Supplementary Text S1 Section S9).

(f) Haloarchaea may contain an NAD-independent L-lactate dehydrogenase, LudBC (HVO_1692 and HVO_1693). The deletion of this gene pair impairs growth on rhamnose, which is catabolized to pyruvate and lactate [21]. There is a very distant relationship (for details, see Supplementary Text S1 Section S9) to the LldABC subunits of the characterized L-lactate dehydrogenase from Pseudomonas stutzeri A1501 [317] and to the LutABC proteins from B. subtilis, which have been shown to be involved in lactate utilization [316].

(g) Hfx. volcanii may be able to convert urate into allantoin using the gene cluster HVO_B0299-HVO_B0302. This could be part of a complete degradation pathway for purines, but this has to be considered highly speculative (see Supplementary Text S1 Section S9 and Supplementary Figure S2). 
(h) Hfx. volcanii may contain an enzyme having a "nickel-pincer cofactor". The biogenesis of this cofactor may be catalyzed by larBCE (as detailed in Supplementary Text S1 Section S9).

(i) Cyclic di-AMP (c-di-AMP) is an important nucleotide signaling molecule in bacteria and archaea. It is generated from two molecules of ATP by diadenylate cyclase (encoded by $d a c Z$ ) and is degraded to pApA by phosphodiesterases [336]. The level of this signaling molecule is strictly controlled $[337,338]$, thus requiring a sophisticated interplay of cyclase and phosphodiesterase. DacZ from Hfx. volcanii has been characterized, and it was shown that the c-di-AMP levels must be tightly regulated [37]. The degrading enzyme, however, has not yet been identified in Haloferax, but candidates have been proposed [332,336,339] (see Supplementary Text S1 Section S9).

(j) HVO_2763 is distantly related to RNase Z (HVO_0144, rnz). The experimental characterization of HVO_2763 [333] excluded activity as an exonuclease but did not reveal its physiological function. Upon transcriptome analysis, the downregulation of several genes was detected. Several of these were uncharacterized at the time of the experiment but have since been shown to be involved in the minor N-glycosylation pathway that was initially detected under low-salt conditions (see Supplementary Text S1 Section S9 for further details).

(k) A pair of genes (dabAB, HVO_2410 and HVO_2411) is predicted to function as a carbon dioxide transporter, based on the identification of such transporters in Halothiobacillus neapolitanus [335]. Being a member of the proton-conducting membrane transporter family, this protein may be misannotated as a subunit of the nuo or mrp complexes (see Supplementary Text S1 Section S9 for further details).

\section{Conclusions}

We described a large number of cases where the protein function cannot be correctly predicted when restricting considerations to the computational analyses without taking the biological contexts into account. An example was the switch from methanopterin to tetrahydrofolate as a C1 carrier in haloarchaea. Homologous enzymes, inherited from the common ancestor, have adapted to the new $\mathrm{C} 1$ carrier, rather than being replaced by non-homologous proteins. Function prediction tools may misannotate haloarchaeal proteins to work with methanopterin. Another example was the nuo complex and its misannotation as a type I NADH dehydrogenase. In other cases, even a distant sequence similarity may allow a valid function prediction if additional evidence (e.g., from a gene neighborhood analysis or from a detailed evaluation of the metabolic pathway gaps) is taken into account. Examples include cobalamin cluster proteins, which probably close the two residual pathway gaps, and the predicted degradation pathway for purines. In all these cases, we presented reasonable hypotheses based on the current knowledge, and in many cases, these were so well-supported as to be compelling, but to be certain, experimental data are required. With this overview, we attempted to arouse the curiosity of our colleagues, hoping that they will confirm or disprove our speculations and, thus, advance the knowledge about haloarchaeal biology. Hfx. volcanii is a model species for halophilic archaea, and the more complete and correctly its genome is annotated, the higher will be its value for system biology analyses (modeling) and for synthetic biology (metabolic engineering) and biotechnology.

Supplementary Materials: The following are available online at https:/ / www.mdpi.com/article/10 .3390/genes12070963/s1: Text S1: Detailed background information for all open annotation issues. Figure S1: Alignment of the 5' end of leuA2 (HVO_1510) from Hfx. volcanii DS2 with homologs from other species of Haloferax. Figure S2: The proposed purine degradation pathway. Table S1: Listing of all proteins mentioned in the text and in Supplementary Text S1. Table S2: Listing of the genomes which are manually curated and kept up to date.

Author Contributions: Conceptualization, F.P.; Data curation, F.P. Project administration, F.P. Formal analysis, F.P. and M.D.-S.; Investigation F.P. and M.D.-S. Validation, F.P. and M.D.-S.; Visualization, 
F.P. and M.D.-S. Writing—original draft, F.P. and M.D.-S. and Writing—review and editing, F.P. and M.D.-S. All authors have read and agreed to the published version of the manuscript.

Funding: This research received no specific grants from any funding agency in the public, commercial or non-for-profit sectors.

Institutional Review Board Statement: Not applicable.

Informed Consent Statement: Not applicable.

Data Availability Statement: Not applicable.

Acknowledgments: We thank all members of the Haloferax community for more than a decade of fruitful cooperation and for sharing their deep knowledge about the biology of this model species. We thank our colleagues for kindly reading and providing thoughtful comments on the manuscript before submission: Sonja-Verena Albers, Thorsten Allers, Maria Jose Bonete, Rosana de Castro, Sebastien Ferreira-Cerca, Anita Marchfelder, Mechthild Pohlschroder and Joerg Soppa. We thank Birgit Scharf for the insightful discussions on the Natronomonas respiratory chain.

Conflicts of Interest: The authors declare no conflict of interest.

\section{References}

1. Hartman, A.L.; Norais, C.; Badger, J.H.; Delmas, S.; Haldenby, S.; Madupu, R.; Robinson, J.; Khouri, H.; Ren, Q.; Lowe, T.M.; et al. The complete genome sequence of Haloferax volcanii DS2, a model archaeon. PLoS ONE 2010, 5, e9605. [CrossRef] [PubMed]

2. Schulze, S.; Adams, Z.; Cerletti, M.; De Castro, R.; Ferreira-Cerca, S.; Fufezan, C.; Gimenez, M.I.; Hippler, M.; Jevtic, Z.; Knuppel, R.; et al. The Archaeal Proteome Project advances knowledge about archaeal cell biology through comprehensive proteomics. Nat. Commun. 2020, 11, 3145. [CrossRef]

3. Leigh, J.A.; Albers, S.V.; Atomi, H.; Allers, T. Model organisms for genetics in the domain Archaea: Methanogens, halophiles, Thermococcales and Sulfolobales. FEMS Microbiol. Rev. 2011, 35, 577-608. [CrossRef]

4. Perez-Arnaiz, P.; Dattani, A.; Smith, V.; Allers, T. Haloferax volcanii-a model archaeon for studying DNA replication and repair. Open Biol 2020, 10, 200293. [CrossRef]

5. Soppa, J. Functional genomic and advanced genetic studies reveal novel insights into the metabolism, regulation, and biology of Haloferax volcanii. Archaea 2011, 2011, 602408. [CrossRef]

6. Haque, R.U.; Paradisi, F.; Allers, T. Haloferax volcanii for biotechnology applications: Challenges, current state and perspectives. Appl Microbiol Biotechnol 2020, 104, 1371-1382. [CrossRef]

7. Allers, T.; Barak, S.; Liddell, S.; Wardell, K.; Mevarech, M. Improved strains and plasmid vectors for conditional overexpression of His-tagged proteins in Haloferax volcanii. Appl Environ Microbiol 2010, 76, 1759-1769. [CrossRef]

8. Allers, T.; Mevarech, M. Archaeal genetics—the third way. Nat. Rev. Genet. 2005, 6, 58-73. [CrossRef] [PubMed]

9. Kiljunen, S.; Pajunen, M.I.; Dilks, K.; Storf, S.; Pohlschroder, M.; Savilahti, H. Generation of comprehensive transposon insertion mutant library for the model archaeon, Haloferax volcanii, and its use for gene discovery. BMC Biol. 2014, 12, 103.

10. Pfeiffer, F.; Broicher, A.; Gillich, T.; Klee, K.; Mejia, J.; Rampp, M.; Oesterhelt, D. Genome information management and integrated data analysis with HaloLex. Arch. Microbiol. 2008, 190, 281-299. [CrossRef] [PubMed]

11. Pfeiffer, F.; Oesterhelt, D. A manual curation strategy to improve genome annotation: Application to a set of haloarchael genomes. Life (Basel) 2015, 5, 1427-1444. [CrossRef] [PubMed]

12. Turkowyd, B.; Schreiber, S.; Wortz, J.; Segal, E.S.; Mevarech, M.; Duggin, I.G.; Marchfelder, A.; Endesfelder, U. Establishing live-cell single-molecule localization microscopy imaging and single-particle tracking in the archaeon Haloferax volcanii. Front. Microbiol. 2020, 11, 583010. [CrossRef]

13. Walsh, J.C.; Angstmann, C.N.; Bisson-Filho, A.W.; Garner, E.C.; Duggin, I.G.; Curmi, P.M.G. Division plane placement in pleomorphic archaea is dynamically coupled to cell shape. Mol. Microbiol. 2019, 112, 785-799. [CrossRef] [PubMed]

14. de Silva, R.T.; Abdul-Halim, M.F.; Pittrich, D.A.; Brown, H.J.; Pohlschroder, M.; Duggin, I.G. Improved growth and morphological plasticity of Haloferax volcanii. Microbiology (Reading) 2021, 167, 001012. [CrossRef]

15. Duggin, I.G.; Aylett, C.H.; Walsh, J.C.; Michie, K.A.; Wang, Q.; Turnbull, L.; Dawson, E.M.; Harry, E.J.; Whitchurch, C.B.; Amos, L.A.; et al. CetZ tubulin-like proteins control archaeal cell shape. Nature 2015, 519, 362-365. [CrossRef]

16. Liao, Y.; Ithurbide, S.; Evenhuis, C.; Lowe, J.; Duggin, I.G. Cell division in the archaeon Haloferax volcanii relies on two FtsZ proteins with distinct functions in division ring assembly and constriction. Nat. Microbiol. 2021, 6, 594-605. [CrossRef]

17. Brasen, C.; Schonheit, P. Mechanisms of acetate formation and acetate activation in halophilic archaea. Arch. Microbiol. 2001, 175, 360-368. [CrossRef]

18. Johnsen, U.; Dambeck, M.; Zaiss, H.; Fuhrer, T.; Soppa, J.; Sauer, U.; Schonheit, P. D-xylose degradation pathway in the halophilic archaeon Haloferax volcanii. J. Biol. Chem. 2009, 284, 27290-27303. [CrossRef]

19. Pickl, A.; Johnsen, U.; Schonheit, P. Fructose degradation in the haloarchaeon Haloferax volcanii involves a bacterial type phosphoenolpyruvate-dependent phosphotransferase system, fructose-1-phosphate kinase, and class II fructose-1,6-bisphosphate aldolase. J. Bacteriol. 2012, 194, 3088-3097. [CrossRef] 
20. Sutter, J.M.; Tastensen, J.B.; Johnsen, U.; Soppa, J.; Schonheit, P. Key enzymes of the semiphosphorylative Entner-Doudoroff pathway in the haloarchaeon Haloferax volcanii: Characterization of glucose dehydrogenase, gluconate dehydratase and 2-keto-3deoxy-6-phosphogluconate aldolase. J. Bacteriol. 2016, 198, 2251-2262. [CrossRef]

21. Reinhardt, A.; Johnsen, U.; Schonheit, P. L-Rhamnose catabolism in archaea. Mol. Microbiol. 2019, 111, 1093-1108. [CrossRef] [PubMed]

22. Kuprat, T.; Ortjohann, M.; Johnsen, U.; Schonheit, P. Glucose metabolism and acetate switch in Archaea: The enzymes in Haloferax volcanii. J. Bacteriol. 2021, 203, e00690-20. [CrossRef]

23. Kuprat, T.; Johnsen, U.; Ortjohann, M.; Schonheit, P. Acetate metabolism in Archaea: Characterization of an acetate transporter and of enzymes involved in acetate activation and gluconeogenesis in Haloferax volcanii. Front. Microbiol. 2020, $11,604926$. [CrossRef]

24. Sutter, J.M.; Johnsen, U.; Reinhardt, A.; Schonheit, P. Pentose degradation in archaea: Halorhabdus species degrade D-xylose, L-arabinose and D-ribose via bacterial-type pathways. Extremophiles 2020, 24, 759-772. [CrossRef]

25. Tästensen, J.B.; Johnsen, U.; Reinhardt, A.; Ortjohann, M.; Schonheit, P. D-galactose catabolism in archaea: Operation of the DeLey-Doudoroff pathway in Haloferax volcanii. FEMS Microbiol. Lett. 2020, 367, fnaa029. [CrossRef] [PubMed]

26. Abdul-Halim, M.F.; Schulze, S.; DiLucido, A.; Pfeiffer, F.; Bisson Filho, A.W.; Pohlschroder, M. Lipid anchoring of archaeosortase substrates and midcell growth in haloarchaea. mBio 2020, 11, e00349-20. [CrossRef]

27. Abdul Halim, M.F.; Rodriguez, R.; Stoltzfus, J.D.; Duggin, I.G.; Pohlschroder, M. Conserved residues are critical for Haloferax volcanii archaeosortase catalytic activity: Implications for convergent evolution of the catalytic mechanisms of non-homologous sortases from archaea and bacteria. Mol. Microbiol. 2018, 108, 276-287. [CrossRef]

28. Abdul Halim, M.F.; Pfeiffer, F.; Zou, J.; Frisch, A.; Haft, D.; Wu, S.; Tolic, N.; Brewer, H.; Payne, S.H.; Pasa-Tolic, L.; et al. . Haloferax volcanii archaeosortase is required for motility, mating, and C-terminal processing of the S-layer glycoprotein. Mol. Microbiol. 2013, 88, 1164-1175. [CrossRef]

29. Storf, S.; Pfeiffer, F.; Dilks, K.; Chen, Z.Q.; Imam, S.; Pohlschroder, M. Mutational and bioinformatic analysis of haloarchaeal lipobox-containing proteins. Archaea 2010, 2010, 410975. [CrossRef]

30. Schiller, H.; Schulze, S.; Mutan, Z.; de Vaulx, C.; Runcie, C.; Schwartz, J.; Rados, T.; Bisson Filho, A.W.; Pohlschroder, M. Haloferax volcanii immersed liquid biofilms develop independently of known biofilm machineries and exhibit rapid honeycomb pattern formation. mSphere 2020, 5, e00976-20. [CrossRef]

31. Pohlschroder, M.; Esquivel, R.N. Archaeal type IV pili and their involvement in biofilm formation. Front. Microbiol. 2015, 6, 190. [CrossRef] [PubMed]

32. Li, Z.; Rodriguez-Franco, M.; Albers, S.V.; Quax, T.E.F. The switch complex ArlCDE connects the chemotaxis system and the archaellum. Mol. Microbiol. 2020, 114, 468-479. [CrossRef]

33. Collins, M.; Afolayan, S.; Igiraneza, A.B.; Schiller, H.; Krespan, E.; Beiting, D.P.; Dyall-Smith, M.; Pfeiffer, F.; Pohlschroder, M. Mutations affecting HVO_1357 or HVO_2248 cause hypermotility in Haloferax volcanii, suggesting roles in motility regulation. Genes (Basel) 2020, 12, 58. [CrossRef] [PubMed]

34. Quax, T.E.F.; Altegoer, F.; Rossi, F.; Li, Z.; Rodriguez-Franco, M.; Kraus, F.; Bange, G.; Albers, S.V. Structure and function of the archaeal response regulator CheY. Proc. Natl. Acad. Sci. USA 2018, 115, E1259-E1268. [CrossRef]

35. Nussbaum, P.; Ithurbide, S.; Walsh, J.C.; Patro, M.; Delpech, F.; Rodriguez-Franco, M.; Curmi, P.M.G.; Duggin, I.G.; Quax, T.E.F.; Albers, S.V. An oscillating MinD protein determines the cellular positioning of the motility machinery in Archaea. Curr. Biol. 2020, 30, 4956-4972. [CrossRef]

36. Shalev, Y.; Turgeman-Grott, I.; Tamir, A.; Eichler, J.; Gophna, U. Cell surface glycosylation is required for efficient mating of Haloferax volcanii. Front. Microbiol. 2017, 8, 1253. [CrossRef]

37. Braun, F.; Thomalla, L.; van der Does, C.; Quax, T.E.F.; Allers, T.; Kaever, V.; Albers, S.V. Cyclic nucleotides in archaea: Cyclic di-AMP in the archaeon Haloferax volcanii and its putative role. Microbiologyopen 2019, 8, e00829. [CrossRef]

38. Maier, L.K.; Stachler, A.E.; Brendel, J.; Stoll, B.; Fischer, S.; Haas, K.A.; Schwarz, T.S.; Alkhnbashi, O.S.; Sharma, K.; Urlaub, H.; et al. The nuts and bolts of the Haloferax CRISPR-Cas system I-B. RNA Biol. 2019, 16, 469-480. [CrossRef]

39. Reuter, C.J.; Maupin-Furlow, J.A. Analysis of proteasome-dependent proteolysis in Haloferax volcanii cells, using short-lived green fluorescent proteins. Appl. Environ. Microbiol. 2004, 70, 7530-7538. [CrossRef] [PubMed]

40. Reuter, C.J.; Uthandi, S.; Puentes, J.A.; Maupin-Furlow, J.A. Hydrophobic carboxy-terminal residues dramatically reduce protein levels in the haloarchaeon Haloferax volcanii. Microbiology (Reading) 2010, 156, 248-255. [CrossRef]

41. Prunetti, L.; Reuter, C.J.; Hepowit, N.L.; Wu, Y.; Barrueto, L.; Miranda, H.V.; Kelly, K.; Maupin-Furlow, J.A. Structural and biochemical properties of an extreme 'salt-loving' proteasome activating nucleotidase from the archaeon Haloferax volcanii. Extremophiles 2014, 18, 283-293. [CrossRef]

42. Cerletti, M.; Paggi, R.; Troetschel, C.; Ferrari, M.C.; Guevara, C.R.; Albaum, S.; Poetsch, A.; De Castro, R. LonB protease is a novel regulator of carotenogenesis controlling degradation of phytoene synthase in Haloferax volcanii. J. Proteome Res. 2018, 17, 1158-1171. [CrossRef]

43. Cerletti, M.; Martinez, M.J.; Gimenez, M.I.; Sastre, D.E.; Paggi, R.A.; De Castro, R.E. The LonB protease controls membrane lipids composition and is essential for viability in the extremophilic haloarchaeon Haloferax volcanii. Environ. Microbiol. 2014, 16, 1779-1792. [CrossRef] [PubMed] 
44. Costa, M.I.; Cerletti, M.; Paggi, R.A.; Trotschel, C.; De Castro, R.E.; Poetsch, A.; Gimenez, M.I. Haloferax volcanii proteome response to deletion of a rhomboid protease gene. J. Proteome Res. 2018, 17, 961-977. [CrossRef]

45. Cao, S.; Hepowit, N.; Maupin-Furlow, J.A. Ubiquitin-like protein SAMP1 and JAMM/MPN+ metalloprotease HvJAMM1 constitute a system for reversible regulation of metabolic enzyme activity in Archaea. PLoS ONE 2015, 10, e0128399. [CrossRef]

46. Kaminski, L.; Eichler, J. Haloferax volcanii N-glycosylation: Delineating the pathway of dTDP-rhamnose biosynthesis. PLoS ONE 2014, 9, e97441. [CrossRef] [PubMed]

47. Tripepi, M.; You, J.; Temel, S.; Onder, O.; Brisson, D.; Pohlschroder, M. N-Glycosylation of Haloferax volcanii flagellins requires known Agl proteins and Is essential for biosynthesis of stable flagella. J. Bacteriol. 2012, 194, 4876-4887. [CrossRef] [PubMed]

48. Gribaldo, S.; Schulze, S.; Pfeiffer, F.; Garcia, B.A.; Pohlschroder, M. Comprehensive glycoproteomics shines new light on the complexity and extent of glycosylation in archaea. PLoS Biol. 2021, 19, e3001277.

49. Shalev, Y.; Soucy, S.M.; Papke, R.T.; Gogarten, J.P.; Eichler, J.; Gophna, U. Comparative analysis of surface layer glycoproteins and genes involved in protein glycosylation in the genus Haloferax. Genes (Basel) 2018, 9, 172. [CrossRef]

50. Kandiba, L.; Lin, C.W.; Aebi, M.; Eichler, J.; Guerardel, Y. Structural characterization of the N-linked pentasaccharide decorating glycoproteins of the halophilic archaeon Haloferax volcanii. Glycobiology 2016, 26, 745-756. [CrossRef] [PubMed]

51. Qi, Q.; Ito, Y.; Yoshimatsu, K.; Fujiwara, T. Transcriptional regulation of dimethyl sulfoxide respiration in a haloarchaeon, Haloferax volcanii. Extremophiles 2016, 20, 27-36. [CrossRef]

52. Rawls, K.S.; Yacovone, S.K.; Maupin-Furlow, J.A. GlpR represses fructose and glucose metabolic enzymes at the level of transcription in the haloarchaeon Haloferax volcanii. J. Bacteriol. 2010, 192, 6251-6260. [CrossRef]

53. Hattori, T.; Shiba, H.; Ashiki, K.; Araki, T.; Nagashima, Y.K.; Yoshimatsu, K.; Fujiwara, T. Anaerobic growth of haloarchaeon Haloferax volcanii by denitrification is controlled by the transcription regulator NarO. J. Bacteriol. 2016, 198, 1077-1086. [CrossRef]

54. Hwang, S.; Cordova, B.; Abdo, M.; Pfeiffer, F.; Maupin-Furlow, J.A. ThiN as a versatile domain of transcriptional repressors and catalytic enzymes of thiamine biosynthesis. J. Bacteriol. 2017, 199, e00810-e00816. [CrossRef] [PubMed]

55. Johnsen, U.; Sutter, J.M.; Schulz, A.C.; Tastensen, J.B.; Schonheit, P. XacR-A novel transcriptional regulator of D-xylose and L-arabinose catabolism in the haloarchaeon Haloferax volcanii. Environ. Microbiol. 2015, 17, 1663-1676. [CrossRef]

56. Zahn, S.; Kubatova, N.; Pyper, D.J.; Cassidy, L.; Saxena, K.; Tholey, A.; Schwalbe, H.; Soppa, J. Biological functions, genetic and biochemical characterization, and NMR structure determination of the small zinc finger protein HVO_2753 from Haloferax volcanii. FEBS J. 2021, 288, 2042-2062. [CrossRef]

57. Nagel, C.; Machulla, A.; Zahn, S.; Soppa, J. Several one-domain zinc finger micro-proteins of Haloferax volcanii are important for stress adaptation, biofilm formation, and swarming. Genes (Basel) 2019, 10, 361. [CrossRef] [PubMed]

58. Kubatova, N.; Jonker, H.R.A.; Saxena, K.; Richter, C.; Vogel, V.; Schreiber, S.; Marchfelder, A.; Schwalbe, H. Solution Structure and Dynamics of the Small Protein HVO_2922 from Haloferax volcanii. ChemBioChem 2020, 21, 149-156. [CrossRef] [PubMed]

59. Straub, J.; Brenneis, M.; Jellen-Ritter, A.; Heyer, R.; Soppa, J.; Marchfelder, A. Small RNAs in haloarchaea: Identification, differential expression and biological function. RNA Biol. 2009, 6, 281-292. [CrossRef] [PubMed]

60. Heyer, R.; Dorr, M.; Jellen-Ritter, A.; Spath, B.; Babski, J.; Jaschinski, K.; Soppa, J.; Marchfelder, A. High throughput sequencing reveals a plethora of small RNAs including tRNA derived fragments in Haloferax volcanii. RNA Biol. 2012, 9, 1011-1018. [CrossRef]

61. Babski, J.; Maier, L.K.; Heyer, R.; Jaschinski, K.; Prasse, D.; Jager, D.; Randau, L.; Schmitz, R.A.; Marchfelder, A.; Soppa, J. Small regulatory RNAs in Archaea. RNA Biol. 2014, 11, 484-493. [CrossRef]

62. Wyss, L.; Waser, M.; Gebetsberger, J.; Zywicki, M.; Polacek, N. mRNA-specific translation regulation by a ribosome-associated ncRNA in Haloferax volcanii. Sci. Rep. 2018, 8, 12502. [CrossRef]

63. Schnoes, A.M.; Brown, S.D.; Dodevski, I.; Babbitt, P.C. Annotation error in public databases: Misannotation of molecular function in enzyme superfamilies. PLoS Comput. Biol. 2009, 5, e1000605. [CrossRef]

64. Promponas, V.J.; Iliopoulos, I.; Ouzounis, C.A. Annotation inconsistencies beyond sequence similarity-based function predictionPhylogeny and genome structure. Stand Genomic Sci 2015, 10, 108. [CrossRef]

65. Danchin, A.; Ouzounis, C.; Tokuyasu, T.; Zucker, J.D. No wisdom in the crowd: Genome annotation in the era of big-Current status and future prospects. Microb. Biotechnol. 2018, 11, 588-605. [CrossRef] [PubMed]

66. Falb, M.; Muller, K.; Konigsmaier, L.; Oberwinkler, T.; Horn, P.; von Gronau, S.; Gonzalez, O.; Pfeiffer, F.; Bornberg-Bauer, E.; Oesterhelt, D. Metabolism of halophilic archaea. Extremophiles 2008, 12, 177-196. [CrossRef]

67. Kanehisa, M.; Sato, Y.; Furumichi, M.; Morishima, K.; Tanabe, M. New approach for understanding genome variations in KEGG. Nucleic Acids Res. 2019, 47, D590-D595. [CrossRef] [PubMed]

68. UniProt, C. UniProt: The universal protein knowledgebase in 2021. Nucleic Acids Res. 2021, 49, D480-D489.

69. Pfeiffer, F.; Losensky, G.; Marchfelder, A.; Habermann, B.; Dyall-Smith, M. Whole-genome comparison between the type strain of Halobacterium salinarum (DSM 3754(T) ) and the laboratory strains R1 and NRC-1. Microbiologyopen 2020, 9, e974. [CrossRef] [PubMed]

70. Tittes, C.; Schwarzer, S.; Pfeiffer, F.; Dyall-Smith, M.; Rodriguez-Franco, M.; Oksanen, H.M.; Quax, T.E.F. Cellular and genomic properties of Haloferax gibbonsii LR2-5, the host of euryarchaeal virus HFTV1. Front. Microbiol. 2021, 12, 625599. [CrossRef] [PubMed]

71. Hunter, S.; Apweiler, R.; Attwood, T.K.; Bairoch, A.; Bateman, A.; Binns, D.; Bork, P.; Das, U.; Daugherty, L.; Duquenne, L.; et al. InterPro: The integrative protein signature database. Nucleic Acids Res. 2009, 37, D211-D215. [CrossRef] 
72. Kriventseva, E.V.; Kuznetsov, D.; Tegenfeldt, F.; Manni, M.; Dias, R.; Simao, F.A.; Zdobnov, E.M. OrthoDB v10: Sampling the diversity of animal, plant, fungal, protist, bacterial and viral genomes for evolutionary and functional annotations of orthologs. Nucleic Acids Res. 2019, 47, D807-D811. [CrossRef]

73. Oberto, J. SyntTax: A web server linking synteny to prokaryotic taxonomy. BMC Bioinformatics 2013, 14, 4. [CrossRef]

74. Johnson, M.; Zaretskaya, I.; Raytselis, Y.; Merezhuk, Y.; McGinnis, S.; Madden, T.L. NCBI BLAST: A better web interface. Nucleic Acids Res. 2008, 36, W5-W9. [CrossRef]

75. Altschul, S.F.; Madden, T.L.; Schaffer, A.A.; Zhang, J.; Zhang, Z.; Miller, W.; Lipman, D.J. Gapped BLAST and PSI-BLAST: A new generation of protein database search programs. Nucleic Acids Res. 1997, 25, 3389-3402. [CrossRef]

76. Rich, P.R.; Marechal, A. The mitochondrial respiratory chain. Essays Biochem. 2010, 47, 1-23. [PubMed]

77. Guo, R.; Gu, J.; Zong, S.; Wu, M.; Yang, M. Structure and mechanism of mitochondrial electron transport chain. Biomed. J. 2018, 41, 9-20. [CrossRef] [PubMed]

78. Crofts, A.R.; Hong, S.; Wilson, C.; Burton, R.; Victoria, D.; Harrison, C.; Schulten, K. The mechanism of ubihydroquinone oxidation at the Qo-site of the cytochrome bc1 complex. Biochim. Biophys. Acta 2013, 1827, 1362-1377. [CrossRef] [PubMed]

79. Kaila, V.R.I.; Wikstrom, M. Architecture of bacterial respiratory chains. Nat. Rev. Microbiol. 2021, 19, 319-330. [CrossRef]

80. Schafer, G.; Engelhard, M.; Muller, V. Bioenergetics of the Archaea. Microbiol. Mol. Biol. Rev. 1999, 63, 570-620. [CrossRef]

81. Scharf, B.; Wittenberg, R.; Engelhard, M. Electron transfer proteins from the haloalkaliphilic archaeon Natronobacterium pharaonis: Possible components of the respiratory chain include cytochrome bc and a terminal oxidase cytochrome ba3. Biochemistry 1997, 36, 4471-4479. [CrossRef] [PubMed]

82. Sreeramulu, K.; Schmidt, C.L.; Schafer, G.; Anemuller, S. Studies of the electron transport chain of the euryarcheon Halobacterium salinarum: Indications for a type II NADH dehydrogenase and a complex III analog. J. Bioenerg. Biomembr. 1998, 30, 443-453. [CrossRef]

83. Gradin, C.H.; Hederstedt, L.; Baltscheffsky, H. Soluble succinate dehydrogenase from the halophilic archaebacterium, Halobacterium halobium. Arch. Biochem. Biophys. 1985, 239, 200-205. [CrossRef]

84. Steinert, K.; Wagner, V.; Kroth Pancic, P.G.; Bickel Sandkoetter, S. Characterization and subunit structure of the ATP synthase of the halophilic archaeon Haloferax volcanii and organization of the ATP synthase genes. J. Biol. Chem. 1997, 272, 6261-6269. [CrossRef]

85. Nanba, T.; Mukohata, Y. A membrane-bound ATPase from Halobacterium halobium: Purification and characterization. J. Biochem. (Tokyo) 1987, 102, 591-598. [CrossRef] [PubMed]

86. Kerscher, L.; Oesterhelt, D. Ferredoxin is the coenzyme of $\alpha$-ketoacid oxidoreductases in Halobacterium halobium. FEBS Lett. 1977, 83, 197-201. [CrossRef]

87. Plaga, W.; Lottspeich, F.; Oesterhelt, D. Improved purification, crystallization and primary structure of pyruvate:ferredoxin oxidoreductase from Halobacterium halobium. Eur. J. Biochem. 1992, 205, 391-397. [CrossRef]

88. Kerscher, L.; Oesterhelt, D. Purification and properties of two 2-oxoacid:ferredoxin oxidoreductases from Halobacterium halobium. Eur. J. Biochem. 1981, 116, 587-594. [CrossRef]

89. Kerscher, L.; Oesterhelt, D. The catalytic mechanism of 2-oxoacid:ferredoxin oxidoreductases from Halobacterium halobium. One-electron transfer at two distinct steps of the catalytic cycle. Eur. J. Biochem. 1981, 116, 595-600. [CrossRef] [PubMed]

90. Zafrilla, B.; Martinez-Espinosa, R.M.; Bonete, M.J.; Butt, J.N.; Richardson, D.J.; Gates, A.J. A haloarchaeal ferredoxin electron donor that plays an essential role in nitrate assimilation. Biochem. Soc. Trans. 2011, 39, 1844-1848. [CrossRef] [PubMed]

91. Falb, M.; Pfeiffer, F.; Palm, P.; Rodewald, K.; Hickmann, V.; Tittor, J.; Oesterhelt, D. Living with two extremes: Conclusions from the genome sequence of Natronomonas pharaonis. Genome Res. 2005, 15, 1336-1343. [CrossRef]

92. Leif, H.; Sled, V.D.; Ohnishi, T.; Weiss, H.; Friedrich, T. Isolation and characterization of the proton-translocating NADH: Ubiquinone oxidoreductase from Escherichia coli. Eur. J. Biochem. 1995, 230, 538-548. [CrossRef]

93. Braun, M.; Bungert, S.; Friedrich, T. Characterization of the overproduced NADH dehydrogenase fragment of the NADH:ubiquinone oxidoreductase (complex I) from Escherichia coli. Biochemistry 1998, 37, 1861-1867. [CrossRef] [PubMed]

94. Mattar, S. Molekularbiologische und Biochemische Charakterisierung zweier Komplexe der Atmungskette von Natronobacterium pharaonis. Ph.D. Thesis, Ruhr-Universität Bochum, Bochum, Germany, 1996.

95. Kletzin, A.; Heimerl, T.; Flechsler, J.; van Niftrik, L.; Rachel, R.; Klingl, A. Cytochromes c in Archaea: Distribution, maturation, cell architecture, and the special case of Ignicoccus hospitalis. Front. Microbiol. 2015, 6, 439. [CrossRef] [PubMed]

96. Sreeramulu, K. Purification and partial characterization of cytochrome c552 from Halobacterium salinarium. Indian J. Biochem. Biophys. 2003, 40, 274-277.

97. Mattar, S.; Scharf, B.; Kent, S.B.; Rodewald, K.; Oesterhelt, D.; Engelhard, M. The primary structure of halocyanin, an archaeal blue copper protein, predicts a lipid anchor for membrane fixation. J. Biol. Chem. 1994, 269, 14939-14945. [CrossRef]

98. Scharf, B.; Engelhard, M. Halocyanin, an archaebacterial blue copper protein (type I) from Natronobacterium pharaonis. Biochemistry 1993, 32, 12894-12900. [CrossRef]

99. Hildebrandt, P.; Matysik, J.; Schrader, B.; Scharf, B.; Engelhard, M. Raman spectroscopic study of the blue copper protein halocyanin from Natronobacterium pharaonis. Biochemistry 1994, 33, 11426-11431. [CrossRef] [PubMed]

100. Kerscher, L.; Oesterhelt, D. A ferredoxin from halobacteria. FEBS Lett. 1976, 67, 320-322. [CrossRef]

101. Kerscher, L.; Oesterhelt, D.; Cammack, R.; Hall, D.O. A new plant-type ferredoxin from halobacteria. Eur. J. Biochem. 1976, 71, 101-107. [CrossRef] [PubMed] 
102. Zhang, P.; Battchikova, N.; Paakkarinen, V.; Katoh, H.; Iwai, M.; Ikeuchi, M.; Pakrasi, H.B.; Ogawa, T.; Aro, E.M. Isolation, subunit composition and interaction of the NDH-1 complexes from Thermosynechococcus elongatus BP-1. Biochem. J. 2005, 390, 513-520. [CrossRef] [PubMed]

103. Schuller, J.M.; Birrell, J.A.; Tanaka, H.; Konuma, T.; Wulfhorst, H.; Cox, N.; Schuller, S.K.; Thiemann, J.; Lubitz, W.; Setif, P.; et al. Structural adaptations of photosynthetic complex I enable ferredoxin-dependent electron transfer. Science 2019, 363, 257-260. [CrossRef]

104. Pan, X.; Cao, D.; Xie, F.; Xu, F.; Su, X.; Mi, H.; Zhang, X.; Li, M. Structural basis for electron transport mechanism of complex I-like photosynthetic NAD(P)H dehydrogenase. Nat. Commun. 2020, 11, 610. [CrossRef] [PubMed]

105. Liu, J.; Krulwich, T.A.; Hicks, D.B. Purification of two putative type II NADH dehydrogenases with different substrate specificities from alkaliphilic Bacillus pseudofirmus OF4. Biochim. Biophys. Acta 2008, 1777, 453-461. [CrossRef] [PubMed]

106. Lee, T.-X.; Metzger, S.U.; Cho, Y.S.; Whitmarsh, J.; Kallas, T. Modification of inhibitor binding sites in the cytochrome bf complex by directed mutagenesis of cytochrome b6 in Synechococcus sp. PCC 7002. Biochim. Biophys. Acta 2001, 1504, 235-247. [CrossRef]

107. Mattar, S.; Engelhard, M. Cytochrome ba3 from Natronobacterium pharaonis-An archaeal four-subunit cytochrome-c-type oxidase. Eur. J. Biochem. 1997, 250, 332-341. [CrossRef] [PubMed]

108. Tanaka, M.; Ogawa, N.; Ihara, K.; Sugiyama, Y.; Mukohata, Y. Cytochrome aa(3) in Haloferax volcanii. J. Bacteriol. 2002, 184, 840-845. [CrossRef]

109. Fujiwara, T.; Fukumori, Y.; Yamanaka, T. Purification and properties of Halobacterium halobium "cytochrome aa3" which lacks CuA and CuB. J. Biochem. (Tokyo) 1989, 105, 287-292. [CrossRef]

110. Denda, K.; Fujiwara, T.; Seki, M.; Yoshida, M.; Fukumori, Y.; Yamanaka, T. Molecular cloning of the cytochrome aa3 gene from the archaeon (Archaebacterium) Halobacterium halobium. Biochem. Biophys. Res. Commun. 1991, 181, 316-322. [CrossRef]

111. Ishikawa, R.; Ishido, Y.; Tachikawa, A.; Kawasaki, H.; Matsuzawa, H.; Wakagi, T. Aeropyrum pernix K1, a strictly aerobic and hyperthermophilic archaeon, has two terminal oxidases, cytochrome ba3 and cytochrome aa3. Arch. Microbiol. 2002, 179, 42-49. [CrossRef]

112. Moshiri, F.; Chawla, A.; Maier, R.J. Cloning, characterization, and expression in Escherichia coli of the genes encoding the cytochrome d oxidase complex from Azotobacter vinelandii. J. Bacteriol. 1991, 173, 6230-6241. [CrossRef]

113. Miller, M.J.; Gennis, R.B. The purification and characterization of the cytochrome d terminal oxidase complex of the Escherichia coli aerobic respiratory chain. J. Biol. Chem. 1983, 258, 9159-9165. [CrossRef]

114. Zimmermann, B.H.; Nitsche, C.I.; Fee, J.A.; Rusnak, F.; Munck, E. Properties of a copper-containing cytochrome ba3: A second terminal oxidase from the extreme thermophile Thermus thermophilus. Proc. Natl. Acad. Sci. USA 1988, 85, 5779-5783. [CrossRef]

115. Keightley, J.A.; Zimmermann, B.H.; Mather, M.W.; Springer, P.; Pastuszyn, A.; Lawrence, D.M.; Fee, J.A. Molecular genetic and protein chemical characterization of the cytochrome ba3 from Thermus thermophilus HB8. J. Biol. Chem. 1995, 270, 20345-20358. [CrossRef] [PubMed]

116. Sisignano, M.; Morbitzer, D.; Gatgens, J.; Oldiges, M.; Soppa, J. A 2-oxoacid dehydrogenase complex of Haloferax volcanii is essential for growth on isoleucine but not on other branched-chain amino acids. Microbiology 2010, 156, 521-529. [CrossRef] [PubMed]

117. Jolley, K.A.; Maddocks, D.G.; Gyles, S.L.; Mullan, Z.; Tang, S.L.; Dyall-Smith, M.L.; Hough, D.W.; Danson, M.J. 2-Oxoacid dehydrogenase multienzyme complexes in the halophilic Archaea? Gene sequences and protein structural predictions. Microbiology (Reading) 2000, 146 Pt 5, 1061-1069. [CrossRef]

118. Al-Mailem, D.M.; Hough, D.W.; Danson, M.J. The 2-oxoacid dehydrogenase multienzyme complex of Haloferax volcanii. Extremophiles 2008, 12, 89-96. [CrossRef]

119. van Ooyen, J.; Soppa, J. Three 2-oxoacid dehydrogenase operons in Haloferax volcanii: Expression, deletion mutants and evolution. Microbiology 2007, 153, 3303-3313. [CrossRef]

120. Wanner, C.; Soppa, J. Functional role for a 2-oxo acid dehydrogenase in the halophilic archaeon Haloferax volcanii. J. Bacteriol. 2002, 184, 3114-3121. [CrossRef] [PubMed]

121. Heath, C.; Posner, M.G.; Aass, H.C.; Upadhyay, A.; Scott, D.J.; Hough, D.W.; Danson, M.J. The 2-oxoacid dehydrogenase multi-enzyme complex of the archaeon Thermoplasma acidophilum-Recombinant expression, assembly and characterization. FEBS J. 2007, 274, 5406-5415. [CrossRef]

122. Oppermann, F.B.; Schmidt, B.; Steinbuchel, A. Purification and characterization of acetoin:2,6-dichlorophenolindophenol oxidoreductase, dihydrolipoamide dehydrogenase, and dihydrolipoamide acetyltransferase of the Pelobacter carbinolicus acetoin dehydrogenase enzyme system. J. Bacteriol. 1991, 173, 757-767. [CrossRef] [PubMed]

123. Huang, M.; Oppermann-Sanio, F.B.; Steinbuchel, A. Biochemical and molecular characterization of the Bacillus subtilis acetoin catabolic pathway. J. Bacteriol. 1999, 181, 3837-3841. [CrossRef] [PubMed]

124. Horie, A.; Tomita, T.; Saiki, A.; Kono, H.; Taka, H.; Mineki, R.; Fujimura, T.; Nishiyama, C.; Kuzuyama, T.; Nishiyama, M. Discovery of proteinaceous N-modification in lysine biosynthesis of Thermus thermophilus. Nat. Chem. Biol. 2009, 5, 673-679. [CrossRef] [PubMed]

125. Yoshida, A.; Tomita, T.; Atomi, H.; Kuzuyama, T.; Nishiyama, M. Lysine biosynthesis of Thermococcus kodakarensis with the capacity to function as an ornithine biosynthetic system. J. Biol. Chem. 2016, 291, 21630-21643. [CrossRef] 
126. Ouchi, T.; Tomita, T.; Horie, A.; Yoshida, A.; Takahashi, K.; Nishida, H.; Lassak, K.; Taka, H.; Mineki, R.; Fujimura, T.; et al. Lysine and arginine biosyntheses mediated by a common carrier protein in Sulfolobus. Nat. Chem. Biol. 2013, 9, 277-283. [CrossRef] [PubMed]

127. Hochuli, M.; Patzelt, H.; Oesterhelt, D.; Wuthrich, K.; Szyperski, T. Amino acid biosynthesis in the halophilic archaeon Haloarcula hispanica. J. Bacteriol. 1999, 181, 3226-3237. [CrossRef]

128. Yoshida, A.; Tomita, T.; Fujimura, T.; Nishiyama, C.; Kuzuyama, T.; Nishiyama, M. Structural insight into amino group-carrier protein-mediated lysine biosynthesis: Crystal structure of the LysZ.LysW complex from Thermus thermophilus. J. Biol. Chem. 2015, 290, 435-447. [CrossRef]

129. Shimizu, T.; Tomita, T.; Kuzuyama, T.; Nishiyama, M. Crystal structure of the LysY.LysW complex from Thermus thermophilus. J. Biol. Chem. 2016, 291, 9948-9959. [CrossRef]

130. Miyazaki, J.; Kobashi, N.; Nishiyama, M.; Yamane, H. Functional and evolutionary relationship between arginine biosynthesis and prokaryotic lysine biosynthesis through alpha-aminoadipate. J. Bacteriol. 2001, 183, 5067-5073. [CrossRef]

131. Fujita, S.; Cho, S.H.; Yoshida, A.; Hasebe, F.; Tomita, T.; Kuzuyama, T.; Nishiyama, M. Crystal structure of LysK, an enzyme catalyzing the last step of lysine biosynthesis in Thermus thermophilus, in complex with lysine: Insight into the mechanism for recognition of the amino-group carrier protein, LysW. Biochem. Biophys. Res. Commun. 2017, 491, 409-415. [CrossRef]

132. Issaly, I.M.; Issaly, A.S. Control of ornithine carbamoyltransferase activityby arginase in Bacillus subtilis. Eur. J. Biochem. 1974, 49, 485-495. [CrossRef] [PubMed]

133. Ruepp, A.; Muller, H.N.; Lottspeich, F.; Soppa, J. Catabolic ornithine transcarbamylase of Halobacterium halobium (salinarium) Purification, characterization, sequence determination, and evolution. J. Bacteriol. 1995, 177, 1129-1136. [CrossRef] [PubMed]

134. Shaheen, N.; Kobayashi, K.; Terazono, H.; Fukushige, T.; Horiuchi, M.; Saheki, T. Characterization of human wild-type and mutant argininosuccinate synthetase proteins expressed in bacterial cells. Enzyme Protein 1994, 48, 251-264. [CrossRef]

135. Lemke, C.; Yeung, M.; Howell, P.L. Expression, purification, crystallization and preliminary X-ray analysis of Escherichia coli argininosuccinate synthetase. Acta Crystallogr. D Biol. Crystallogr. 1999, 55, 2028-2030. [CrossRef]

136. Cohen-Kupiec, R.; Kupiec, M.; Sandbeck, K.; Leigh, J.A. Functional conservation between the argininosuccinate lyase of the archaeon Methanococcus maripaludis and the corresponding bacterial and eukaryal genes. FEMS Microbiol. Lett. 1999, 173, 231-238. [CrossRef]

137. Kato, C.; Kurihara, T.; Kobashi, N.; Yamane, H.; Nishiyama, M. Conversion of feedback regulation in aspartate kinase by domain exchange. Biochem. Biophys. Res. Commun. 2004, 316, 802-808. [CrossRef] [PubMed]

138. Faehnle, C.R.; Ohren, J.F.; Viola, R.E. A new branch in the family: Structure of aspartate-beta-semialdehyde dehydrogenase from Methanococcus jannaschii. J. Mol. Biol. 2005, 353, 1055-1068. [CrossRef] [PubMed]

139. Kaur, N.; Gautam, A.; Kumar, S.; Singh, A.; Singh, N.; Sharma, S.; Sharma, R.; Tewari, R.; Singh, T.P. Biochemical studies and crystal structure determination of dihydrodipicolinate synthase from Pseudomonas aeruginosa. Int. J. Biol. Macromol. 2011, 48, 779-787. [CrossRef]

140. Reddy, S.G.; Sacchettini, J.C.; Blanchard, J.S. Expression, purification, and characterization of Escherichia coli dihydrodipicolinate reductase. Biochemistry 1995, 34, 3492-3501. [CrossRef]

141. Simms, S.A.; Voige, W.H.; Gilvarg, C. Purification and characterization of succinyl-CoA: Tetrahydrodipicolinate Nsuccinyltransferase from Escherichia coli. J. Biol. Chem. 1984, 259, 2734-2741. [CrossRef]

142. Lin, Y.K.; Myhrman, R.; Schrag, M.L.; Gelb, M.H. Bacterial N-succinyl-L-diaminopimelic acid desuccinylase. Purification, partial characterization, and substrate specificity. J. Biol. Chem. 1988, 263, 1622-1627. [CrossRef]

143. Wiseman, J.S.; Nichols, J.S. Purification and properties of diaminopimelic acid epimerase from Escherichia coli. J. Biol. Chem. 1984, 259, 8907-8914. [CrossRef]

144. White, P.J.; Kelly, B. Purification and properties of diaminopimelate decarboxylase from Escherichia coli. Biochem. J. 1965, 96, 75-84. [CrossRef] [PubMed]

145. Gulko, M.K.; Dyall-Smith, M.; Gonzalez, O.; Oesterhelt, D. How do haloarchaea synthesize aromatic amino acids? PLoS ONE 2014, 9, e107475. [CrossRef]

146. White, R.H. L-Aspartate semialdehyde and a 6-deoxy-5-ketohexose 1-phosphate are the precursors to the aromatic amino acids in Methanocaldococcus jannaschii. Biochemistry 2004, 43, 7618-7627. [CrossRef] [PubMed]

147. Porat, I.; Waters, B.W.; Teng, Q.; Whitman, W.B. Two biosynthetic pathways for aromatic amino acids in the archaeon Methanococcus maripaludis. J. Bacteriol. 2004, 186, 4940-4950. [CrossRef]

148. Phillips, R.S.; Gollnick, P.D. Evidence that cysteine 298 Is in the active site of tryptophan indole-lyase. J. Biol. Chem. 1989, 264, 10627-10632. [CrossRef]

149. Newton, W.A.; Morino, Y.; Snell, E.E. Properties of crystalline tryptophanase. J. Biol. Chem. 1965, 240, 1211-1218. [CrossRef]

150. Oda, M.; Sugishita, A.; Furukawa, K. Cloning and nucleotide sequences of histidase and regulatory genes in the Bacillus subtilis hut operon and positive regulation of the operon. J. Bacteriol. 1988, 170, 3199-3205. [CrossRef]

151. Hartwell, L.H.; Magasanik, B. The molecular basis of histidase induction in Bacillus subtilis. J. Mol. Biol. 1963, 7, 401-420. [CrossRef]

152. Kaminskas, E.; Kimhi, Y.; Magasanik, B. Urocanase and N-formimino-L-glutamate formiminohydrolase of Bacillus subtilis, two enzymes of the histidine degradation pathway. J. Biol. Chem. 1970, 245, 3536-3544. [CrossRef] 
153. Yu, Y.; Liang, Y.H.; Brostromer, E.; Quan, J.M.; Panjikar, S.; Dong, Y.H.; Su, X.D. A catalytic mechanism revealed by the crystal structures of the imidazolonepropionase from Bacillus subtilis. J. Biol. Chem. 2006, 281, 36929-36936. [CrossRef] [PubMed]

154. Howell, D.M.; Xu, H.; White, R.H. (R)-citramalate synthase in methanogenic archaea. J. Bacteriol. 1999, 181, 331-333. [CrossRef]

155. Howell, D.M.; Harich, K.; Xu, H.M.; White, R.H. Alpha-keto acid chain elongation reactions involved in the biosynthesis of coenzyme b (7-mercaptoheptanoyl threonine phosphate) in methanogenic archaea. Biochemistry 1998, 37, 10108-10117. [CrossRef] [PubMed]

156. Porat, I.; Sieprawska-Lupa, M.; Teng, Q.; Bohanon, F.J.; White, R.H.; Whitman, W.B. Biochemical and genetic characterization of an early step in a novel pathway for the biosynthesis of aromatic amino acids and p-aminobenzoic acid in the archaeon Methanococcus maripaludis. Mol. Microbiol. 2006, 62, 1117-1131. [CrossRef] [PubMed]

157. Large, A.; Stamme, C.; Lange, C.; Duan, Z.; Allers, T.; Soppa, J.; Lund, P.A. Characterization of a tightly controlled promoter of the halophilic archaeon Haloferax volcanii and its use in the analysis of the essential cct1 gene. Mol. Microbiol. 2007, 66, 1092-1106. [CrossRef]

158. Bali, S.; Lawrence, A.D.; Lobo, S.A.; Saraiva, L.M.; Golding, B.T.; Palmer, D.J.; Howard, M.J.; Ferguson, S.J.; Warren, M.J. Molecular hijacking of siroheme for the synthesis of heme and d1 heme. Proc. Natl. Acad. Sci. USA 2011, 108, 18260-18265. [CrossRef]

159. Siddaramappa, S.; Challacombe, J.F.; Decastro, R.E.; Pfeiffer, F.; Sastre, D.E.; Gimenez, M.I.; Paggi, R.A.; Detter, J.C.; Davenport, K.W.; Goodwin, L.A.; et al. A comparative genomics perspective on the genetic content of the alkaliphilic haloarchaeon Natrialba magadii ATCC 43099T . BMC Genomics 2012, 13, 165. [CrossRef]

160. Moore, S.J.; Lawrence, A.D.; Biedendieck, R.; Deery, E.; Frank, S.; Howard, M.J.; Rigby, S.E.; Warren, M.J. Elucidation of the anaerobic pathway for the corrin component of cobalamin (vitamin B12). Proc. Natl. Acad. Sci. USA 2013, 110, 14906-14911. [CrossRef]

161. Rodionov, D.A.; Vitreschak, A.G.; Mironov, A.A.; Gelfand, M.S. Comparative genomics of the vitamin B12 metabolism and regulation in prokaryotes. J. Biol. Chem. 2003, 278, 41148-41159. [CrossRef]

162. Kosugi, N.; Araki, T.; Fujita, J.; Tanaka, S.; Fujiwara, T. Growth phenotype analysis of heme synthetic enzymes in a halophilic archaeon, Haloferax volcanii. PLoS ONE 2017, 12, e0189913. [CrossRef] [PubMed]

163. Raux, E.; Leech, H.K.; Beck, R.; Schubert, H.L.; Santander, P.J.; Roessner, C.A.; Scott, A.I.; Martens, J.H.; Jahn, D.; Thermes, C.; et al Identification and functional analysis of enzymes required for precorrin-2 dehydrogenation and metal ion insertion in the biosynthesis of sirohaem and cobalamin in Bacillus megaterium. Biochem. J. 2003, 370, 505-516. [CrossRef] [PubMed]

164. Brindley, A.A.; Raux, E.; Leech, H.K.; Schubert, H.L.; Warren, M.J. A story of chelatase evolution: Identification and characterization of a small 13-15-kDa "ancestral" cobaltochelatase (CbiXS) in the archaea. J. Biol. Chem. 2003, 278, 22388-22395. [CrossRef] [PubMed]

165. Yin, J.; Xu, L.X.; Cherney, M.M.; Raux-Deery, E.; Bindley, A.A.; Savchenko, A.; Walker, J.R.; Cuff, M.E.; Warren, M.J.; James, M.N. Crystal structure of the vitamin B12 biosynthetic cobaltochelatase, CbiXS, from Archaeoglobus fulgidus. J. Struct. Funct. Genomics 2006, 7, 37-50. [CrossRef]

166. Storbeck, S.; Rolfes, S.; Raux-Deery, E.; Warren, M.J.; Jahn, D.; Layer, G. A novel pathway for the biosynthesis of heme in Archaea: Genome-based bioinformatic predictions and experimental evidence. Archaea 2010, 2010, 175050. [CrossRef]

167. Stroupe, M.E.; Leech, H.K.; Daniels, D.S.; Warren, M.J.; Getzoff, E.D. CysG structure reveals tetrapyrrole-binding features and novel regulation of siroheme biosynthesis. Nat. Struct. Biol. 2003, 10, 1064-1073. [CrossRef]

168. Pennington, J.M.; Kemp, M.; McGarry, L.; Chen, Y.; Stroupe, M.E. Siroheme synthase orients substrates for dehydrogenase and chelatase activities in a common active site. Nat. Commun. 2020, 11, 864. [CrossRef]

169. Schubert, H.L.; Rose, R.S.; Leech, H.K.; Brindley, A.A.; Hill, C.P.; Rigby, S.E.; Warren, M.J. Structure and function of SirC from Bacillus megaterium: A metal-binding precorrin-2 dehydrogenase. Biochem. J. 2008, 415, 257-263. [CrossRef]

170. Roessner, C.A.; Warren, M.J.; Santander, P.J.; Atshaves, B.P.; Ozaki, S.-i.; Stolowich, N.J.; Iida, K.; Scott, A.I. Expression of 9 Salmonella typhimurium enzymes for cobinamide synthesis. Identification of the 11-methyl and 20-methyl transferases of corrin biosynthesis. FEBS Lett. 1992, 301, 73-78. [CrossRef]

171. Santander, P.J.; Roessner, C.A.; Stolowich, N.J.; Holderman, M.T.; Scott, A.I. How corrinoids are synthesized without oxygen: Nature's first pathway to vitamin B12. Chem. Biol. 1997, 4, 659-666. [CrossRef]

172. Santander, P.J.; Kajiwara, Y.; Williams, H.J.; Scott, A.I. Structural characterization of novel cobalt corrinoids synthesized by enzymes of the vitamin B12 anaerobic pathway. Bioorg. Med. Chem. 2006, 14, 724-731. [CrossRef]

173. Kajiwara, Y.; Santander, P.J.; Roessner, C.A.; Perez, L.M.; Scott, A.I. Genetically engineered synthesis and structural characterization of cobalt-precorrin $5 \mathrm{~A}$ and $-5 \mathrm{~B}$, two new intermediates on the anaerobic pathway to vitamin B12: Definition of the roles of the CbiF and CbiG enzymes. J. Am. Chem. Soc. 2006, 128, 9971-9978. [CrossRef]

174. Fresquet, V.; Williams, L.; Raushel, F.M. Mechanism of cobyrinic acid a,c-diamide synthetase from Salmonella typhimurium LT2. Biochemistry 2004, 43, 10619-10627. [CrossRef]

175. Buan, N.R.; Rehfeld, K.; Escalante-Semerena, J.C. Studies of the CobA-type ATP:Co(I)rrinoid adenosyltransferase enzyme of Methanosarcina mazei strain Go1. J. Bacteriol. 2006, 188, 3543-3550. [CrossRef]

176. Fonseca, M.V.; Buan, N.R.; Horswill, A.R.; Rayment, I.; Escalante-Semerena, J.C. The ATP:Co(I)rrinoid adenosyltransferase (CobA) enzyme of Salmonella enterica requires the 2'-OH group of ATP for function and yields inorganic triphosphate as its reaction byproduct. J. Biol. Chem. 2002, 277, 33127-33131. [CrossRef] 
177. Johnson, C.L.; Pechonick, E.; Park, S.D.; Havemann, G.D.; Leal, N.A.; Bobik, T.A. Functional genomic, biochemical, and genetic characterization of the Salmonella $p d u O$ gene, an ATP:cob(I)alamin adenosyltransferase gene. J. Bacteriol. 2001, 183, 1577-1584. [CrossRef]

178. Woodson, J.D.; Zayas, C.L.; Escalante-Semerena, J.C. A new pathway for salvaging the coenzyme B12 precursor cobinamide in archaea requires cobinamide-phosphate synthase (CbiB) enzyme activity. J. Bacteriol. 2003, 185, 7193-7201. [CrossRef]

179. Woodson, J.D.; Escalante-Semerena, J.C. CbiZ, an amidohydrolase enzyme required for salvaging the coenzyme B12 precursor cobinamide in archaea. Proc. Natl. Acad. Sci. USA 2004, 101, 3591-3596. [CrossRef]

180. Woodson, J.D.; Peck, R.F.; Krebs, M.P.; Escalante-Semerena, J.C. The cobY gene of the archaeon Halobacterium sp. strain NRC-1 is required for de novo cobamide synthesis. J. Bacteriol. 2003, 185, 311-316. [CrossRef] [PubMed]

181. Zayas, C.L.; Escalante-Semerena, J.C. Reassessment of the late steps of coenzyme B12 synthesis in Salmonella enterica: Evidence that dephosphorylation of adenosylcobalamin-5'-phosphate by the CobC phosphatase is the last step of the pathway. J. Bacteriol. 2007, 189, 2210-2218. [CrossRef]

182. O'Toole, G.A.; Trzebiatowski, J.R.; Escalante-Semerena, J.C. The cobC gene of Salmonella typhimurium codes for a novel phosphatase involved in the assembly of the nucleotide loop of cobalamin. J. Biol. Chem. 1994, 269, 26503-26511. [CrossRef]

183. Brushaber, K.R.; O'Toole, G.A.; Escalante-Semerena, J.C. CobD, a novel enzyme with L-threonine-O-3-phosphate decarboxylase activity, is responsible for the synthesis of (R)-1-amino-2-propanol O-2-phosphate, a proposed new intermediate in cobalamin biosynthesis in Salmonella typhimurium LT2. J. Biol. Chem. 1998, 273, 2684-2691. [CrossRef]

184. Trzebiatowski, J.R.; O'Toole, G.A.; Escalante-Semerena, J.C. The cobT gene of Salmonella typhimurium encodes the NaMN: 5,6-dimethylbenzimidazole phosphoribosyltransferase responsible for the synthesis of N1-(5-phospho-alpha-D-ribosyl)-5,6dimethylbenzimidazole, an intermediate in the synthesis of the nucleotide loop of cobalamin. J. Bacteriol. 1994, 176, 3568-3575.

185. Debussche, L.; Couder, M.; Thibaut, D.; Cameron, B.; Crouzet, J.; Blanche, F. Assay, purification, and characterization of cobaltochelatase, a unique complex enzyme catalyzing cobalt insertion in hydrogenobyrinic acid a,c-diamide during coenzyme B12 biosynthesis in Pseudomonas denitrificans. J. Bacteriol. 1992, 174, 7445-7451. [CrossRef]

186. Jensen, P.E.; Gibson, L.C.; Henningsen, K.W.; Hunter, C.N. Expression of the chlI, chlD, and chlH genes from the Cyanobacterium Synechocystis PCC6803 in Escherichia coli and demonstration that the three cognate proteins are required for magnesiumprotoporphyrin chelatase activity. J. Biol. Chem. 1996, 271, 16662-16667. [CrossRef] [PubMed]

187. Jensen, P.E.; Gibson, L.C.; Hunter, C.N. Determinants of catalytic activity with the use of purified I, D and H subunits of the magnesium protoporphyrin IX chelatase from Synechocystis PCC6803. Biochem. J. 1998, 334 Pt 2, 335-344. [CrossRef]

188. Kuhner, M.; Haufschildt, K.; Neumann, A.; Storbeck, S.; Streif, J.; Layer, G. The alternative route to heme in the methanogenic archaeon Methanosarcina barkeri. Archaea 2014, 2014, 327637. [CrossRef] [PubMed]

189. Dailey, H.A.; Dailey, T.A.; Gerdes, S.; Jahn, D.; Jahn, M.; O’Brian, M.R.; Warren, M.J. Prokaryotic heme biosynthesis: Multiple pathways to a common essential product. Microbiol. Mol. Biol. Rev. 2017, 81, e00048-16. [CrossRef] [PubMed]

190. Eirich, L.D.; Vogels, G.D.; Wolfe, R.S. Distribution of coenzyme F420 and properties of its hydrolytic fragments. J. Bacteriol. 1979, 140, 20-27. [CrossRef]

191. Jaenchen, R.; Schonheit, P.; Thauer, R.K. Studies on the biosynthesis of coenzyme F420 in methanogenic bacteria. Arch. Microbiol. 1984, 137, 362-365. [CrossRef]

192. Lin, X.L.; White, R.H. Occurrence of coenzyme F420 and its gamma-monoglutamyl derivative in nonmethanogenic archaebacteria. J. Bacteriol. 1986, 168, 444-448. [CrossRef]

193. de Wit, L.E.A.; Eker, A.P.M. 8-Hydroxy-5-deazaflavin-dependent electron transfer in the extreme halophile Halobacterium cutirubrum. FEMS Microbiol. Lett. 1987, 48, 121-125. [CrossRef]

194. Grochowski, L.L.; Xu, H.; White, R.H. Identification and characterization of the 2-phospho-L-lactate guanylyltransferase involved in coenzyme F420 biosynthesis. Biochemistry 2008, 47, 3033-3037. [CrossRef]

195. Bashiri, G.; Antoney, J.; Jirgis, E.N.M.; Shah, M.V.; Ney, B.; Copp, J.; Stuteley, S.M.; Sreebhavan, S.; Palmer, B.; Middleditch, M.; et al. A revised biosynthetic pathway for the cofactor F420 in prokaryotes. Nat. Commun. 2019, 10, 1558. [CrossRef]

196. Braga, D.; Last, D.; Hasan, M.; Guo, H.; Leichnitz, D.; Uzum, Z.; Richter, I.; Schalk, F.; Beemelmanns, C.; Hertweck, C.; et al. Metabolic pathway rerouting in Paraburkholderia rhizoxinica evolved long-overlooked derivatives of coenzyme F420. ACS Chem. Biol. 2019, 14, 2088-2094. [CrossRef]

197. Selengut, J.D.; Haft, D.H. Unexpected abundance of coenzyme F(420)-dependent enzymes in Mycobacterium tuberculosis and other actinobacteria. J. Bacteriol. 2010, 192, 5788-5798. [CrossRef]

198. Graham, D.E.; Xu, H.; White, R.H. Identification of the 7,8-didemethyl-8-hydroxy-5-deazariboflavin synthase required for coenzyme F(420) biosynthesis. Arch. Microbiol. 2003, 180, 455-464. [CrossRef]

199. Philmus, B.; Decamps, L.; Berteau, O.; Begley, T.P. Biosynthetic versatility and coordinated action of 5'-deoxyadenosyl radicals in deazaflavin biosynthesis. J. Am. Chem. Soc. 2015, 137, 5406-5413. [CrossRef] [PubMed]

200. Decamps, L.; Philmus, B.; Benjdia, A.; White, R.; Begley, T.P.; Berteau, O. Biosynthesis of F0, precursor of the F420 cofactor, requires a unique two radical-SAM domain enzyme and tyrosine as substrate. J. Am. Chem. Soc. 2012, 134, 18173-18176. [CrossRef] [PubMed]

201. Forouhar, F.; Abashidze, M.; Xu, H.; Grochowski, L.L.; Seetharaman, J.; Hussain, M.; Kuzin, A.; Chen, Y.; Zhou, W.; Xiao, R.; et al. Molecular insights into the biosynthesis of the F420 coenzyme. J. Biol. Chem. 2008, 283, 11832-11840. [CrossRef] [PubMed] 
202. Graupner, M.; Xu, H.; White, R.H. Characterization of the 2-phospho-L-lactate transferase enzyme involved in coenzyme F(420) biosynthesis in Methanococcus jannaschii. Biochemistry 2002, 41, 3754-3761. [CrossRef]

203. Nocek, B.; Evdokimova, E.; Proudfoot, M.; Kudritska, M.; Grochowski, L.L.; White, R.H.; Savchenko, A.; Yakunin, A.F.; Edwards, A.; Joachimiak, A. Structure of an amide bond forming F(420):gamma-glutamyl ligase from Archaeoglobus fulgidus-A member of a new family of non-ribosomal peptide synthases. J. Mol. Biol. 2007, 372, 456-469. [CrossRef]

204. Li, H.; Graupner, M.; Xu, H.; White, R.H. CofE catalyzes the addition of two glutamates to F420-0 in F420 coenzyme biosynthesis in Methanococcus jannaschii. Biochemistry 2003, 42, 9771-9778. [CrossRef]

205. Kunow, J.; Schwoërer, B.; Stetter, K.O.; Thauer, R.K. A F420-dependent NADP reductase in the extremely thermophilic sulfatereducing Archaeoglobus fulgidus. Arch. Microbiol. 1993, 160, 199-205.

206. Purwantini, E.; Mukhopadhyay, B. Rv0132c of Mycobacterium tuberculosis encodes a coenzyme F420-dependent hydroxymycolic acid dehydrogenase. PLoS ONE 2013, 8, e81985. [CrossRef]

207. Klein, A.R.; Berk, H.; Purwantini, E.; Daniels, L.; Thauer, R.K. Si-face stereospecificity at C5 of coenzyme F420 for F420dependent glucose-6-phosphate dehydrogenase from Mycobacterium smegmatis and F420-dependent alcohol dehydrogenase from Methanoculleus thermophilicus. Eur. J. Biochem. 1996, 239, 93-97. [CrossRef]

208. Aufhammer, S.W.; Warkentin, E.; Berk, H.; Shima, S.; Thauer, R.K.; Ermler, U. Coenzyme binding in F420-dependent secondary alcohol dehydrogenase, a member of the bacterial luciferase family. Structure 2004, 12, 361-370. [CrossRef] [PubMed]

209. Haase, P.; Deppenmeier, U.; Blaut, M.; Gottschalk, G. Purification and characterization of F420H2-dehydrogenase from Methanolobus tindarius. Eur. J. Biochem. 1992, 203, 527-531. [CrossRef]

210. Westenberg, D.J.; Braune, A.; Ruppert, C.; Muller, V.; Herzberg, C.; Gottschalk, G.; Blaut, M. The F420H2-dehydrogenase from Methanolobus tindarius: Cloning of the ffd operon and expression of the genes in Escherichia coli. FEMS Microbiol. Lett. 1999, 170, 389-398. [CrossRef] [PubMed]

211. Johnson, E.F.; Mukhopadhyay, B. A new type of sulfite reductase, a novel coenzyme F420-dependent enzyme, from the methanarchaeon Methanocaldococcus jannaschii. J. Biol. Chem. 2005, 280, 38776-38786. [CrossRef]

212. te Brömmelstroet, B.W.; Hensgens, C.M.; Keltjens, J.T.; van der Drift, C.; Vogels, G.D. Purification and properties of 5,10methylenetetrahydromethanopterin reductase, a coenzyme F420-dependent enzyme, from Methanobacterium thermoautotrophicum strain delta H. J. Biol. Chem. 1990, 265, 1852-1857. [CrossRef]

213. Vaupel, M.; Thauer, R.K. Coenzyme F420-dependent N5,N10-methylenetetrahydromethanopterin reductase (Mer) from Methanobacterium thermoautotrophicum strain Marburg. Cloning, sequencing, transcriptional analysis, and functional expression in Escherichia coli of the mer gene. Eur. J. Biochem. 1995, 231, 773-778. [CrossRef] [PubMed]

214. Shima, S.; Warkentin, E.; Grabarse, W.; Sordel, M.; Wicke, M.; Thauer, R.K.; Ermler, U. Structure of coenzyme F(420) dependent methylenetetrahydromethanopterin reductase from two methanogenic archaea. J. Mol. Biol. 2000, 300, 935-950. [CrossRef]

215. Takao, M.; Kobayashi, T.; Oikawa, A.; Yasui, A. Tandem arrangement of photolyase and superoxide dismutase genes in Halobacterium halobium. J. Bacteriol. 1989, 171, 6323-6329. [CrossRef] [PubMed]

216. McCready, S.; Marcello, L. Repair of UV damage in Halobacterium salinarum. Biochem. Soc. Trans. 2003, 31, 694-698. [CrossRef] [PubMed]

217. Brudler, R.; Hitomi, K.; Daiyasu, H.; Toh, H.; Kucho, K.-i.; Ishiura, M.; Kanehisa, M.; Roberts, V.A.; Todo, T.; Tainer, J.A.; et al. Identification of a new cryptochrome class. Mol. Cell 2003, 11, 59-67. [CrossRef]

218. Kleine, T.; Lockhart, P.; Batschauer, A. An Arabidopsis protein closely related to Synechocystis cryptochrome is targeted to organelles. Plant J. 2003, 35, 93-103. [CrossRef]

219. Selby, C.P.; Sancar, A. A cryptochrome/photolyase class of enzymes with single-stranded DNA-specific photolyase activity. Proc. Natl. Acad. Sci. USA 2006, 103, 17696-17700. [CrossRef]

220. Zhang, F.; Scheerer, P.; Oberpichler, I.; Lamparter, T.; Krauss, N. Crystal structure of a prokaryotic (6-4) photolyase with an Fe-S cluster and a 6,7-dimethyl-8-ribityllumazine antenna chromophore. Proc. Natl. Acad. Sci. USA 2013, 110, 7217-7222. [CrossRef]

221. White, R.H. Analysis and characterization of the folates in the nonmethanogenic archaebacteria. J. Bacteriol. 1988, 170, 4608-4612. [CrossRef]

222. Maden, B.E. Tetrahydrofolate and tetrahydromethanopterin compared: Functionally distinct carriers in C1 metabolism. Biochem. J. 2000, 350 Pt 3, 609-629. [CrossRef] [PubMed]

223. de Crecy-Lagard, V. Variations in metabolic pathways create challenges for automated metabolic reconstructions: Examples from the tetrahydrofolate synthesis pathway. Comput. Struct. Biotechnol. J. 2014, 10, 41-50. [CrossRef] [PubMed]

224. Pfeiffer, F.; Schuster, S.C.; Broicher, A.; Falb, M.; Palm, P.; Rodewald, K.; Ruepp, A.; Soppa, J.; Tittor, J.; Oesterhelt, D. Evolution in the laboratory: The genome of Halobacterium salinarum strain R1 compared to that of strain NRC-1. Genomics 2008, 91, 335-346. [CrossRef]

225. Sato, S.; Nakada, Y.; Kanaya, S.; Tanaka, T. Molecular cloning and nucleotide sequence of Thermus thermophilus HB8 trpE and trpG. Biochim. Biophys. Acta 1988, 950, 303-312. [CrossRef]

226. Slock, J.; Stahly, D.P.; Han, C.Y.; Six, E.W.; Crawford, I.P. An apparent Bacillus subtilis folic acid biosynthetic operon containing pab, an amphibolic trpG gene, a third gene required for synthesis of para-aminobenzoic acid, and the dihydropteroate synthase gene. J. Bacteriol. 1990, 172, 7211-7226. [CrossRef] [PubMed]

227. Schadt, H.S.; Schadt, S.; Oldach, F.; Sussmuth, R.D. 2-Amino-2-deoxyisochorismate is a key intermediate in Bacillus subtilis p-aminobenzoic acid biosynthesis. J. Am. Chem. Soc. 2009, 131, 3481-3483. [CrossRef] 
228. Isupov, M.N.; Boyko, K.M.; Sutter, J.M.; James, P.; Sayer, C.; Schmidt, M.; Schonheit, P.; Nikolaeva, A.Y.; Stekhanova, T.N.; Mardanov, A.V.; et al. Thermostable branched-chain amino acid transaminases from the archaea Geoglobus acetivorans and Archaeoglobus fulgidus: Biochemical and structural characterization. Front. Bioeng. Biotechnol. 2019, 7, 7. [CrossRef]

229. El Yacoubi, B.; Phillips, G.; Blaby, I.K.; Haas, C.E.; Cruz, Y.; Greenberg, J.; de Crecy-Lagard, V. A Gateway platform for functional genomics in Haloferax volcanii: Deletion of three tRNA modification genes. Archaea 2009, 2, 211-219. [CrossRef]

230. Grochowski, L.L.; Xu, H.; Leung, K.; White, R.H. Characterization of an Fe(2+)-dependent archaeal-specific GTP cyclohydrolase, MptA, from Methanocaldococcus jannaschii. Biochemistry 2007, 46, 6658-6667. [CrossRef]

231. Mashhadi, Z.; Xu, H.; White, R.H. An Fe ${ }^{2+}$-dependent cyclic phosphodiesterase catalyzes the hydrolysis of 7,8-dihydro-Dneopterin 2', 3'-cyclic phosphate in methanopterin biosynthesis. Biochemistry 2009, 48, 9384-9392. [CrossRef]

232. Scott, J.W.; Rasche, M.E. Purification, overproduction, and partial characterization of beta-RFAP synthase, a key enzyme in the methanopterin biosynthesis pathway. J. Bacteriol. 2002, 184, 4442-4448. [CrossRef]

233. Dumitru, R.V.; Ragsdale, S.W. Mechanism of 4-(beta-D-ribofuranosyl)aminobenzene 5'-phosphate synthase, a key enzyme in the methanopterin biosynthetic pathway. J. Biol. Chem. 2004, 279, 39389-39395. [CrossRef]

234. Vaupel, M.; Vorholt, J.A.; Thauer, R.K. Overproduction and one-step purification of the N5,N10-methenyltetrahydromethanopterin cyclohydrolase (Mch) from the hyperthermophilic Methanopyrus kandleri. Extremophiles 1998, 2, 15-22. [CrossRef] [PubMed]

235. Zerulla, K.; Chimileski, S.; Nather, D.; Gophna, U.; Papke, R.T.; Soppa, J. DNA as a phosphate storage polymer and the alternative advantages of polyploidy for growth or survival. PLoS ONE 2014, 9, e94819. [CrossRef]

236. Rodionova, I.A.; Vetting, M.W.; Li, X.; Almo, S.C.; Osterman, A.L.; Rodionov, D.A. A novel bifunctional transcriptional regulator of riboflavin metabolism in Archaea. Nucleic Acids Res. 2017, 45, 3785-3799. [CrossRef] [PubMed]

237. Kawai, S.; Mori, S.; Mukai, T.; Suzuki, S.; Yamada, T.; Hashimoto, W.; Murata, K. Inorganic Polyphosphate/ATP-NAD kinase of Micrococcus flavus and Mycobacterium tuberculosis H37Rv. Biochem. Biophys. Res. Commun. 2000, 276, 57-63. [CrossRef] [PubMed]

238. Raffaelli, N.; Pisani, F.M.; Lorenzi, T.; Emanuelli, M.; Amici, A.; Ruggieri, S.; Magni, G. Characterization of nicotinamide mononucleotide adenylyltransferase from thermophilic archaea. J. Bacteriol. 1997, 179, 7718-7723. [CrossRef] [PubMed]

239. Raffaelli, N.; Emanuelli, M.; Pisani, F.M.; Amici, A.; Lorenzi, T.; Ruggieri, S.; Magni, G. Identification of the archaeal NMN adenylyltransferase gene. Mol. Cell. Biochem. 1999, 193, 99-102. [CrossRef]

240. Eustaquio, A.S.; Harle, J.; Noel, J.P.; Moore, B.S. S-Adenosyl-L-methionine hydrolase (adenosine-forming), a conserved bacterial and archaeal protein related to SAM-dependent halogenases. ChemBioChem 2008, 9, 2215-2219. [CrossRef]

241. Deng, H.; Botting, C.H.; Hamilton, J.T.; Russell, R.J.; O’Hagan, D. S-adenosyl-L-methionine:hydroxide adenosyltransferase: A SAM enzyme. Angew. Chem. Int. Ed. Engl. 2008, 47, 5357-5361. [CrossRef]

242. Fischer, M.; Romisch, W.; Schiffmann, S.; Kelly, M.; Oschkinat, H.; Steinbacher, S.; Huber, R.; Eisenreich, W.; Richter, G.; Bacher, A. Biosynthesis of riboflavin in archaea studies on the mechanism of 3,4-dihydroxy-2-butanone-4-phosphate synthase of Methanococcus jannaschii. J. Biol. Chem. 2002, 277, 41410-41416. [CrossRef] [PubMed]

243. Haase, I.; Mortl, S.; Kohler, P.; Bacher, A.; Fischer, M. Biosynthesis of riboflavin in archaea. 6,7-dimethyl-8-ribityllumazine synthase of Methanococcus jannaschii. Eur. J. Biochem. 2003, 270, 1025-1032. [CrossRef] [PubMed]

244. Phillips, G.; Grochowski, L.L.; Bonnett, S.; Xu, H.; Bailly, M.; Blaby-Haas, C.; El Yacoubi, B.; Iwata-Reuyl, D.; White, R.H.; de Crecy-Lagard, V. Functional promiscuity of the COG0720 family. ACS Chem. Biol. 2012, 7, 197-209. [CrossRef]

245. Graham, D.E.; Xu, H.; White, R.H. A member of a new class of GTP cyclohydrolases produces formylaminopyrimidine nucleotide monophosphates. Biochemistry 2002, 41, 15074-15084. [CrossRef] [PubMed]

246. Graupner, M.; Xu, H.; White, R.H. The pyrimidine nucleotide reductase step in riboflavin and $\mathrm{F}(420)$ biosynthesis in archaea proceeds by the eukaryotic route to riboflavin. J. Bacteriol. 2002, 184, 1952-1957. [CrossRef]

247. Romisch-Margl, W.; Eisenreich, W.; Haase, I.; Bacher, A.; Fischer, M. 2,5-diamino-6-ribitylamino-4(3H)-pyrimidinone 5'-phosphate synthases of fungi and archaea. FEBS J. 2008, 275, 4403-4414. [CrossRef]

248. Ammelburg, M.; Hartmann, M.D.; Djuranovic, S.; Alva, V.; Koretke, K.K.; Martin, J.; Sauer, G.; Truffault, V.; Zeth, K.; Lupas, A.N.; et al. A CTP-dependent archaeal riboflavin kinase forms a bridge in the evolution of cradle-loop barrels. Structure 2007, 15, 1577-1590. [CrossRef]

249. Mashhadi, Z.; Xu, H.; Grochowski, L.L.; White, R.H. Archaeal RibL: A new FAD synthetase that is air sensitive. Biochemistry 2010, 49, 8748-8755. [CrossRef]

250. Caforio, A.; Driessen, A.J.M. Archaeal phospholipids: Structural properties and biosynthesis. Biochim. Biophys. Acta Mol. Cell Biol. Lipids 2017, 1862, 1325-1339. [CrossRef]

251. Vannice, J.C.; Skaff, D.A.; Keightley, A.; Addo, J.K.; Wyckoff, G.J.; Miziorko, H.M. Identification in Haloferax volcanii of phosphomevalonate decarboxylase and isopentenyl phosphate kinase as catalysts of the terminal enzyme reactions in an archaeal alternate mevalonate pathway. J. Bacteriol. 2014, 196, 1055-1063. [CrossRef]

252. De Rosa, M.; Gambacorta, A. The lipids of archaebacteria. Prog. Lipid Res. 1988, 27, 153-175. [CrossRef]

253. Dawson, K.S.; Freeman, K.H.; Macalady, J.L. Molecular characterization of core lipids from halophilic archaea grown under different salinity conditions. Org. Geochem. 2012, 48, 1-8. [CrossRef]

254. Oren, A.; Ventosa, A.; Grant, W.D. Proposed minimal standards for description of new taxa in the order Halobacteriales. Int. J. Syst. Bacteriol. 1997, 47, 233-238. [CrossRef]

255. Oren, A. Molecular ecology of extremely halophilic Archaea and Bacteria. FEMS Microbiol. Ecol. 2002, 39, 1-7. [CrossRef] 
256. Kushwaha, S.C.; Kramer, J.K.G.; Kates, M. Isolation and characterization of C50-carotenoid pigments and other polar isoprenoids from Halobacterium cutirubrum. Biochim. Biophys. Acta 1975, 398, 303-314. [CrossRef]

257. Yang, Y.; Yatsunami, R.; Ando, A.; Miyoko, N.; Fukui, T.; Takaichi, S.; Nakamura, S. Complete biosynthetic pathway of the C50 carotenoid bacterioruberin from lycopene in the extremely halophilic archaeon Haloarcula japonica. J. Bacteriol. 2015, 197, 1614-1623. [CrossRef]

258. Giani, M.; Miralles-Robledillo, J.M.; Peiro, G.; Pire, C.; Martinez-Espinosa, R.M. Deciphering pathways for carotenogenesis in haloarchaea. Molecules 2020, 25, 1197. [CrossRef]

259. Dummer, A.M.; Bonsall, J.C.; Cihla, J.B.; Lawry, S.M.; Johnson, G.C.; Peck, R.F. Bacterioopsin-mediated regulation of bacterioruberin biosynthesis in Halobacterium salinarum. J. Bacteriol. 2011, 193, 5658-5667. [CrossRef] [PubMed]

260. Tachibana, A. A novel prenyltransferase, farnesylgeranyl diphosphate synthase, from the haloalkaliphilic archaeon, Natronobacterium pharaonis. FEBS Lett. 1994, 341, 291-294. [CrossRef]

261. Bale, N.J.; Sorokin, D.Y.; Hopmans, E.C.; Koenen, M.; Rijpstra, W.I.C.; Villanueva, L.; Wienk, H.; Sinninghe Damste, J.S. New insights into the polar lipid composition of extremely halo(alkali)philic euryarchaea from hypersaline lakes. Front. Microbiol. 2019, 10, 377. [CrossRef]

262. Kates, M. Biology of halophilic bacteria, Part II. Membrane lipids of extreme halophiles: Biosynthesis, function and evolutionary significance. Experientia 1993, 49, 1027-1036. [CrossRef] [PubMed]

263. Kates, M.; Moldoveanu, N.; Stewart, L.C. On the revised structure of the major phospholipid of Halobacterium salinarium. Biochim. Biophys. Acta 1993, 1169, 46-53. [CrossRef]

264. Kellermann, M.Y.; Yoshinaga, M.Y.; Valentine, R.C.; Wormer, L.; Valentine, D.L. Important roles for membrane lipids in haloarchaeal bioenergetics. Biochim. Biophys. Acta 2016, 1858, 2940-2956. [CrossRef]

265. Elling, F.J.; Becker, K.W.; Konneke, M.; Schroder, J.M.; Kellermann, M.Y.; Thomm, M.; Hinrichs, K.U. Respiratory quinones in Archaea: Phylogenetic distribution and application as biomarkers in the marine environment. Environ. Microbiol. 2016, 18, 692-707. [CrossRef]

266. Petrova, T.E.; Boyko, K.M.; Nikolaeva, A.Y.; Stekhanova, T.N.; Gruzdev, E.V.; Mardanov, A.V.; Stroilov, V.S.; Littlechild, J.A.; Popov, V.O.; Bezsudnova, E.Y. Structural characterization of geranylgeranyl pyrophosphate synthase GACE1337 from the hyperthermophilic archaeon Geoglobus acetivorans. Extremophiles 2018, 22, 877-888. [CrossRef] [PubMed]

267. Tachibana, A.; Yano, Y.; Otani, S.; Nomura, N.; Sako, Y.; Taniguchi, M. Novel prenyltransferase gene encoding farnesylgeranyl diphosphate synthase from a hyperthermophilic archaeon, Aeropyrum pernix-Molecular evolution with alteration in product specificity. Eur. J. Biochem. 2000, 267, 321-328. [CrossRef]

268. Jain, S.; Caforio, A.; Fodran, P.; Lolkema, J.S.; Minnaard, A.J.; Driessen, A.J.M. Identification of CDP-archaeol synthase, a missing link of ether lipid biosynthesis in Archaea. Chem. Biol. 2014, 21, 1392-1401. [CrossRef]

269. Morii, H.; Koga, Y. CDP-2,3-Di-O-geranylgeranyl-sn-glycerol:L-serine O-archaetidyltransferase (archaetidylserine synthase) in the methanogenic archaeon Methanothermobacter thermautotrophicus. J. Bacteriol. 2003, 185, 1181-1189. [CrossRef]

270. Morii, H.; Kiyonari, S.; Ishino, Y.; Koga, Y. A novel biosynthetic pathway of archaetidyl-myo-inositol via archaetidyl-myo-inositol phosphate from CDP-archaeol and D-glucose 6-phosphate in methanoarchaeon Methanothermobacter thermautotrophicus cells. J. Biol. Chem. 2009, 284, 30766-30774. [CrossRef]

271. Vences-Guzman, M.A.; Geiger, O.; Sohlenkamp, C. Sinorhizobium meliloti mutants deficient in phosphatidylserine decarboxylase accumulate phosphatidylserine and are strongly affected during symbiosis with alfalfa. J. Bacteriol. 2008, 190, 6846-6856. [CrossRef]

272. Conover, R.K.; Doolittle, W.F. Characterization of a gene involved in histidine biosynthesis in Halobacterium (Haloferax) volcanii: Isolation and rapid mapping by transformation of an auxotroph with cosmid DNA. J. Bacteriol. 1990, 172, 3244-3249. [CrossRef] [PubMed]

273. Grisolia, V.; Carlomagno, M.S.; Nappo, A.G.; Bruni, C.B. Cloning, structure, and expression of the Escherichia coli K-12 hisC gene. J. Bacteriol. 1985, 164, 1317-1323. [CrossRef] [PubMed]

274. Loc'h, J.; Blaud, M.; Rety, S.; Lebaron, S.; Deschamps, P.; Bareille, J.; Jombart, J.; Robert-Paganin, J.; Delbos, L.; Chardon, F.; et al. RNA mimicry by the fap7 adenylate kinase in ribosome biogenesis. PLoS Biol. 2014, 12, e1001860. [CrossRef]

275. Ren, H.; Wang, L.; Bennett, M.; Liang, Y.; Zheng, X.; Lu, F.; Li, L.; Nan, J.; Luo, M.; Eriksson, S.; et al. The crystal structure of human adenylate kinase 6: An adenylate kinase localized to the cell nucleus. Proc. Natl. Acad. Sci. USA 2005, 102, 303-308. [CrossRef] [PubMed]

276. Moon, S.; Kim, J.; Koo, J.; Bae, E. Structural and mutational analyses of psychrophilic and mesophilic adenylate kinases highlight the role of hydrophobic interactions in protein thermal stability. Struct. Dyn. 2019, 6, 024702. [CrossRef]

277. Chen, L.; Zhou, C.; Yang, H.; Roberts, M.F. Inositol-1-phosphate synthase from Archaeoglobus fulgidus is a class II aldolase. Biochemistry 2000, 39, 12415-12423. [CrossRef]

278. Neelon, K.; Roberts, M.F.; Stec, B. Crystal structure of a trapped catalytic intermediate suggests that forced atomic proximity drives the catalysis of mIPS. Biophys. J. 2011, 101, 2816-2824. [CrossRef]

279. Maurer, S.; Ludt, K.; Soppa, J. Characterization of copy number control of two Haloferax volcanii replication origins using deletion mutants and haloarchaeal artificial chromosomes. J. Bacteriol. 2018, 200, e00517-17. [CrossRef]

280. Chamovitz, D.; Misawa, N.; Sandmann, G.; Hirschberg, J. Molecular cloning and expression in Escherichia coli of a cyanobacterial gene coding for phytoene synthase, a carotenoid biosynthesis enzyme. FEBS Lett. 1992, 296, 305-310. [CrossRef] 
281. Serino, L.; Reimmann, C.; Baur, H.; Beyeler, M.; Visca, P.; Haas, D. Structural genes for salicylate biosynthesis from chorismate in Pseudomonas aeruginosa. Mol. Gen. Genet. 1995, 249, 217-228. [CrossRef]

282. Dawson, A.; Chen, M.; Fyfe, P.K.; Guo, Z.; Hunter, W.N. Structure and reactivity of Bacillus subtilis MenD catalyzing the first committed step in menaquinone biosynthesis. J. Mol. Biol. 2010, 401, 253-264. [CrossRef]

283. Schmidt, D.M.; Hubbard, B.K.; Gerlt, J.A. Evolution of enzymatic activities in the enolase superfamily: Functional assignment of unknown proteins in Bacillus subtilis and Escherichia coli as L-Ala-D/L-Glu epimerases. Biochemistry 2001, 40, 15707-15715. [CrossRef]

284. Palmer, D.R.; Garrett, J.B.; Sharma, V.; Meganathan, R.; Babbitt, P.C.; Gerlt, J.A. Unexpected divergence of enzyme function and sequence: "N-acylamino acid racemase" is o-succinylbenzoate synthase. Biochemistry 1999, 38, 4252-4258. [CrossRef]

285. Chen, Y.; Jiang, Y.; Guo, Z. Mechanistic insights from the crystal structure of Bacillus subtilis o-succinylbenzoyl-CoA synthetase complexed with the adenylate intermediate. Biochemistry 2016, 55, 6685-6695. [CrossRef]

286. Jiang, M.; Chen, M.; Guo, Z.F.; Guo, Z. A bicarbonate cofactor modulates 1,4-dihydroxy-2-naphthoyl-coenzyme a synthase in menaquinone biosynthesis of Escherichia coli. J. Biol. Chem. 2010, 285, 30159-30169. [CrossRef]

287. Suvarna, K.; Stevenson, D.; Meganathan, R.; Hudspeth, M.E. Menaquinone (vitamin K2) biosynthesis: Localization and characterization of the menA gene from Escherichia coli. J. Bacteriol. 1998, 180, 2782-2787. [CrossRef]

288. Cheng, Z.; Sattler, S.; Maeda, H.; Sakuragi, Y.; Bryant, D.A.; DellaPenna, D. Highly divergent methyltransferases catalyze a conserved reaction in tocopherol and plastoquinone synthesis in cyanobacteria and photosynthetic eukaryotes. Plant Cell 2003, 15, 2343-2356. [CrossRef] [PubMed]

289. Koike-Takeshita, A.; Koyama, T.; Ogura, K. Identification of a novel gene cluster participating in menaquinone (vitamin K2) biosynthesis. Cloning and sequence determination of the 2-heptaprenyl-1,4-naphthoquinone methyltransferase gene of Bacillus stearothermophilus. J. Biol. Chem. 1997, 272, 12380-12383. [CrossRef]

290. Leffers, H.; Gropp, F.; Lottspeich, F.; Zillig, W.; Garrett, R.A. Sequence, organization, transcription and evolution of RNA polymerase subunit genes from the archaebacterial extreme halophiles Halobacterium halobium and Halococcus morrhuae. J. Mol. Biol. 1989, 206, 1-17. [CrossRef]

291. Madon, J.; Zillig, W. A form of the DNA-dependent RNA polymerase of Halobacterium halobium, containing an additional component, is able to transcribe native DNA. Eur. J. Biochem. 1983, 133, 471-474. [CrossRef] [PubMed]

292. Rivlin, A.A.; Chan, Y.L.; Wool, I.G. The contribution of a zinc finger motif to the function of yeast ribosomal protein YL37a. J. Mol. Biol. 1999, 294, 909-919. [CrossRef]

293. de Crecy-Lagard, V.; Forouhar, F.; Brochier-Armanet, C.; Tong, L.; Hunt, J.F. Comparative genomic analysis of the DUF71/COG2102 family predicts roles in diphthamide biosynthesis and B12 salvage. Biol. Direct 2012, 7, 32. [CrossRef] [PubMed]

294. Ng, S.Y.; Chaban, B.; VanDyke, D.J.; Jarrell, K.F. Archaeal signal peptidases. Microbiology (Reading) 2007, 153, 305-314. [CrossRef]

295. Raut, P.; Glass, J.B.; Lieberman, R.L. Archaeal roots of intramembrane aspartyl protease siblings signal peptide peptidase and presenilin. Proteins 2021, 89, 232-241. [CrossRef] [PubMed]

296. Arndt, E.; Scholzen, T.; Kromer, W.; Hatakeyama, T.; Kimura, M. Primary structures of ribosomal proteins from the archaebacterium Halobacterium marismortui and the eubacterium Bacillus stearothermophilus. Biochimie 1991, 73, 657-668. [CrossRef]

297. Scholzen, T.; Arndt, E. Organization and nucleotide sequence of ten ribosomal protein genes from the region equivalent to the spectinomycin operon in the archaebacterium Halobacterium marismortui. Mol. Genet. Genomics 1991, 228, 70-80. [CrossRef]

298. Otaka, E.; Higo, K.; Itoh, T. Yeast ribosomal proteins. VIII. Isolation of two proteins and sequence characterization of twenty-four proteins from cytoplasmic ribosomes. Mol. Gen. Genet. 1984, 195, 544-546. [CrossRef]

299. Ban, N.; Nissen, P.; Hansen, J.; Moore, P.B.; Steitz, T.A. The complete atomic structure of the large ribosomal subunit at 2.4 A resolution. Science 2000, 289, 905-920. [CrossRef]

300. Dresios, J.; Chan, Y.L.; Wool, I.G. The role of the zinc finger motif and of the residues at the amino terminus in the function of yeast ribosomal protein YL37a. J. Mol. Biol. 2002, 316, 475-488. [CrossRef]

301. Zhu, X.; Dzikovski, B.; Su, X.; Torelli, A.T.; Zhang, Y.; Ealick, S.E.; Freed, J.H.; Lin, H. Mechanistic understanding of Pyrococcus horikoshii Dph2, a [4Fe-4S] enzyme required for diphthamide biosynthesis. Mol. Biosyst. 2011, 7, 74-81. [CrossRef]

302. Zhu, X.; Kim, J.; Su, X.; Lin, H. Reconstitution of diphthine synthase activity in vitro. Biochemistry 2010, 49, 9649-9657. [CrossRef] [PubMed]

303. Su, X.; Lin, Z.; Chen, W.; Jiang, H.; Zhang, S.; Lin, H. Chemogenomic approach identified yeast YLR143W as diphthamide synthetase. Proc. Natl. Acad. Sci. USA 2012, 109, 19983-19987. [CrossRef] [PubMed]

304. Uthman, S.; Bar, C.; Scheidt, V.; Liu, S.; ten Have, S.; Giorgini, F.; Stark, M.J.; Schaffrath, R. The amidation step of diphthamide biosynthesis in yeast requires DPH6, a gene identified through mining the DPH1-DPH5 interaction network. PLoS Genet. 2013, 9 , e1003334. [CrossRef]

305. Bolhuis, A.; Matzen, A.; Hyyrylainen, H.L.; Kontinen, V.P.; Meima, R.; Chapuis, J.; Venema, G.; Bron, S.; Freudl, R.; van Dijl, J.M. Signal peptide peptidase- and ClpP-like proteins of Bacillus subtilis required for efficient translocation and processing of secretory proteins. J. Biol. Chem. 1999, 274, 24585-24592. [CrossRef] [PubMed]

306. Nam, S.E.; Kim, A.C.; Paetzel, M. Crystal structure of Bacillus subtilis signal peptide peptidase A. J. Mol. Biol. 2012, 419, 347-358. [CrossRef] 
307. Rangaswamy, V.; Altekar, W. Ketohexokinase (ATP:D-fructose 1-phosphotransferase) from a halophilic archaebacterium, Haloarcula vallismortis: Purification and properties. J. Bacteriol. 1994, 176, 5505-5512. [CrossRef] [PubMed]

308. Anderson, I.; Scheuner, C.; Goker, M.; Mavromatis, K.; Hooper, S.D.; Porat, I.; Klenk, H.P.; Ivanova, N.; Kyrpides, N. Novel insights into the diversity of catabolic metabolism from ten haloarchaeal genomes. PLoS ONE 2011, 6, e20237. [CrossRef]

309. Williams, T.J.; Allen, M.A.; Liao, Y.; Raftery, M.J.; Cavicchioli, R. Sucrose metabolism in haloarchaea: Reassessment using genomics, proteomics, and metagenomics. Appl. Environ. Microbiol. 2019, 85, e02935-18. [CrossRef]

310. Chaga, G.; Porath, J.; Illeni, T. Isolation and purification of amyloglucosidase from Halobacterium sodomense. Biomed. Chromatogr. 1993, 7, 256-261. [CrossRef]

311. Rudolph, B.; Hansen, T.; Schonheit, P. Glucose-6-phosphate isomerase from the hyperthermophilic archaeon Methanococcus jannaschii: Characterization of the first archaeal member of the phosphoglucose isomerase superfamily. Arch. Microbiol. 2004, 181, 82-87.

312. Aulkemeyer, P.; Ebner, R.; Heilenmann, G.; Jahreis, K.; Schmid, K.; Wrieden, S.; Lengeler, J.W. Molecular analysis of two fructokinases involved in sucrose metabolism of enteric bacteria. Mol. Microbiol. 1991, 5, 2913-2922. [CrossRef]

313. Qu, Q.; Lee, S.J.; Boos, W. Molecular and biochemical characterization of a fructose-6-phosphate-forming and ATP-dependent fructokinase of the hyperthermophilic archaeon Thermococcus litoralis. Extremophiles 2004, 8, 301-308. [CrossRef] [PubMed]

314. Ohnishi, H.; Kitamura, H.; Minowa, T.; Sakai, H.; Ohta, T. Molecular cloning of a glucoamylase gene from a thermophilic Clostridium and kinetics of the cloned enzyme. Eur. J. Biochem. 1992, 207, 413-418. [CrossRef]

315. Ahmed, H.; Ettema, T.J.; Tjaden, B.; Geerling, A.C.; van der Oost, J.; Siebers, B. The semi-phosphorylative Entner-Doudoroff pathway in hyperthermophilic archaea: A re-evaluation. Biochem. J. 2005, 390, 529-540. [CrossRef]

316. Chai, Y.; Kolter, R.; Losick, R. A widely conserved gene cluster required for lactate utilization in Bacillus subtilis and its involvement in biofilm formation. J. Bacteriol. 2009, 191, 2423-2430. [CrossRef]

317. Gao, C.; Wang, Y.; Zhang, Y.; Lv, M.; Dou, P.; Xu, P.; Ma, C. NAD-independent L-lactate dehydrogenase required for L-lactate utilization in Pseudomonas stutzeri A1501. J. Bacteriol. 2015, 197, 2239-2247. [CrossRef]

318. Pfrimer, P.; de Moraes, L.M.; Galdino, A.S.; Salles, L.P.; Reis, V.C.; De Marco, J.L.; Prates, M.V.; Bloch, C., Jr.; Torres, F.A. Cloning, purification, and partial characterization of Bacillus subtilis urate oxidase expressed in Escherichia coli. J. Biomed. Biotechnol. 2010, 2010, 674908. [CrossRef]

319. Lee, Y.; Lee, D.H.; Kho, C.W.; Lee, A.Y.; Jang, M.; Cho, S.; Lee, C.H.; Lee, J.S.; Myung, P.K.; Park, B.C.; et al. Transthyretin-related proteins function to facilitate the hydrolysis of 5-hydroxyisourate, the end product of the uricase reaction. FEBS Lett. 2005, 579, 4769-4774. [CrossRef] [PubMed]

320. Kim, K.; Park, J.; Rhee, S. Structural and functional basis for (S)-allantoin formation in the ureide pathway. J. Biol. Chem. 2007, 282, 23457-23464. [CrossRef] [PubMed]

321. Xu, Z.; Jiang, W.H.; Jiao, R.S.; Yang, Y.L. [Cloning, sequencing and high expression in Escherichia coli of D-hydantoinase gene from Burkholderia pickettii]. Sheng Wu Gong Cheng Xue Bao 2002, 18, 149-154.

322. Ho, Y.Y.; Huang, Y.H.; Huang, C.Y. Chemical rescue of the post-translationally carboxylated lysine mutant of allantoinase and dihydroorotase by metal ions and short-chain carboxylic acids. Amino Acids 2013, 44, 1181-1191. [CrossRef]

323. Schultz, A.C.; Nygaard, P.; Saxild, H.H. Functional analysis of 14 genes that constitute the purine catabolic pathway in Bacillus subtilis and evidence for a novel regulon controlled by the PucR transcription activator. J. Bacteriol. 2001, 183, 3293-3302 [CrossRef] [PubMed]

324. Martinez-Rodriguez, S.; Garcia-Pino, A.; Las Heras-Vazquez, F.J.; Clemente-Jimenez, J.M.; Rodriguez-Vico, F.; Garcia-Ruiz, J.M.; Loris, R.; Gavira, J.A. Mutational and structural analysis of L-N-carbamoylase reveals new insights into a peptidase M20/M25/M40 family member. J. Bacteriol. 2012, 194, 5759-5768. [CrossRef]

325. Werner, A.K.; Romeis, T.; Witte, C.P. Ureide catabolism in Arabidopsis thaliana and Escherichia coli. Nat. Chem. Biol. 2010, 6, 19-21. [CrossRef]

326. Werner, A.K.; Medina-Escobar, N.; Zulawski, M.; Sparkes, I.A.; Cao, F.Q.; Witte, C.P. The ureide-degrading reactions of purine ring catabolism employ three amidohydrolases and one aminohydrolase in Arabidopsis, soybean, and rice. Plant Physiol. 2013, 163, 672-681. [CrossRef] [PubMed]

327. Kardinahl, S.; Schmidt, C.L.; Hansen, T.; Anemuller, S.; Petersen, A.; Schafer, G. The strict molybdate-dependence of glucosedegradation by the thermoacidophile Sulfolobus acidocaldarius reveals the first crenarchaeotic molybdenum containing enzymeAn aldehyde oxidoreductase. Eur. J. Biochem. 1999, 260, 540-548. [CrossRef]

328. Kang, B.S.; Kim, Y.M. Cloning and molecular characterization of the genes for carbon monoxide dehydrogenase and localization of molybdopterin, flavin adenine dinucleotide, and iron-sulfur centers in the enzyme of Hydrogenophaga pseudoflava. J. Bacteriol. 1999, 181, 5581-5590. [CrossRef]

329. Xi, H.; Schneider, B.L.; Reitzer, L. Purine catabolism in Escherichia coli and function of xanthine dehydrogenase in purine salvage. J. Bacteriol. 2000, 182, 5332-5341. [CrossRef]

330. Karatza, P.; Frillingos, S. Cloning and functional characterization of two bacterial members of the NAT/NCS2 family in Escherichia coli. Mol. Membr. Biol. 2005, 22, 251-261. [CrossRef]

331. Desguin, B.; Soumillion, P.; Hols, P.; Hausinger, R.P. Nickel-pincer cofactor biosynthesis involves LarB-catalyzed pyridinium carboxylation and LarE-dependent sacrificial sulfur insertion. Proc. Natl. Acad. Sci. USA 2016, 113, 5598-5603. [CrossRef] [PubMed] 
332. He, J.; Yin, W.; Galperin, M.Y.; Chou, S.H. Cyclic di-AMP, a second messenger of primary importance: Tertiary structures and binding mechanisms. Nucleic Acids Res. 2020, 48, 2807-2829. [CrossRef] [PubMed]

333. Fischer, S.; John von Freyend, S.; Sabag-Daigle, A.; Daniels, C.J.; Allers, T.; Marchfelder, A. Assigning a function to a conserved archaeal metallo-beta-lactamase from Haloferax volcanii. Extremophiles 2012, 16, 333-343. [CrossRef] [PubMed]

334. Spath, B.; Schubert, S.; Lieberoth, A.; Settele, F.; Schutz, S.; Fischer, S.; Marchfelder, A. Two archaeal tRNase Z enzymes: Similar but different. Arch. Microbiol. 2008, 190, 301-308. [CrossRef] [PubMed]

335. Desmarais, J.J.; Flamholz, A.I.; Blikstad, C.; Dugan, E.J.; Laughlin, T.G.; Oltrogge, L.M.; Chen, A.W.; Wetmore, K.; Diamond, S.; Wang, J.Y.; et al. DABs are inorganic carbon pumps found throughout prokaryotic phyla. Nat. Microbiol. 2019, 4, $2204-2215$. [CrossRef]

336. Corrigan, R.M.; Grundling, A. Cyclic di-AMP: Another second messenger enters the fray. Nat. Rev. Microbiol. 2013, 11, 513-524. [CrossRef]

337. Gundlach, J.; Mehne, F.M.; Herzberg, C.; Kampf, J.; Valerius, O.; Kaever, V.; Stulke, J. An essential poison: Synthesis and degradation of cyclic di-AMP in Bacillus subtilis. J. Bacteriol. 2015, 197, 3265-3274. [CrossRef]

338. Commichau, F.M.; Heidemann, J.L.; Ficner, R.; Stulke, J. Making and breaking of an essential poison: The cyclases and phosphodiesterases that produce and degrade the essential second messenger cyclic di-AMP in bacteria. J. Bacteriol. 2019, 201, e00462-18. [CrossRef]

339. Yin, W.; Cai, X.; Ma, H.; Zhu, L.; Zhang, Y.; Chou, S.H.; Galperin, M.Y.; He, J. A decade of research on the second messenger c-di-AMP. FEMS Microbiol. Rev. 2020, 44, 701-724. [CrossRef] 